University of Tennessee Health Science Center

UTHSC Digital Commons

$12-2012$

\title{
Verification of the Accuracy of Electronic Mandibular Movement Recording Devices: : An in vitro investigation
}

Joshua Heath Balch

University of Tennessee Health Science Center

Follow this and additional works at: https://dc.uthsc.edu/dissertations

Part of the Prosthodontics and Prosthodontology Commons

\section{Recommended Citation}

Balch, Joshua Heath , "Verification of the Accuracy of Electronic Mandibular Movement Recording Devices: : An in vitro investigation" (2012). Theses and Dissertations (ETD). Paper 21. http://dx.doi.org/ 10.21007/etd.cghs.2012.0021.

This Thesis is brought to you for free and open access by the College of Graduate Health Sciences at UTHSC Digital Commons. It has been accepted for inclusion in Theses and Dissertations (ETD) by an authorized administrator of UTHSC Digital Commons. For more information, please contact jwelch30@uthsc.edu. 


\title{
Verification of the Accuracy of Electronic Mandibular Movement Recording Devices: : An in vitro investigation
}

\begin{abstract}
One goal of restorative dentistry is to truly capture maxillomandibular relationships that accurately reproduce mandibular border movements and that would prescribe the best occlusal interface.

Registration of horizontal and sagittal movements of the patient allows maximum cusp height and fossae depth with proper placement of occlusal ridges and grooves. The goal is to develop an occlusion that is interference free and entails the concepts of organic occlusion. Methods to transfer patient information to a highly adjustable articulator include mechanical recorders, mechano-electronic recorders and optoelectronic recorders. The purpose of this study is to verify the accuracy of electronic mandibular movement recording devices in vitro. For this investigation an articulator (Denar ${ }^{\circledR}$ D5A, Whip Mix Corp., Louisville, KY) with known condylar settings was employed as a mock patient. An experimental apparatus was fabricated to attach recording devices to the mock patient simulating clinical conditions. Mock patient movements were accomplished under clinically relevant conditions.

The primary use of a pantograph is to record patient mandibular border movement and program an articulator so that the movements of the articulator simulate the border movements of the patient. The objectives of this four part investigation was to assess the accuracy of an optoelectronic pantograph (Freecorder ${ }^{\circledR}$ Bluefox, Dentron, Germany) in locating a known transverse horizontal axis (THA), assess the ability of an optoelectronic pantograph (Freecorder ${ }^{\circledR}$ Bluefox, Dentron) to accurately determine preset values of the mock patient, assess the ability of a mechano-electronic pantograph (Cadiax Compact $2 \AA$, GAMMA Dental, Austria) to accurately determine the preset values of the mock patient and compare the accuracy of the optoelectronic pantograph and mechano-electronic pantograph through statistical analysis mean values generated for each condylar setting were compared to known mock patient condylar settings. Settings were the same for the right and left condylar guide assemblies.
\end{abstract}

Results of this investigation demonstrated that: 1) the optoelectronic pantograph did not locate a known transverse horizontal axis; 2 ) the optoelectronic pantograph did not record mandibular movement accurately; 3) the mechano-electronic pantograph did not record mandibular movement accurately; and 4) there were differences in accuracy between the optoelectronic pantograph and mechano-electronic pantograph.

The majority of condylar guide assembly mean values predicted by the optoelectronic pantograph and mechano-electronic pantograph were statistically inaccurate and there were differences in accuracy between the optoelectronic and mechano-electronic pantographs. Clinically, the predicted mean values for the Lateral Condylar Inclination ( $\mathrm{LCl}$ ) and Progressive Mandibular Lateral Translation (PMLT) were within five degrees of the known mock patient settings. The values predicted by the optoelectronic pantograph over-compensated mandibular movement requiring shorter cusps for the restoration. The mechano-electronic pantograph prescribed longer cusps, for the restoration, that potentially induce interferences. Though statistically significant inaccuracies were identified, both mandibular recording devices may be considered clinically acceptable. However, the use of both mandibular recording devices investigated here will potentially result in occlusal restorations that require adjustment when placed in the oral cavity.

\section{Document Type}

Thesis

Degree Name

Master of Dental Science (MDS) 


\section{Program}

Prosthodontics

Research Advisor

David R. Cagna, DMD, MS

\section{Keywords}

mandibular recording devices, optoelectronic, mechano-electronic, electronic.

\section{Subject Categories}

Dentistry | Medicine and Health Sciences | Prosthodontics and Prosthodontology 


\title{
VERIFICATION OF THE ACCURACY OF ELECTRONIC MANDIBULAR
} MOVEMENT RECORDING DEVICES: AN IN VITRO INVESTIGATION

\author{
A Thesis \\ Presented for \\ The Graduate Studies Council \\ The University of Tennessee \\ Health Science Center \\ In Partial Fulfillment \\ Of the Requirements for the Degree \\ Masters of Dental Science \\ From The University of Tennessee
}

By

Joshua Heath Balch

December 2012 
Copyright (C) 2012 by Joshua Heath Balch. All rights reserved. 


\section{DEDICATION}

To "My Love" Dana who truly made this entire program possible. Without her total support, prayers, willingness to do whatever was needed and many hours of support this task would not have been accomplished. Her sacrifices were immeasurable. I am forever grateful and am blessed by having you in my life. 


\section{ACKNOWLEDGEMENTS}

I would like to express my gratitude to everyone who has helped me in my endeavor of pursuing a Master of Dental Science in Prosthodontics. I am grateful to Dr. David Cagna, who has been a mentor and advisor in this project. I would also like to thank my committee members, Dr. Swati Ahuja, Dr. William McHorris, Dr. Gregory Paprocki, Dr. Mark Scarbecz and Dr. Russell Wicks for their advice and experience. I would also like to extend by special thanks to Whip Mix Corporation especially Jim Robinson for coordinationand Royce Thompson for his engineering and technical support in fabricating the maxillary face bow mounting apparatus. 


\begin{abstract}
One goal of restorative dentistry is to truly capture maxillomandibular relationships that accurately reproduce mandibular border movements and that would prescribe the best occlusal interface. Registration of horizontal and sagittal movements of the patient allows maximum cusp height and fossae depth with proper placement of occlusal ridges and grooves. The goal is to develop an occlusion that is interference free and entails the concepts of organic occlusion. Methods to transfer patient information to a highly adjustable articulator include mechanical recorders, mechano-electronic recorders and optoelectronic recorders. The purpose of this study is to verify the accuracy of electronic mandibular movement recording devices in vitro. For this investigation an articulator (Denar ${ }^{\circledR}$ D5A, Whip Mix Corp., Louisville, KY) with known condylar settings was employed as a mock patient. An experimental apparatus was fabricated to attach recording devices to the mock patient simulating clinical conditions. Mock patient movements were accomplished under clinically relevant conditions.

The primary use of a pantograph is to record patient mandibular border movement and program an articulator so that the movements of the articulator simulate the border movements of the patient. The objectives of this four part investigation was to assess the accuracy of an optoelectronic pantograph (Freecorder ${ }^{\circledR}$ Bluefox, Dentron, Germany) in locating a known transverse horizontal axis (THA), assess the ability of an optoelectronic pantograph (Freecorder ${ }^{\circledR}$ Bluefox, Dentron) to accurately determine preset values of the mock patient, assess the ability of a mechano-electronic pantograph (Cadiax Compact $2^{\circledR}$, GAMMA Dental, Austria) to accurately determine the preset values of the mock patient and compare the accuracy of the optoelectronic pantograph and mechano-electronic pantograph through statistical analysis mean values generated for each condylar setting were compared to known mock patient condylar settings. Settings were the same for the right and left condylar guide assemblies.
\end{abstract}

Results of this investigation demonstrated that: 1) the optoelectronic pantograph did not locate a known transverse horizontal axis; 2) the optoelectronic pantograph did not record mandibular movement accurately; 3) the mechano-electronic pantograph did not record mandibular movement accurately; and 4) there were differences in accuracy between the optoelectronic pantograph and mechano-electronic pantograph.

The majority of condylar guide assembly mean values predicted by the optoelectronic pantograph and mechano-electronic pantograph were statistically inaccurate and there were differences in accuracy between the optoelectronic and mechano-electronic pantographs. Clinically, the predicted mean values for the Lateral Condylar Inclination (LCI) and Progressive Mandibular Lateral Translation (PMLT) were within five degrees of the known mock patient settings. The values predicted by the optoelectronic pantograph over-compensated mandibular movement requiring shorter cusps for the restoration. The mechano-electronic pantograph prescribed longer cusps, for the restoration, that potentially induce interferences. Though statistically significant inaccuracies were identified, both mandibular recording devices may be considered 
clinically acceptable. However, the use of both mandibular recording devices investigated here will potentially result in occlusal restorations that require adjustment when placed in the oral cavity. 


\section{TABLE OF CONTENTS}

CHAPTER 1. INTRODUCTION ................................................................................

CHAPTER 2. LITERATURE REVIEW .................................................................6

Articulation and Mandibular Movement: A Historical Perspective ................................6

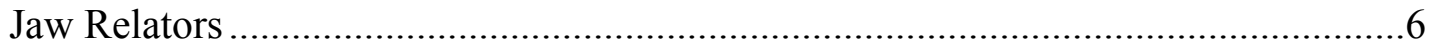

Anatomical Relationships ……………............................................................

Methods and Devices to Record Mandibular Movement ...............................................

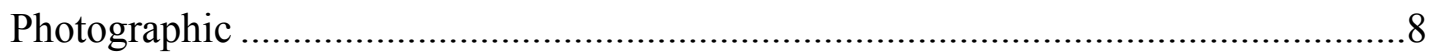

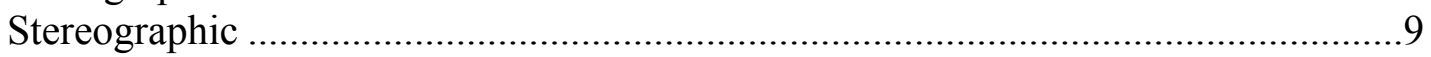

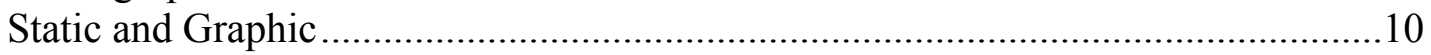

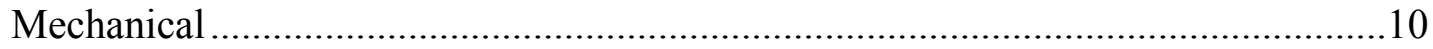

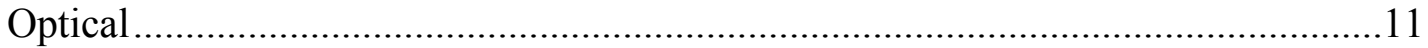

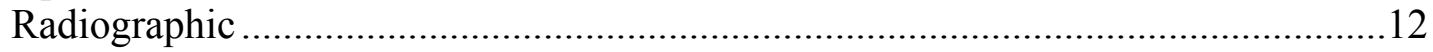

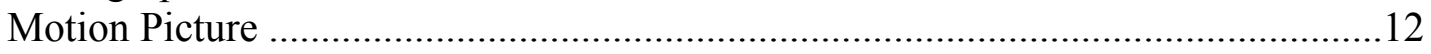

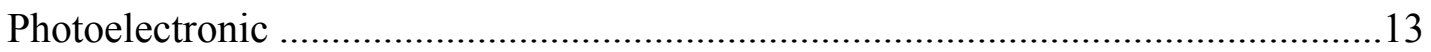

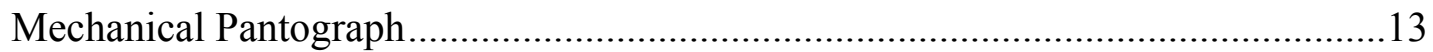

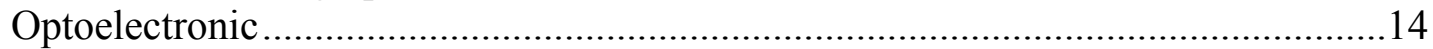

Mechano-electronic Pantograph ..........................................................................15

Evaluation and Comparison of Mandibular Recording Devices ....................................15

CHAPTER 3. MATERIALS AND METHODS........................................................18

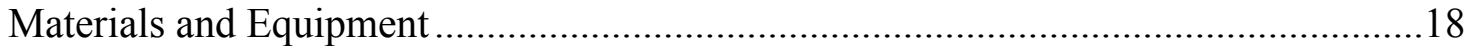

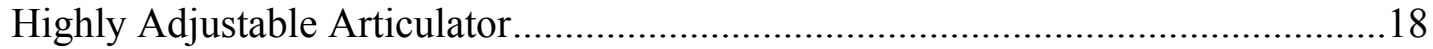

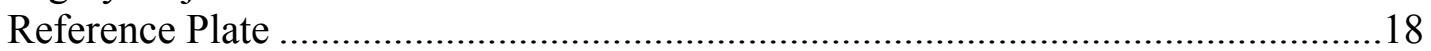

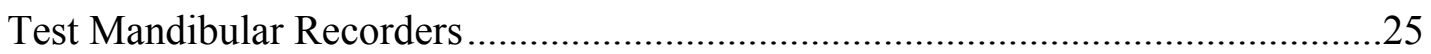

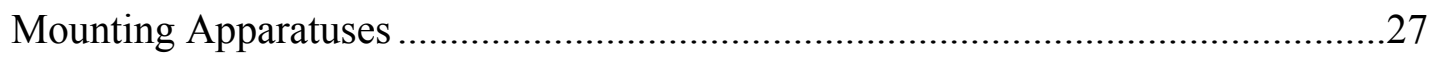

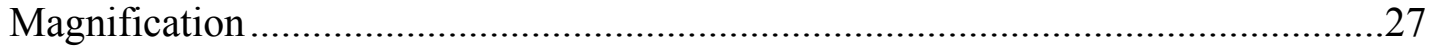

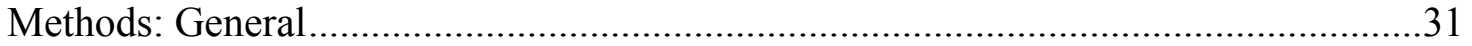

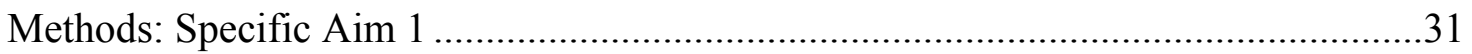

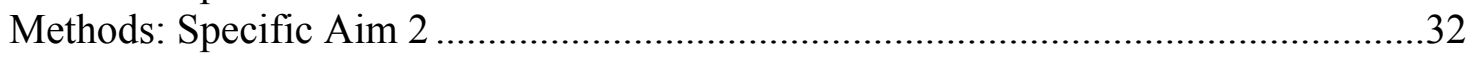

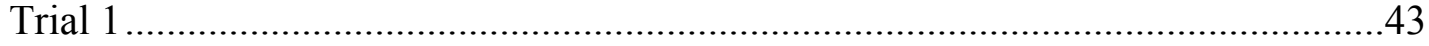

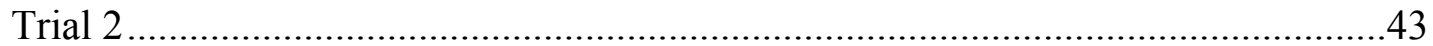

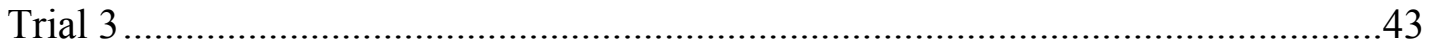

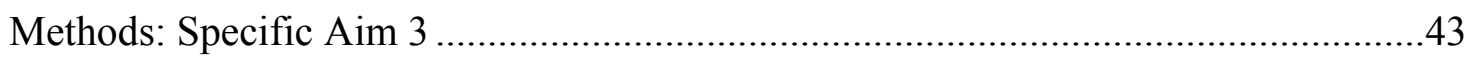

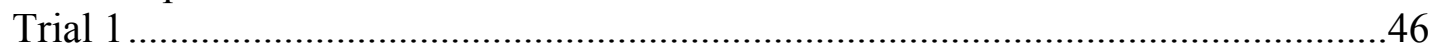

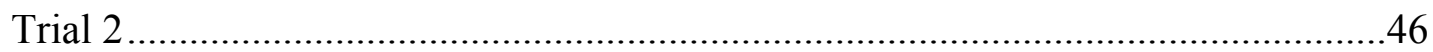

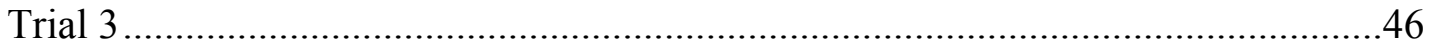

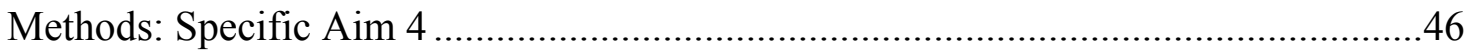

CHAPTER 4. RESULTS.........................................................................................................50

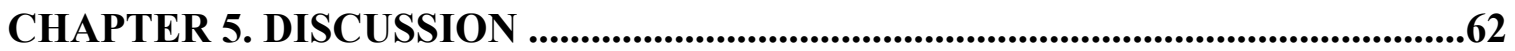


CHAPTER 6. CONCLUSION ......................................................................................75

CHAPTER 7. LIMITATIONS AND FUTURE DIRECTIONS.....................................76

LIST OF REFERENCES................................................................................................77

VITA 


\section{LIST OF TABLES}

Table 1-1. Methods of recording mandibular movement and adjusting 3-D

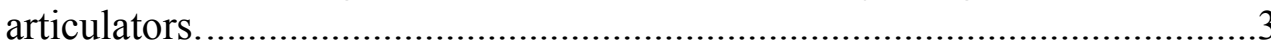

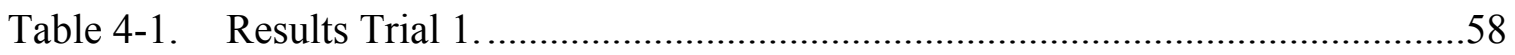

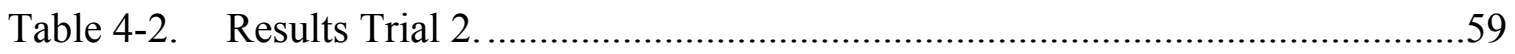

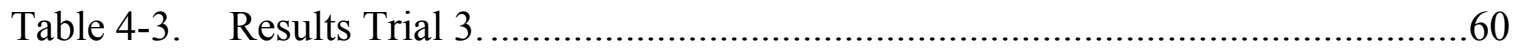

Table 5-1. Accuracy of arbitrary horizontal axis points........................................63

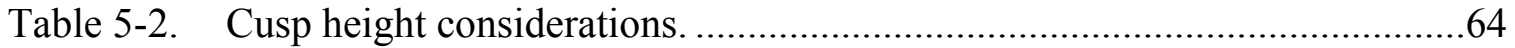




\section{LIST OF FIGURES}

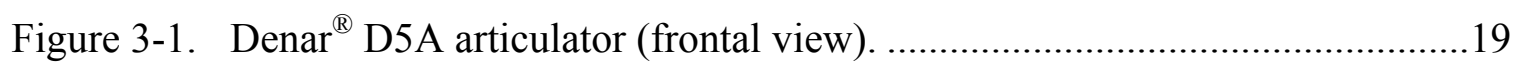

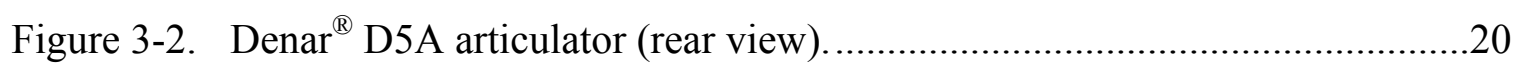

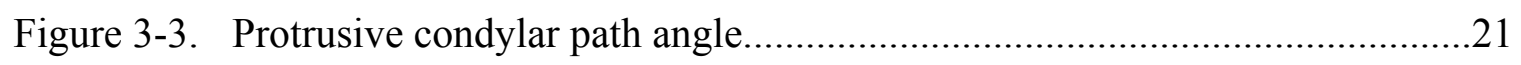

Figure 3-4. Medial wall angle adjustment. .............................................................22

Figure 3-5. Medial wall linear adjustment............................................................22

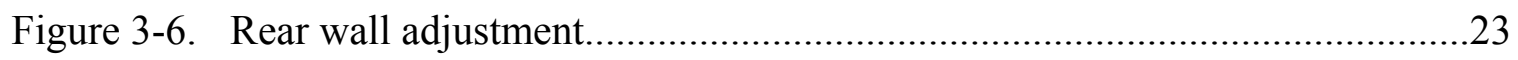

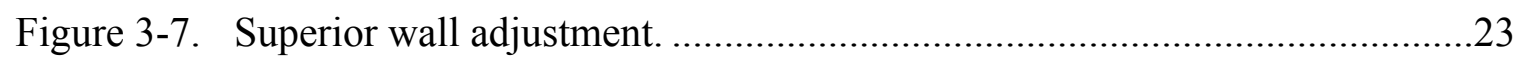

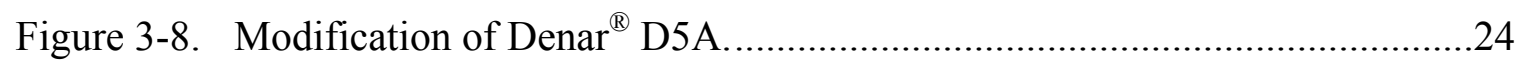

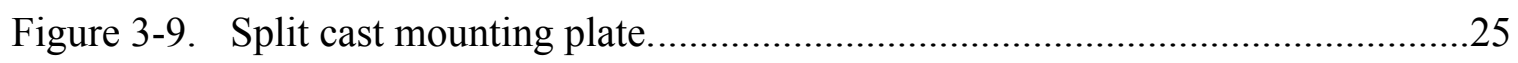

Figure 3-10. Freecorder ${ }^{\circledR}$ maxillary and mandibular face-bows attached to mock

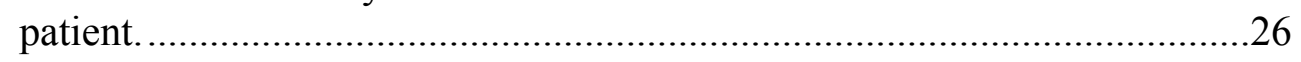

Figure 3-11. Close up view of Freecorder ${ }^{\circledR}$ Bluefox maxillary and mandibular face-

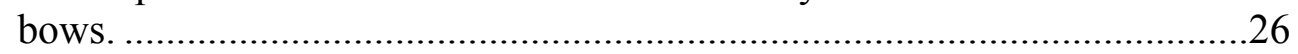

Figure 3-12. Cadiax maxillary and mandibular face-bows attached to mock patient. ......28

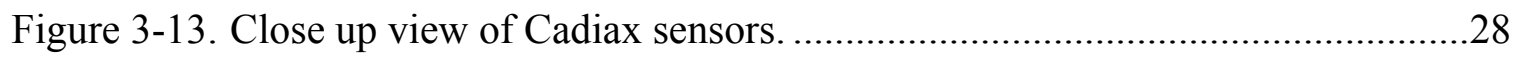

Figure 3-14. Maxillary face-bow mounting apparatus............................................29

Figure 3-15. Close up view of maxillary face-bow mounting apparatus. .......................29

Figure 3-16. Articulator holding and suspending apparatus.......................................30

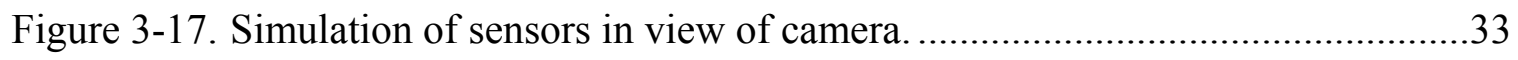

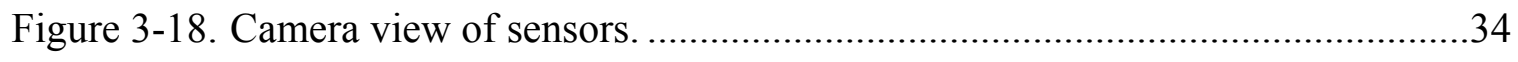

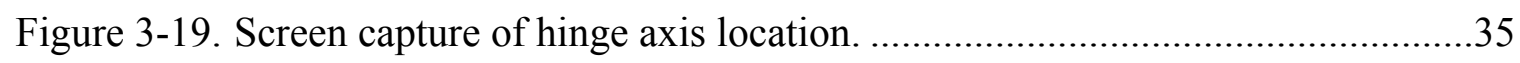

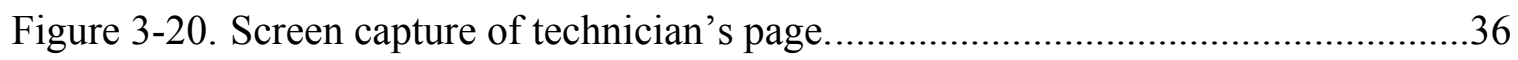

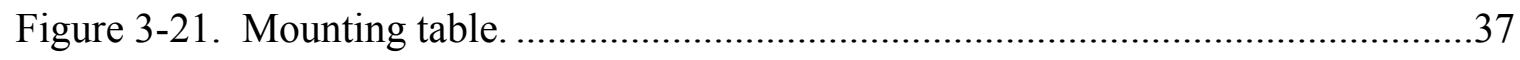

Figure 3-22. Comparison of patient and mock patient positioned in Freecorder ${ }^{\circledR}$ Bluefox. 


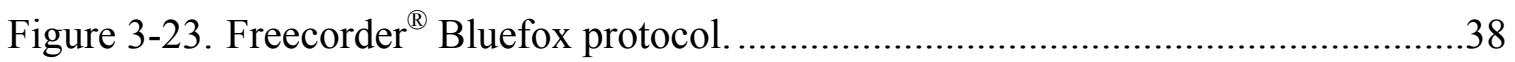

Figure 3-24. Technician page to program articulator.........................................................39

Figure 3-25. Screen capture of protrusive recording.......................................................40

Figure 3-26. Screen capture of right lateral movement....................................................41

Figure 3-27. Screen capture of left lateral movement. ......................................................42

Figure 3-28. Comparision of patient and mock patient with Cadiax Compact $2^{\circledR}$ mandibular recorder. ……………………...................................................44

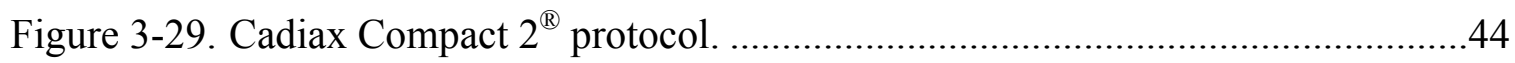

Figure 3-30. Screen capture of articulator page..............................................................

Figure 3-31. Screen capture of a protrusive movement......................................................47

Figure 3-32. Screen capture of left lateral movement. ......................................................48

Figure 3-33. Screen capture of right lateral movement.................................................49

Figure 4-1. Lateral view comparing mock patient mounting with Freecorder ${ }^{\circledR}$ Bluefox mounting.......................................................................................

Figure 4-2. Rear view comparing mock patient mounting with Freecorder ${ }^{\circledR}$ Bluefox

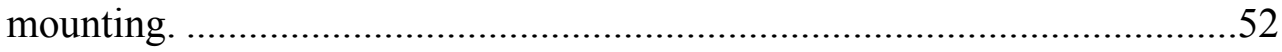

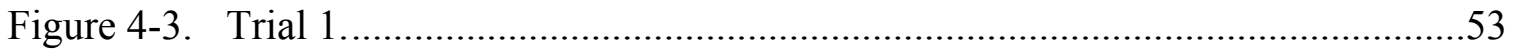

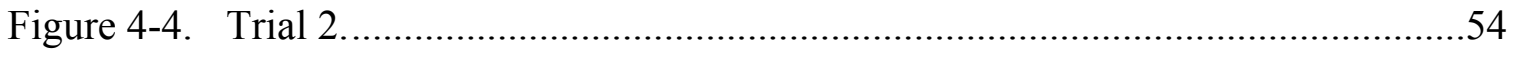

Figure 4-5. Trial 2 Immediate Mandibular Lateral Translation. .....................................55

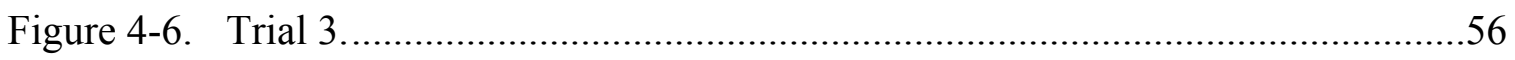

Figure 4-7. Trial 3 Immediate Mandibular Lateral Translation. .....................................57

Figure 5-1. Teeth with tall cusps and deep fossae.........................................................66

Figure 5-2. Mock patient settings. ..........................................................................67

Figure 5-3. Mock patient relative to Freecorder ${ }^{\circledR}$ Bluefox............................................68

Figure 5-4. Mock patient relative to Cadiax Compact $2^{\circledR}$.............................................69

Figure 5-5. Relative relationship of the mock patient, Freecorder ${ }^{\circledR}$ Bluefox and Cadiax Compact $2^{\mathbb{B}}$...... . .70 
Figure 5-6. Cusp pathway mock patient. .......................................................... 71

Figure 5-7. Cusp paths based on Freecorder ${ }^{\circledR}$ Bluefox mean values.............................72

Figure 5-8. Cusp paths based on Cadiax Compact $2^{\circledR}$ mean values................................73

Figure 5-9. Cusp paths of mock patient, Freecorder ${ }^{\circledR}$ Bluefox and Cadiax Compact

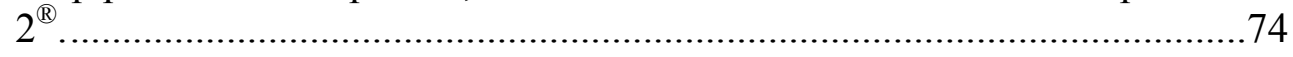




\section{LIST OF ABBREVIATIONS}

CI

IMLT

LCI

PMLT

THA

TMJ
Confidence Interval

Immediate Mandibular Lateral Translation

Lateral Condylar Inclination

Progressive Mandibular Lateral Translation

Transverse Horizontal Axis

Temporomandibular Joint 


\section{CHAPTER 1. INTRODUCTION}

The study and treatment of the stomatognathic system is called "gnathology." This term was coined by Stallard in 1924 to describe an approach to dentistry as a whole (Stuart and Golden 1984 and Pokorny et al 2008). Gnathology is defined as the science of the anatomy, histology, physiology and pathology of the stomatognathic system in which treatment of the system is based on examination, diagnosis and planning. The system includes the teeth, supporting tissues, temporomandibular joints (TMJ) and associated hard and soft tissues of the head and neck (Bauer and Gutowski 1976, Starke 2002, GPT-8 2005, and Pokorny et al 2008).

To understand and treat the stomatognathic system requires knowledge of the component parts and their relationships (McCollum 1955, Aull 1963, Bauer and Gutowski 1976 and Pokorny et al 2008). The goal of the restorative doctor, when reconstructing a patient's mouth, is to register maxillomandibular relationships that accurately reproduce border movements and prescribe the best occlusal interface. Registration of the horizontal and sagittal movements of patients allows the maximum cusp height and fossae depth with proper placement of occlusal ridges and grooves (McCollum 1955, Stuart 1959 and Pokorny et al 2008).

A goal of restorative dentistry is to develop an occlusion that is interference free and entails the concepts of organic occlusion (Stuart and Stallard 1969 and Pokorny et al 2008). Organic occlusion is an organized occlusion encompassing disocclusion, cuspfossa relationship, centric relation occlusion, uniform centric contacts, forces directed over the long axis of the teeth, tripodized cusps, cross tooth stability, narrow occlusal table, maximum cusp height and fossa depth with supplemental anatomy (Stuart 1959, Stuart and Stallard 1969, Bauer and Gutowski 1976, Stuart and Golden 1981 and Pokorny et al 2008). Gnathology is based on the following fundamentals: centric relation, anterior guidance, occlusal vertical dimension, the intercuspal design and the relationship of determinants of mandibular movements using mandibular recording instruments to occlusion in fixed prosthodontics (Stuart and Golden 1981 and Pokorny et al 2008).

To review the clinical problem, the goals of restorative dentistry are to achieve an accurate occlusal relationship, copy mandibular movement of the patient in the laboratory and organize the occlusion. In designing occlusal surfaces, the taller cusps allow for masticatory efficiency, have better esthetics, stabilize the tooth and stabilize the arch (Stuart and Stallard 1960, Stallard and Stuart 1963, Stuart 1964, Stuart 1979 and McHorris 2010). The shorter cusps decrease the risk of occlusal interferences. The disadvantage to taller cusps is an increased risk of interferences during mandibular movement. The disadvantages to shorter cusps are the opposite of the advantages of tall cusps.

Medial wall position and angulation settings will dictate whether the cusp tips may be longer or MUST be shorter, and whether the placement of the cusp pathways (the 
grooves) will be more mesial or more distal. The angle of the emenetia influences the cusp height and shape of the lingual concavity of maxillary anterior teeth (Stuart and Stallard 1969, Stuart 1976 and Huffman and Regenos 1989). The closer a tooth is to a control, i.e. the condyle, the more the tooth is influenced by the control (McHorris 1989). If the misdiagnosis is "may have longer cusps," then potential interferences are incorporated. If the misdiagnosis is "cusps MUST be shorter," then potential interferences are avoided; however, masticatory efficiency, tooth stability, arch stability and esthetics are compromised. Aull (1965) demonstrated that large changes in the condylar guide assembly resulted in dramatic changes in cusp height and cusp paths.

Centric relation is "the physiologic relationship of the mandible to the maxilla and the cranial base, when both condyles are properly related to their articular discs whereby the condyle-disc assemblies are stabilized against the posterior slopes of the articular eminence of the glenoid fossae. This relationship may occur at varying vertical dimensions of rotation of the mandible preceding any translation of the condyles" (McHorris 1986, p. 20). Centric relation is a repeatable reference point relating the mandibular and maxillary dental arches. The centric relation records, when transferred to an articulator with mounted casts serve to replicate the patient's maxillary-mandibular relationship. From this anatomically correct position, accurate relative interarch movements of the articulator are possible. Centric relation is currently defined as "the maxillomandibular relationship in which the condyles articulate with the thinnest avascular portion of their respective disks with the complex in the anterior-superior position against the shapes of the articular eminencies. The mandible (condyles) is directed superior and anteriorly. It (the mandible) is restricted to a purely rotary movement about the transverse horizontal axis" (GPT-8 2005, pp. 21-22).

Once the condyles are seated against the fossa, a repeatable movement of the mandible is produced. The repeated opening and closing occurs around an axis of rotation of the mandible. "An imaginary line connecting the center of rotation of one condyle to the center of rotation of the other condyle" is termed the transverse hinge axis (Lucia 1983). The imaginary line does not necessarily have to be parallel to any anatomical landmarks. The two condyles function as a unit. Weinberg (1959) states the importance of locating the terminal hinge axis, or the starting point, for all mandibular movements. The importance of the terminal hinge axis is also supported by Charles $\mathrm{E}$. Stuart (Stuart and Stallard 1964), as he states that all articulator adjustments will be incorrect if the terminal hinge axis is incorrect. The basis for mounting casts correctly on an articulator is dependent upon properly positioning the condyles within the fossa.

The transverse hinge axis is more properly termed the transverse horizontal axis, and is defined as "an imaginary line around which the mandible may rotate in the sagittal plane" (GPT-8 2005, p. 78). Manual methods for locating the transverse horizontal axis using kinematics evolved from the California Gnathologic Society by B.B. McCollum and Charles Stuart. Robert Harlan is credited with the idea of a mechanical location of a hinge axis through kinematics (Preston 1979). Kinematics is defined as the phase of mechanics that deals with the possible motions of a material body (GPT-8). It has been suggested that improper location of the transverse horizontal axis can lead to more time 
spent on occlusal equilibration than it would have taken to locate the hinge axis, and the results of occlusal equilibration leads to less satisfactory prosthetic results than those produced on the articulator (Gordon et al 1984). Transferring patient information to a properly selected articulator allows the dentist and technician to more accurately evaluate and design restorations that will later be delivered to the patient. McCollum (1960) suggested that the articulator must duplicate the hinge axis of the mandible so that other movements can be reproduced.

A pantograph, in dentistry, is an instrument used to graphically record in one or more planes, the paths of mandibular movement and to provide information for the programming an articulator so that articulator movements will be in harmony with the patient's mandibular movements (McCollum 1955, Stuart 1959, Clayton 1971, Curtis and Sorensen 1986). A pantographic tracing is a graphic record of mandibular movement, usually recorded in the horizontal, sagittal and frontal planes as registered by styli on the recording tables of the pantograph or by means of electronic sensors (Curtis and Sorensen 1986 and GPT-8 2005). Pantography is currently considered to be the most accurate and complete means of recording jaw movement and border positions (Clayton 1971 and Lucia 1983). Restorations fabricated on articulators programmed using pantography should function in the patient's mouth without interference (Anderson et al 1987). Types of pantography include mechanical, mechano-electronic and optoelectronic (Table 1-1).

Mechanical pantography is considered to be accurate and reliable (McCollum 1955, Clayton et al 1971, Beard et al 1986 and Pelletier 1991). However, the time and complexity of recording movements and programming the articulator from the tracing are considered major shortcomings (Coye 1977 and Price et al 1989).

Mechanical mandibular recorders are so named because styli make physical contact with the recording plates to register movement. The apparatus is relatively heavy and the process is considered by some to be a relatively time consuming. Compared to electronic mandibular motion recorders, mechanical recorders are relatively inexpensive.

Mechano-electronic recorders and optoelectronic recorders that register mandibular movement electronically have been developed in an attempt to improve

Table 1-1. Methods of recording mandibular movement and adjusting 3-D articulators.

\begin{tabular}{|c|c|c|c|c|}
\hline Method & Contact & Weight & $\begin{array}{c}\text { Time } \\
\text { (Expert User) }\end{array}$ & Cost \\
\hline Mechanical & Styli & $\begin{array}{c}\text { Relatively } \\
\text { heavy }\end{array}$ & $2 \mathrm{hrs}$ & $\$ 5,000$ \\
\hline $\begin{array}{l}\text { Mechano- } \\
\text { electronic }\end{array}$ & Styli/wired & Relatively light & 30 mins & $\$ 8,165$ \\
\hline Optoelectronic & Sensors/wireless & Lightweight & 15 mins & $\$ 30,000$ \\
\hline
\end{tabular}


precision and efficiency. In theory, the computerized pantograph quickly analyses patient movements and minimizes articulator programming errors by generating numerical condylar values. In vivo and in vitro studies have suggested the electronic pantographs to be an acceptable alternative to mechanical pantography (Clayton et al 1983, Beard et al 1986, Anderson et al 1987, Pelletier 1991, Celar and Tamaki 2001 and Chang et al 2004).

Mechano-electronic recorders are so named because styli physically move across digital recording plates. Mandibular movement is recorded by the digital contact plates and processed by the software. Values for programming most articulators are then generated by the computer. The recording apparatus is relatively light compared to mechanical devices and require less time to complete a full recording. However, there is increased cost for the system.

Optoelectronic recorders have coded sensors attached to maxillary and mandibular facebows. The device is optoelectronic because sensor movement is optically tracked by cameras. The sensors are wireless. Three-dimensional information is processed by the computer and articulator values are generated. The recording apparatus is light weight and the recording session requires relatively little time. However, system costs are substantially high.

A new optoelectronic, computerized pantograph has been developed (Freecorder ${ }^{\circledR}$ Bluefox, Dentron, Germany). However, the accuracy and reliability of this optoelectronic pantograph has not been investigated.

The aim of the present investigation was to assess the accuracy of a relatively new optoelectronic pantograph in locating a known transverse horizontal axis, assess the ability of this optoelectronic pantograph to accurately determine preset values of the articulator, assess the ability of a mechano-electronic pantograph to accurately determine the preset values of the articulator and compare the accuracy of the optoelectronic pantograph and mechano-electronic pantograph through statistical analysis.

This investigation utilized a bench top or in vitro approach. Beard et al (1986) and Pelletier (1991) advocated the bench top investigations for pantograph testing to minimize variables and eliminate patient-related error. Additional studies have also used the bench top approach to evaluate mechanical, mechano-electronic and optoelectronic devices (Graver 2001, Celar and Tamaki 2002 and Chang et al 2004). This investigation was designed to make comparisons of instrument capabilities and validate instrument accuracy.

In a preliminary study, an apparatus was fabricated to securely mount an articulator to serve as an experimental or mock patient. The apparatus allowed movement of only the mandibular element of the articulator. Manipulation of this articulator clinically represented patient guided mandibular motion. During this investigation, when referring to manipulation of the articulator which incorporates known adjustments, the term mock patient will be used. When referring to programing the 
articulator based on values generated by the computerized pantographs, the term programmed articulator will be used.

Recording instruments investigated in this study were attached to the mock patient in a clinically realistic manner. Computerized pantographs recorded guided mock patient movements through clinically relevant means permitting in vitro analysis of the computerized pantographs.

A Denar ${ }^{\circledR}$ D5A fully adjustable articulator served as the mock patient in this investigation. The Denar ${ }^{\circledR}$ D5A has been used in previous studies to evaluate pantographs (Beard et al 1986, Anderson et al 1987 and Chang et al 2004). The beneficial features of the Denar ${ }^{\circledR}$ D5A include a centric holding latch to aid in the transverse horizontal axis (THA) determinations, adjustable lateral condylar inclination (LCI) angles, progressive mandibular lateral translation (PMLT) angles, adjustable immediate mandibular lateral translation (IMLT) and laterotrusion controls. By attaching recording instruments to this articulator, direct comparison of numerical output from computerized pantographs could be made with the articulator's settings (Anderson et al 1987).

The Freecorder ${ }^{\circledR}$ Bluefox optoelectronic pantograph is said to accurately perform transverse horizontal axis recording. The Freecorder ${ }^{\circledR}$ Bluefox optoelectronic and Cadiax Compact $2^{\circledR}$ mechano-electronic pantographs were used to determine the lateral condylar inclination (LCI), progressive mandibular lateral translation (PMLT) angle and amount of immediate mandibular lateral translation (IMLT). The Cadiax Compact $2^{\circledR}$ mechanoelectronic pantograph was also used to determine values for the rear wall (lateroprotrusion or latero-retrusion) and superior wall (latero-surtrusion or latero-detrusion) angles of the condylar guide assembly. 


\section{CHAPTER 2. LITERATURE REVIEW}

Treatment of the stomatognathic system requires knowledge of the component parts and their relationships (McCollum 1955, Aull 1963, Bauer and Gutowski 1976 and Pokorny et al 2008). The study of mandibular motion and the need to duplicate the movements extraorally have long been recognized by dental professionals (Gysi 1910 and McCollum 1955). Many methods to analyze and record mandibular movements have been employed by dental researchers and clinicians. The most notable advances include the development of articulators, face-bows and mandibular movement recording devices (Bauer and Gutowski 1976, Solnit and Curnitt 1988 and Graver 2001).

\section{Articulation and Mandibular Movement: A Historical Perspective}

\section{Jaw Relators}

Starke (1999a, 1999b, 2000a and 2000b) in a series of articles describes the history of the development of articulators and devices to record mandibular movement. The early history of articulator development is based on anecdotal information, inadequate historical records and little early scientific research (Starke 1999a and Graver 2001). Philip Pffaff is traditionally credited with making the first copies of edentulous maxillary and mandibular dental arches using beeswax impressions poured with plaster around 1750. In 1756, Pfaff has also been credited with creating the Pfaff slab articulator. This device was described as a static relator of dental casts that lacked the ability to duplicate patient mandibular movement (Bauer and Gutowski 1976, Mitchell and Wilkie 1978 and Graver 2001).

Gariot is credited in 1805 with developing the first articulator capable of movement. His articulator design is described as having a metallic hinge which was restricted to simple rotational movement (Bauer and Gutowski 1976, Mitchell and Wilkie 1978 and Graver 2001).

Articles by Starke (1999a, 1999b, 2000a) question the credit given to Pfaff and Gariot. Starke has credited Pfaff with describing a method of making plaster casts in 1756 and with making a wax bite if the patient had teeth. However, Pfaff did not describe using the registration to preserve the relationship of the casts (Graver 2001).

Starke (1999a) has credited Gariot, in 1805 with describing a method of generating plaster casts and extending them posteriorly to provide an indexing mechanism for preserving the relationship of the casts. Therefore, Gariot was the first to describe a plaster articulator. The plaster articulator was a simple indexing device, which became known as the "oiled board" articulator (Starke 1999a and Graver 2001). 
Starke (1999a) stated that regarding dental articulators, "all that can be said with assurance is two documented facts: 1) Pfaff was the first to describe a wax impression technique and a method for generating plaster casts; and 2) Gariot was the first to describe a method for mounting casts and preserving their relationship with plaster index" (p:210).

Starke (1999b) contended that the exact origins of the first mechanical hinge articulator may never be known. The term "articulator" was not the preferred term for these instruments. The more common terms were "antagonizing frames," "occluding frames," "occlusion frames," and "antagonizers."

The earliest studies did not record mandibular movement. The investigators attempted to relate the maxilla and mandible in devices that preserved the interarch relationship. The device described as a plaster articulator was a static relator of casts that lacked the ability to copy any patient mandibular movement. Additionally, the development of the first articulator with movement was restricted to a simple nonanatomic rotational movement (Bauer and Gutowski 1976, Mitchell and Wilkie 1978 and Graver 2001).

\section{Anatomical Relationships}

Bonwill in 1859 developed his articulator that he thought closely mimicked the anatomy and movement of the temporomandibular joint. His articulator had horizontal condylar paths and the distance between the condyles, the intercondylar distance, was established at an anatomical distance of $100 \mathrm{~mm}$ (McCollum 1960, Bauer and Gutowski 1976 and Grave 2001). This articulator allowed the mounted casts to make centric opening and closing, left lateral, right lateral and protrusive movements (Chance 1984). Bonwill arbitrarily located the casts in the articulator by means of dividers, setting the mesial line of the trial plate at four inches from the condyles or joints of the articulator. He found this to be the average measurement in his investigations (Brandrup-Wognsen 1953 and Graver 2001).

In 1866, Balkwill used anatomical investigations to describe mandibular movements. He first described an opening and closing axis that ran through the mandibular condyles. He also noted downward, forward and lateral glide movement of the mandibular condyles (McCollum 1960 and Bauer and Gutowski 1976). He designed his articulator based on these concepts. Balkwill is also noteworthy for having an illustration in his article showing a Gothic arch tracing; however, he does not mention this illustration in the text (Graver 2001).

Hayes received a patent in 1889 for his articulator that was the first to incorporate a fixed descending condylar path (Starke 1999b). Hayes' design concept featured fixed curved condylar paths and individual condylar tension springs. The articulator had nonadjustable condylar elements and is classified as a "fixed condylar guide" articulator. Hayes' design is most likely the first example of an articulator that can be identified as an 
"arcon articulator" (Starke 1999b and Graver 2001). Starke (1999b) credited Hayes for inventing the "articulating caliper." The caliper is the first instrument on record that attempted to locate casts in an anatomically correct position on the articulator. However, it simply enabled him to set the median incisal point in relation to its distance from the two condyles. There was no third reference point; therefore, no orientation to the occlusal plane. It also did not account for a medial-lateral position relative to the condyles (Hall 1930, Brandrup-Wognsen 1953 and Graver 2001).

\section{Methods and Devices to Record Mandibular Movement}

\section{Photographic}

In 1889, Luce was the first investigator to make a photographic recording of mandibular motion. Luce's subject sat in a brightly-lit area; small reflective sphere was attached to the end of a wooden rod between the subject's mandibular incisors. The ball reflected light onto a photographic plate in the sagittal plane. This recorded the path of the ball on opening. He later fabricated an improved recording device consisting of a framework with reflectors extending to the condyle and the mandibular angle areas. Luce analyzed the recordings and concluded that the condyle traveled in a curved path, the mandible moved downward and forward during anterior movement and the concave portion of the curved path is located superiorly. Luce's investigations confirmed Balkwill's findings that condylar path is downward and forward (Sonstebo 1961, Bauer and Gutowski 1976, Graver 2001 and Starke 2001).

In Sweden, the same year as Walker, Ulrich recorded mandibular movement with a "photographic" method similar to Luce and Marey. The devices attached to the mandibular teeth and had a splint designed to avoid occlusal interferences during mandibular lateral movements. The device was adjustable. Movements were recorded with silver beads attached to the device. Photographs were made from above to record lateral condylar paths in the horizontal plane. He concluded that because the condyles' forward motion occurs immediately upon opening, there were a series of instantaneous axes responsible for the opening movement (Starke 2001).

Kurth (1942) evaluated mandibular movement by attaching a polished steel ball to the mandibular incisors. A strobe light set at twenty-five flashes per second illuminated the balls. Photographic plates in the frontal, sagittal and horizontal planes recorded the images. He used the results to measure directions of mandibular movement and noted that mastication only involved lateral and opening movements (Graver 2001).

Lundeen et al (1959) made multiple exposures of mandibular recording points using a stroboscopic method. A strobe light set at ten flashes per second reflected off the steel balls attached to the mandibular framework positioned at the condylar area near the premolars and midway between the two. The recording took place on photographic plates in the sagittal plane. 
Rudd et al (1967) used ultraviolet light to illuminate two anterior reference spheres coated with fluorescent paint attached to the maxillary and mandibular arches. The spheres were recorded in three planes using mirrors. Time-exposure photography made permanent records of the mandibular movements (Graver 2001).

Joire in 1978 used a light source to record Posselt's envelope of motion in the frontal and sagittal planes. He used a strobe light to photographically record the chronological component of mandibular border tracings. He determined the relative length of time the mandible stayed in a border position (Graver 2001).

\section{Stereographic}

In 1892, Warnekros introduced an engraving method for recording mandibular movement. This was the first attempt at a stereographic system of jaw-movement recording. He used his recording to adjust the individual lateral movements of his articulator, which was a modification of Bonwill's articulator (Starke 2004).

Needles in 1922 modified Luce's intraoral recording technique. The maxillary and mandibular occlusal rims were shaped to a four-inch radius sphere to establish the occlusal curvature. He embedded four wires into the maxillary occlusal rim to serve as styli. The wires carved Gothic arch stereographs in to the wax on the mandibular occlusal rim (Starke 2004).

Luce developed a technique to record mandibular motion in edentulous subjects. His device used five roundhead nails mounted to a mandibular occlusal rim. The nail heads scribed the movements of the mandible on a rim of softened impression compound applied to a maxillary record base. His recordings produced Gothic arch tracings. Centric relation, lateral and protrusive paths were recorded and used to program an articulator (Starke 2004).

House (1931) developed a device similar to Needle's and Luce's intraoral recording instruments. House used three cutting styli on a vulcanite central bearing device. Three Gothic arch stereographs were cut simultaneously as the mandible moved. His tracings recorded the position and movement of the mandible in two dimensions. The device became known as the "Needles-House Chew-in" (Bauer and Gutowski 1976, Graver 2001, Starcke 2004 p:118 and Starcke 2005).

Swanson in 1965 modified Luce's, Needles' and House's technique (Starke 2005). He used custom-fabricated maxillary and mandibular clutches with a central bearing device. The maxillary clutch had four triangular-shaped cutting styli to carve Gothic arch tracings in chemically-activated acrylic resin prior to polymerization. He also developed the TMJ Articulator capable of accepting the stereographic record. The stereograph was retraced manually. The maxillary member of the articulator accepted plastic boxes filled with chemically-activated acrylic resin. The mandibular condylar elements were used to create replicas of the temporomandibular fossa in the chemically- 
activated acrylic resin. The fossa replicas allowed the articulator to simulate mandibular movement based on the recorded movements of the patient (Graver 2001).

Lee (1969) developed an extra oral stereographic research instrument (Analog Articulator). High-speed air turbines engraved condylar movements into clear plastic blocks. The engraved plastic blocks could be used as condylar guides for the articulator. Lundeen et al (1978) used the recording instrument developed by Lee to analyze mandibular border movements and cusp movement. They found that patients with excessive immediate mandibular lateral translation and little or no anterior guidance are challenging. They also found the average IMLT to be $0.75 \mathrm{~mm}$.

\section{Static and Graphic}

Christensen described a method in 1901 to record mandibular movement intraorally. He used wax rims on vulcanized rubber bases to record the forward and downward movement of the mandible and condylar path slopes. He also recorded lateral movements of the mandible. This method probably led to the "checkbite" (Starcke 2000b). He also developed an articulator with adjustable condylar paths utilizing his recordings (Bauer and Gutowski 1976, Becker and Kaiser 1993 and Graver 2001).

Hight (1911) also developed a mandibular recorder. His device was similar to Luce's. The intraoral device had styli connected to the maxilla. The paths were recorded on the mandibular plate. His tracings recorded the position and movement of the mandible in two dimensions (Bauer and Gutowski 1976 and Graver 2001).

Stansberry (1929) used a central bearing device with his recording instrument and removed the influence of the record base on the Gothic arch tracing. The central bearing device allowed for adjustments of the vertical dimension. He developed the Denture tripod articulator.

\section{Mechanical}

Walker in 1896 developed the first articulator with adjustable condylar paths and a provision for adjustable lateral movement. His articulator permitted a greater range of motion and closer approximation of individual patient function (Bauer and Gutowski 1976 and Starke 2001a). Walker stated that the curvature of the roof of the glenoid fossa caused the condyle to move forward and downward on the orbiting side and slightly upward and backward on the rotating side. The Walker "Facial Clinometer" was a mechanical device consisting of two devices. One device consisted of a mandibular facebow to record individual "condylo-facial" angles and the distance traveled by both condyles. The second device recorded the "occluso-facial" angle. His results were similar to Luce. He further verified Luce's finding by replacing the "bright beads" with pencil lead to trace mandibular movement on sheets of paper attached to the subject's 
face. Walker's device was confusing to dentist at the time and difficult to use (Starke 2001a).

Campion in 1902 was the first to rigidly fix a face-bow to the mandibular arch and study mandibular motion. The movements were recorded on the skin with a rouge and oil mixture. The dots were transferred to paper for evaluation. The recordings were made at extreme right, extreme left and maximal opening. He described an initial rotational movement around an axis that ran through both condyles followed by a translational motion downward and forward. He also stated that casts should be mounted in articulators so that the rotational axis of the articulator coincides with the opening and closing of the mandible (Campion 1905 and Bauer and Gutowski 1976).

Zola and Rothschild (1961) fabricated a "condylar thesiograph" to trace and record condylar positions. The thesiograph is a hinge bow consisting of separate left and right sections cemented to the buccal surfaces of mandibular teeth. This arrangement allowed the teeth to contact in passive and "power closures." They made physiologic rest position, passive closure, power closure, forced retrusion and "autoretrusion" records to evaluate condylar positions of each record. They found that the rest position of the mandible had no predictable relationship to the hinge axis position.

Boucher (1961) severed the temporomandibular ligaments of human cadavers and on living humans (one side only) requiring this treatment. Measurements were made prior to and after severing of the ligament. They found that extraoral needle point tracings (Gothic arch tracings) on the cadavers were identical pre and post ligament severing. There were no lateral changes on the live human subjects. They concluded that the ligament did not limit mandibular retrusion. These findings contradicted a previous study (Aprile 1947). In a similar study, Boucher and Jacoby (1961) demonstrated a difference in mandibular positions of conscious and unconscious subjects. The unconscious subjects' mandibles could be retruded more posteriorly than the conscious subjects' mandibles. They found no differences in Gothic arch tracings of conscious patients and premedicated patients.

Griffin (1961) described a mandibular recording device he called the "mandibular kinematograph." The device consisted of a recording stylus, spring loaded writing device, concave recording panel with moving graph paper, an electronic motor and magnifying tool all positioned on a traymobile that could rotate ninety degrees to record frontal and lateral tracings. There were no intraoral components. A horizontal rod was attached to the subject's chin by a chin cap. The instrument measured the threedimensional displacement of the rod (Graver 2001).

\section{Optical}

Bennett discussed the rotational and lateral movements of the mandible and condyles in 1907. Lights attached to the mandibular frame over the condyle and at the symphysis were focused with a lens onto a sheet of paper in the sagittal plane. The 
focused spots were recorded at several intervals. He concluded that there was an instantaneous center of rotation that varied with different condylar movements and positions. He noticed a lateral shift of the working condyle, recorded in the frontal plane, towards the side to which the movement was being made. Bennett noted that as the mandible moved bodily to one side, the condyle on the side of the movement rotated in place or moved slightly and the opposite condyle moved downward and forward (Bennett 1907, McCollum 1955, DePietro 1963 and Bauer and Gutowski 1976). The same movement was described previously by Balkwill and Marey and demonstrated by Ulrich (Starke 1999a and Starke 1999b).

Shanahan and Leff (1959) recorded mandibular movement with small light bulbs attached to the chin. The recording point measured opening and closing paths differences between humans and articulators. They found that humans and articulators open and close on different paths.

\section{Radiographic}

Jankelson et al (1953) and Berry and Hoffman (1956) evaluated mandibular movement and the function of the stomatognathic system utilizing cineradiography. They analyzed denture movement, bolus position, phonetics and velopharyngeal functions. Their studies were limited to two dimensions recordings of mandibular movement (Graver 2001).

\section{Motion Picture}

Atkinson and Shepard (1955) affixed two indicator balls to the anterior maxillary and mandibular incisors and filmed the motion. They used a mirror so that the movement of the mandibular ball was seen in the sagittal and frontal planes. A frame-by-frame analysis of masticatory function was made utilizing reference grids placed in front of the ball during filming (Graver 2001).

Woefel et al (1962) attached indicators to maxillary and mandibular complete dentures. Three balls were attached to anterior portion of each denture. They recorded the border movements of the subjects and masticatory function with different occlusal forms. The recording points were captured on film. An electronic device plotted the positions of the recorded points. They were able to evaluate individual cyclic mandibular movement simultaneously (Graver 2001).

Hickey et al (1963) used three small light sources as recording points to make motion pictures of functional masticatory movements. The light source was inserted into each condyle and one attached to the mandibular anterior teeth. Three cameras in different planes recorded all three light sources simultaneously. Reference grids allowed for analysis of the movements when each frame was projected onto graph paper. 
Weinberg (1964) made motion pictures of mandibular border movements of dentate subjects. That same year, Martone (1964) made motion pictures of edentulous subjects.

\section{Photoelectronic}

Gillings (1967) developed a device that consisted of a mandibular rod and lights attached to the labial surfaces of mandibular anterior teeth and a headframe with recording photocells attached. As the mandible moves, the light moves in relation to the photocells changing the electrical output. The output is recorded on a moving-paper oscillograph.

Rudd et al (1969) developed recorded mandibular movement with a computerized photoanthropometry system. An ultraviolet light source illuminated acrylic resin spheres coated with fluorescent paint attached to maxillary and mandibular wire frameworks. The camera recorded mandibular movement and the reference grid in three planes. A film motion analyzer transposed the data to the computer data sheets. The computer plotted the data and envelopes of motion in all three planes could be evaluated.

Waysenson and Salomon (1977) recorded mandibular movement using an optoelectronic device that did not attach to or interfere with subject. The device consisted of three photoelectronic cells positioned perpendicular to each other. Two of the cells were placed at right angles to each other in a light tight box. The two sensors detected opening, closing and anterior-posterior movements when a horizontal light beam struck both cells simultaneously after passing through narrow windows in the box. A third sensor perpendicular to the other two measured lateral movements with a vertical beam of light. A dual-beam memory oscilloscope received input from the electrical signals of the photocells and displayed three-dimensional mandibular movements in twodimensions. This system did not provide absolute three-coordinate locations.

\section{Mechanical Pantograph}

Gysi (1910) used a modified Snow face-bow to create the first pantograph and record a continuous-line graphic illustration of mandibular movements. He used a pantograph framework to make registrations of the orbiting movement of each condyle in the posterior horizontal plane. He made graphic recordings of the path of an incisor point in the horizontal plane. The extraoral tracer was attached to the maxillary arch and the recording plate to the mandibular arch. His recordings were classic "Gothic arch" tracings. "Gysi's pantograph is considered a major improvement in mandibular motion analyzers" (Bauer and Gutowski 1976, Graver 2001 and Starke 2001b).

McCollum began the development of a new pantograph in 1924 (the Gnathograph) with cemented intraoral clutches with a central bearing screw and detachable maxillary and mandibular frames with adjustable arms. Posterior horizontal 
and vertical styli traced condylar inclinations and Bennett paths and two anterior styli traced lateral movements (Starke 2002). The tracings made with McCollum's pantograph could be transferred to his highly adjustable articulator (the Gnathoscope) and manually retraced.

Stuart joined McCollum in 1924 and assisted him in developing the Gnathograph and Gnathoscope. Stuart continued to work to develop the fully adjustable Stuart® Gnathological Computer. The mechanical mandibular recording device was used to program the articulator. This method allowed for an accurate mechanical representation of the functioning stomatognathic system (Donaldson and Clayton 1986). The pantograph consisted of six graphic tracings, two vertical and two horizontal plates in the condylar region attached to the maxillary frame and two horizontal plates anterior attached to the mandibular frame. The axis-orbitale plane defined the condylar angle and the recording reference position was the kinematically located THA. The two anatomical references made consecutive recordings more comparable. Stuart (1959) made note that the tracings were magnifications of the true condylar paths, not the paths themselves.

Cohen (1956) evaluated the relationship of anterior guidance in mandibular movement and pantographic recordings. He found no effect on posterior tracings when changing the vertical dimension on clutch-bearing surfaces. However, the anterior tracings changed with changes in vertical dimension due to the orientation of the straight anterior styli (Graver 2001).

Guichet (1970) developed a pantograph similar to Stuart's and an articulator $\left(\right.$ Denar $\left.^{\circledR}\right)$ to retrace the recording. The posterior recording plates were attached to the mandibular frames instead of the maxillary frames. Guichet's styli were powered by compressed carbon dioxide cartridges and allowed for one person to operate all six styli during a recording. Individual programming of the articulator was defined by the patient's condylar characteristics (Graver 2001).

\section{Optoelectronic}

Knap et al (1975) developed a digital system consisting of optical sensors, electronic module, analog tape recorder, mandibular movement duplicator and computer. The electronic module transfers the signal from the sensors to the analog tape recorder. The electronic module sends impulses to the motion duplicator. The mandibular motion duplicator which is designed similar to the mandibular recorder attaches to mounted casts and simulates mandibular movement. This system provided graphic display, numerical analysis and visualization of recorded mandibular movement.

Jemt (1982) evaluated an optoelectronic system (Selspot system) which utilizes one diode attached to a mandibular incisor and three diodes arranged in a triangle attached to glass frames. Two cameras with photosensitive detectors record light impulses emitted from the diodes to a digital tape recorder. The impulses are plotted and analyzed by a computer. 


\section{Mechano-electronic Pantograph}

Hobo and Mochizuki (1983) developed an electronic measuring system capable of recording mandibular movement. They developed sensors that could measure in two spatial dimensions. The system was designed to generate six independent measurements utilizing three styli recording in two directions. The styli tips formed a triangle and connected to the mandible via a clutch. Three conductive plastic sensors attached to the maxilla via a clutch. The styli made contact with the sensors. A computer processed the data and mandibular movement was displayed graphically by the graphic plotter.

\section{Evaluation and Comparison of Mandibular Recording Devices}

Stuart (1959) described and recorded mandibular movement with his recording device. He stated that the dental articulator needs to accurately reproduce mandibular border movements and that the translative movements and timing of jaw and articulator movements are important. Mandibular recording devices record border movements and the recordings are used to program the articulator.

Clayton et al (1971a) determined that graphic tracings of mandibular movement can be affected by changes in occlusal vertical dimension, by different shapes of central bearing guidance surfaces and tooth guidance because conclusions about mandibular movement are made directly from the graphic tracing. Whereas, conclusions about mandibular movement recorded by pantographic tracings are made from the movement of casts on an adjusted articulator. They noted that border movements give stable and repeatable tracings and recordings.

Clayton (1971) in a different study concluded; "A pantograph graphically reflects individual anatomic characteristics of the temporomandibular joints which influence mandibular paths of movement or paths of movements of cusp. An articulator is used to interpret the information recorded by the pantograph. The articulator is then used to produce motions, which determine occlusal anatomy" (p:526).

Clayton et al (1971b) determined the relationship of functional movements (chewing) to border tracings recorded by a mechanical pantograph. They found that the functional movements did not go beyond the recorded border movements. They did note; "The instrument had some effect on mandibular movement but not enough to eliminate the pantograph as a research tool in studying mandibular movement or as a practical tool in restoring occlusal surfaces" (p:395).

Coye (1977) in an in vitro study evaluated the variability involved in programing a highly adjustable articulator using a mechanical pantographic recording of one articulator (Denar ${ }^{\circledR}$ D5A) with known condylar settings. He found the greatest variance involved setting the top wall, vertical axis and rear wall. He also found statistical differences among the different tracings. The operators used to program the articulators consistently had settings higher than the known articulator values. 
Clayton et al (1983) in an in vivo study of 20 subjects found that recordings made by an electronic pantograph (Denar ${ }^{\circledR}$ Pantronic) were comparable to recordings made by a mechanical pantograph. The recordings were also consistent over time and between operators.

Donaldson and Clayton (1986) evaluated the ability of two mechanical pantographs (Stuart ${ }^{\mathbb{R}}$ and Denar ${ }^{\mathbb{R}}$ )to record the same mandibular movements. He determined that mandibular movements recorded by the two pantographs recorded had a mean difference of less than $0.1 \mathrm{~mm}$.

Beard et al (1986) found that an electronic pantograph (Denar ${ }^{\circledR}$ Pantronic) was accurate and reliable in consistently recording articulator settings and comparable to the mechanical pantograph.

Anderson et al (1987) found that the electronic pantograph was accurate and reliable in recording IMLT, PMLT and LCI on a highly adjustable articulator (Denar ${ }^{\circledR}$ D5A) with known condylar settings. The instrument exhibited intrainstrument and interinstrument reliability in recording IMLT, PMLT and LCI.

Price et al (1988) compared articulator settings obtained using lateral interocclusal records with settings obtained from an electronic pantographic recording (Denar ${ }^{\circledR}$ Pantronic). He noted that articulator's (Denar ${ }^{\circledR}$ D5A) settings by the electronic pantograph were more consistent than those obtained from interocclusal records.

Pelletier (1991) in a bench top study compared condylar settings obtained using three different methods. He found that both mechanical (Denar ${ }^{\circledR}$ ) and electronic (Denar ${ }^{\circledR}$ Pantronic) pantographs were accurate and reliable. He stated that the electronic pantograph was the most accurate and reliable method.

Catic and Naeije (1999) used an optoelectronic recording device (OKAS-3D ${ }^{\circledR}$ ) to compare the location of the hinge axis with the kinematic center in patients with symptomatic an asymptomatic temporomandibular joints. He found significant differences in the axis location and repeatability of the axis location in both groups of patients. He suggests the use of the kinematic center as the reference point for the study of mandibular movements.

Olthoff et al (2000) used data obtained form an optoelectronic pantograph $\left(\right.$ Condylocomp $\left.{ }^{\circledR}\right)$ to design occlusal surfaces of a posterior restoration with the aid of the CICERO CAD/CAM system. He compared the dynamic occlusion restoration generated by the CAD/CAM system to a crown design for static occlusion. He found the crown designed for static occlusion had more interferences that did the crown designed for dynamic occlusion. He noted that the dynamic occlusion crown had fewer centric contacts. He commented that computer techniques and electronic pantographs have the potential to monitor the ideal articulation in restorative dentistry. 
Graver (2001) compared the accuracy, repeatability and procedure time of an optoelectronic pantograph (Condylocomp $\left.{ }^{\mathbb{R}}\right)$, mechano-electronic pantograph $\left(\right.$ Denar $^{\mathbb{R}}$ Pantronic), mechanical pantograph (Denar ${ }^{\mathbb{B}}$ ) and the kinematic face-bow (Denar ${ }^{\mathbb{B}}$ Axis Locator). He found the kinematic face-bow was better than the optoelectronic pantograph in determining the THA, but required more procedure time. The mechanoelectronic device was more accurate in determining the PMLT and LCI and the mechanical pantograph was more accurate in determining the IMLT. The mechanoelectronic device required less procedure time to determine PMLT, IMLT and LCI values.

Celar and Tamaki (2002) evaluated the accuracy of a mechano-electronic device (Cadiax Compact ${ }^{\circledR}$ ) in measuring condylar settings of an articulator using a 3-D digitizer. He found significant differences between articulator settings and the measurements of the mechano-electronic device for all condylar measurements except the $40^{\circ}$ LCI setting. He concluded that the mechano-electronic device was clinically acceptable because of the small mean differences. The mechano-electronic device showed less fluctuation than the mechanical pantograph and was more consistent than settings obtained from interocclusal records.

Wagner (2003) compared an optoelectronic (Polaris ${ }^{\circledR}$ ) and mechano-electronic $\left(\right.$ Cadiax $\left.^{\circledR}\right)$ pantographs. He suggested that the optoelectronic device was less bulky and he believed it had less impairment to temporomandibular joint movements during the recordings. He found the accuracy of the optoelectronic device to be comparable to the mechano-electronic device.

Bernhardt et al (2003) measured the accuracy of a mechano-electronic device $\left(\right.$ Cadiax Compact ${ }^{\mathbb{B}}$ ) to determine if there was a clinically significant difference between measurements recorded from a kinematically located THA or an arbitrary located THA. He found no clinically significant differences between the two methods.

Chang et al (2004) tested the reliability and validity of a mechano-electronic device (Cadiax Compact ${ }^{B}$ ) in calculating the condylar settings of five different articulators (Denar ${ }^{\mathbb{B}}$ D5A, Denar ${ }^{\circledR}$ Mark II, Whip Mix ${ }^{\circledR} 8500$, Hanau ${ }^{\circledR}$ Modular and Panadent $\left.t^{\circledR} \mathrm{PCH}\right)$. They found the ten millimeter recording distance, for the most part, provided the most reliable and valid readings for the articulators tested and recommended using the ten millimeter distance in programing the articulators tested. 


\section{CHAPTER 3. MATERIALS AND METHODS}

\section{Materials and Equipment}

\section{Highly Adjustable Articulator}

The Denar ${ }^{\circledR}$ D5A articulator (Whip Mix Corp., Fort Collin, CO) served as the mock patient for this investigation. The Denar ${ }^{\mathbb{B}}$ D5A components include a centric holding latch, vertical axis adjustment, adjustable protrusive condylar path angle, adjustable progressive mandibular lateral translation angle, adjustable immediate mandibular lateral translation, rear wall and superior wall adjustment. Figures 3-1, 3-2, 3-3, 3-4, 3-5, 3-6 and 3-7 illustrate several of the design features of the Denar ${ }^{\circledR}$ D5A articulator.

The mandibular member and condylar guide assemblies of the Denar ${ }^{\circledR}$ D5A articulator were modified to accept posterior elastics. The posterior elastics maintained contact of the condylar guide path elements against the superior, rear and medial walls of the condylar guide assembly. Figure 3-8 illustrates the modifications of the Denar D5A articulator. Modifications were made by Whip Mix Corporation as instructed by investigator of this study.

\section{Reference Plate}

Chemically activated acrylic resin (Orthodontic Resin, DENTSPLY International, York, PA) formed with a Denar ${ }^{\mathbb{B}}$ clutch die (Whip Mix Corp., Fort Collins, CO) served as the guiding surface of the maxillary cast.

The Freecorder ${ }^{\circledR}$ Bluefox $0^{\circ}$ bitefork (Dentron, Germany) and Denar central bearing screw (Whip Mix Corp., Fort Colllins, CO) were embedded in chemically activated resin (Orthodontic Resin, DENTSPLY International, York, PA) and served as the attachment to the mandibular member of the articulator and the mandibular Freecorder ${ }^{\circledR}$ Bluefox face-bow (Dentron, Germany).

The Cadiax Compact $2^{\circledR}$ metal clutch (Whip Mix Corp., Louisville, KY) and Denar central bearing screw were embedded in a low-expansion die stone (Silky Rock, WhipMix Corp, Louisville, KY) and served as the attachment to the mandibular member of the articulator and the mandibular Cadiax Compact $2^{\circledR}$ face-bow (Whip Mix Corp., Louisville, KY).

The resin maxillary guiding surface, mandibular attachments for both face-bows were mounted in the Denar ${ }^{\mathbb{B}}$ D5A with low-expansion mounting stone (Mounting Stone, Whip Mix Corp., Louisville, KY). The maxillary cast was attached to the maxillary member of the articulator with a metal mounting plate (Denar metal mounting plate, 


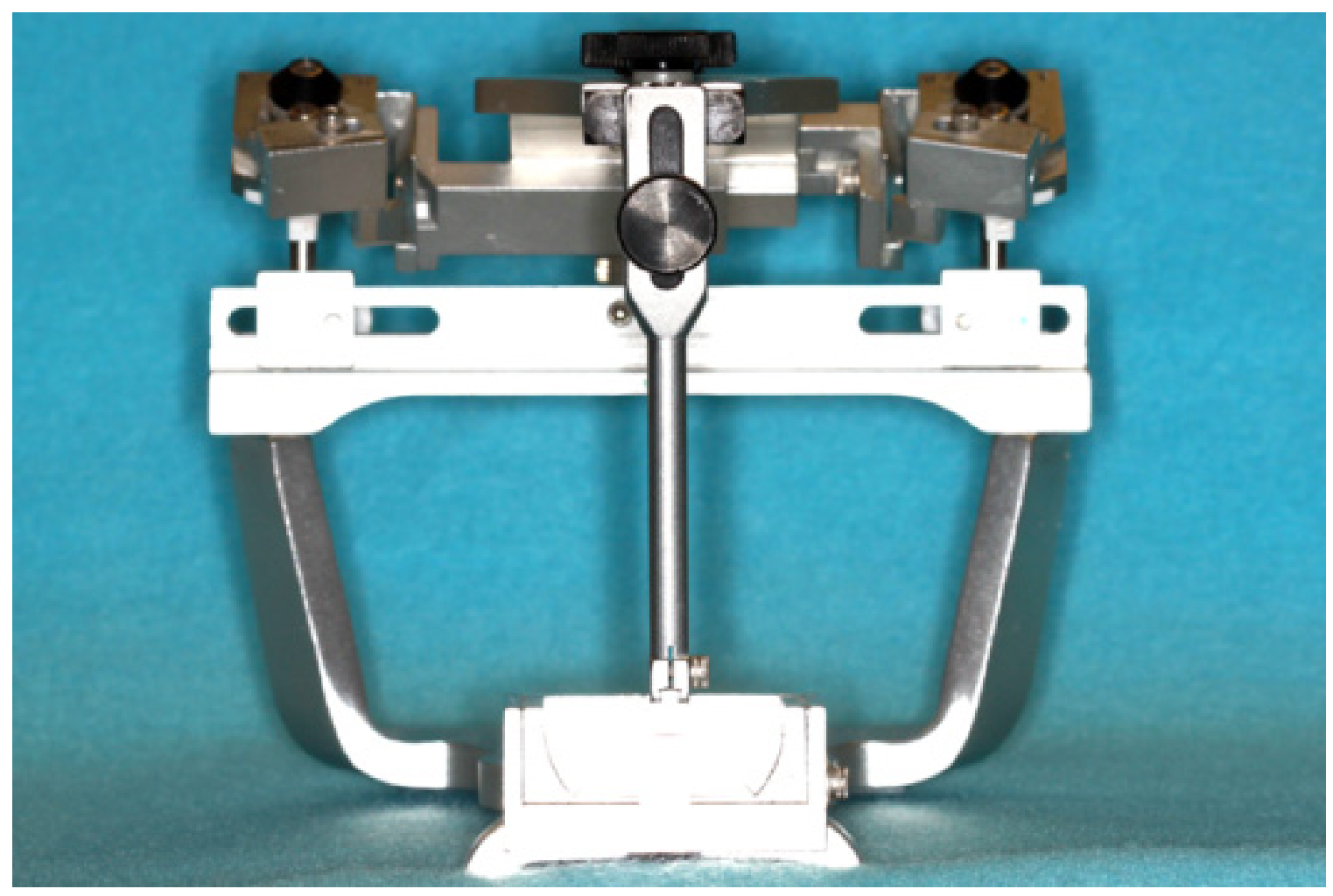

\section{Figure 3-1. Denar ${ }^{\circledR}$ D5A articulator (frontal view).}

The Denar ${ }^{\circledR}$ D5A articulator used in this study consists of a maxillary member, mandibular member, incisal pin, incisal table, a left fossa-slide and a right fossa-slide. The condylar guide assemblies and condylar elements allow for adjustment of the vertical axes, antero-posterior adjustment measured from the horizontal plane, progressive mandibular lateral translation measured from the sagittal plane, immediate mandibular lateral translation measured in millimeters, rotating condylar path inclination measured from coronal plane (rear wall) and horizontal plane (superior wall) and superior and medial fossa wall inserts. The incisal pin allows for vertical dimension and horizontal overjet adjustment. The incisal table allows for changes of the protrusive and lateral wing inclination [Source of notes: Denar Fully Adjustable Procedure Manual. (N. D. FN R0808). Whip Mix Corp., Fort Collins, CO]. 


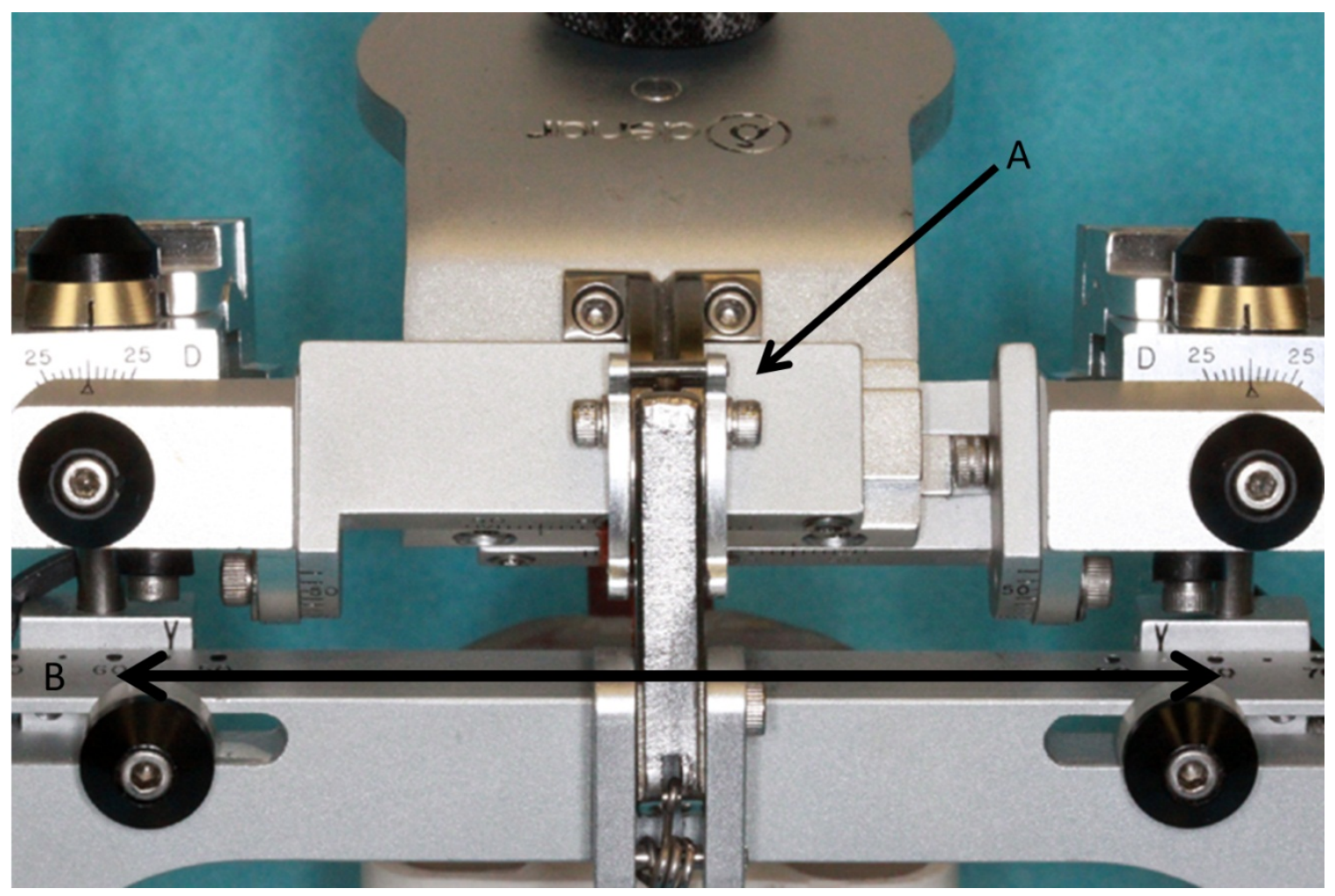

\section{Figure 3-2. $\quad$ Denar $^{\circledR}$ D5A articulator (rear view).}

The rear view of the Denar ${ }^{\circledR}$ D5A articulator depicting the centric latch $(A)$ and the adjustable vertical axes (B). The centric latch maintains the correct medio-lateral orientation of the maxillary and mandibular members. The vertical axis can be adjusted medio-laterally by the maxillary left and right fossae-slides and the mandibular condylar elements. The values are expressed in millimeters from the mid-sagittal plane [Source of notes: Denar Fully Adjustable Procedure Manual. (N. D. FN R0808). Whip Mix Corp., Fort Collins, CO]. 


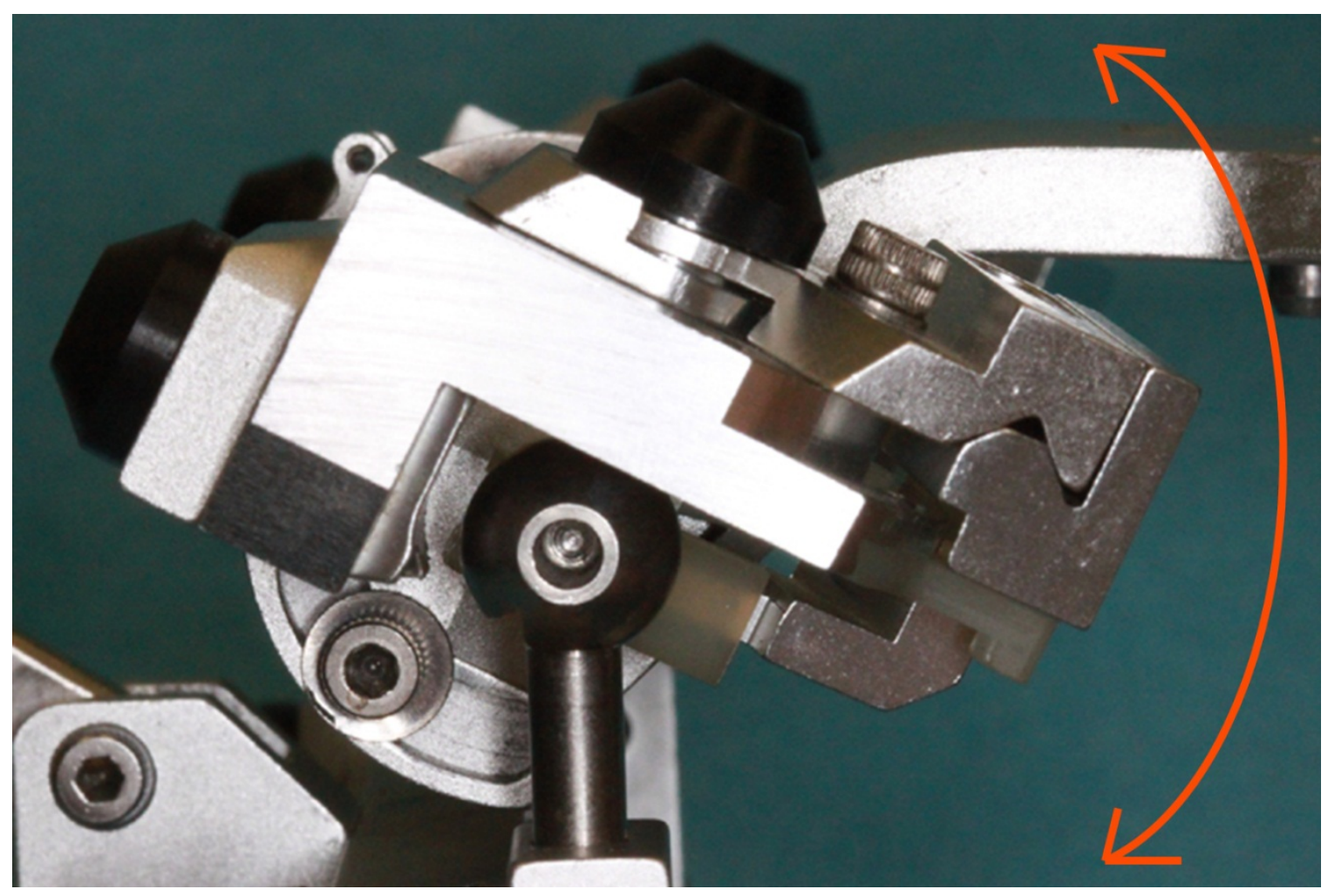

Figure 3-3. Protrusive condylar path angle.

The protrusive condylar path angle corresponds to the angle of the emenetia and is a measure of lateral condylar inclination. The value is expressed in degrees and is measured from the horizontal plane. The arrow direction illustrates the range of adjustment. The inclination of the superior fossa wall can be adjusted from $0-60^{\circ}$. The scale is in $5^{\circ}$ increments. A flat superior fossa insert was used in this study [Source of notes: Denar Fully Adjustable Procedure Manual. (N. D. FN R0808). Whip Mix Corp., Fort Collins, CO]. 

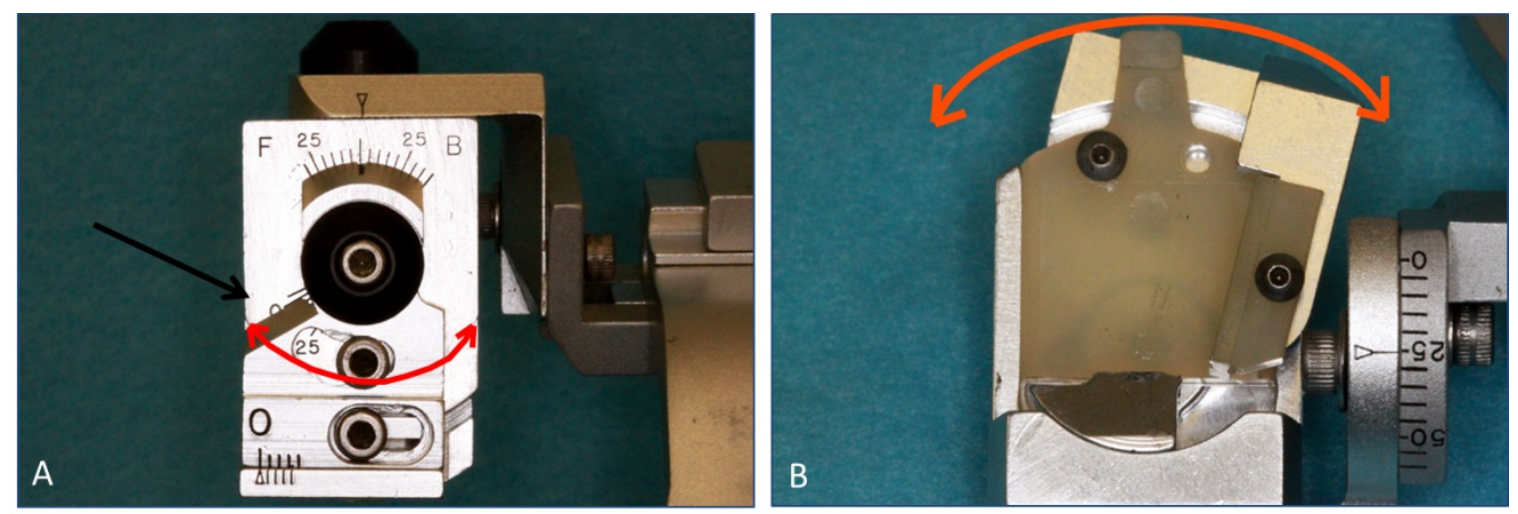

Figure 3-4. Medial wall angle adjustment.

The medial wall to show PMLT adjustment. A. Superior view of condylar guide assembly. The medial wall can be adjusted from $0-30^{\circ}$ to the sagittal plane (black arrow). The scale is in $5^{\circ}$ increments. B. Inferior view of the condylar guide assembly. A straight medial wall insert (shown) was used in this study. The red arrows depict the angular direction of movement for the medial wall [Source of notes: Denar Fully Adjustable Procedure Manual. (N. D. FN R0808). Whip Mix Corp., Fort Collins, CO].
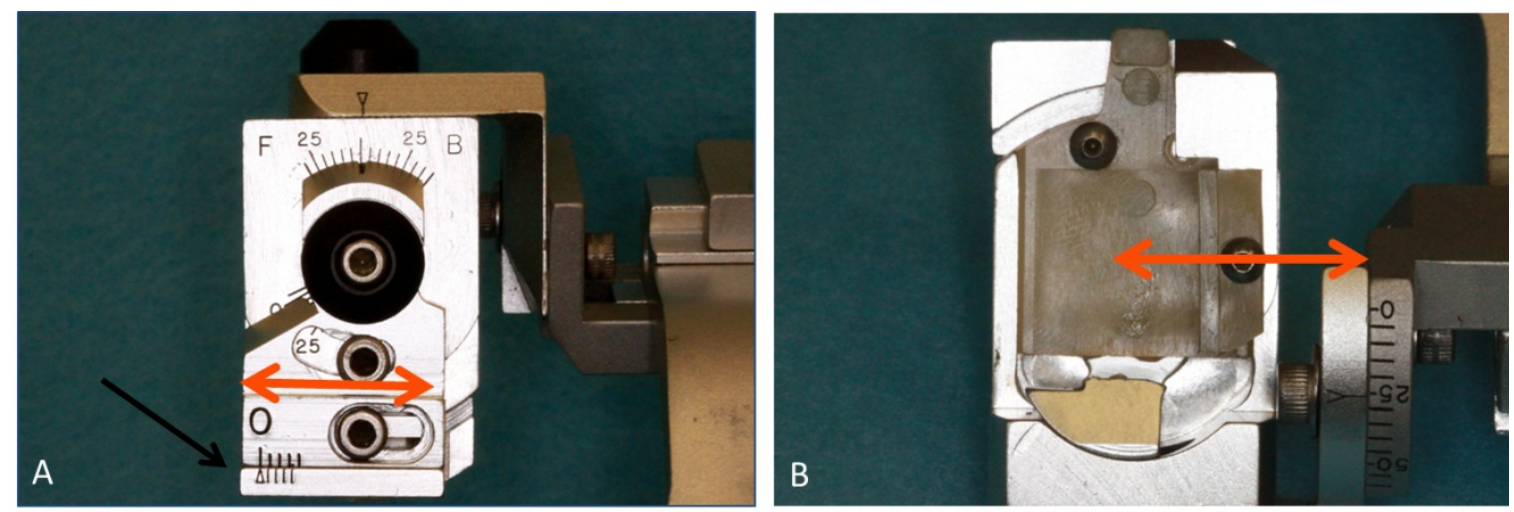

\section{Figure 3-5. Medial wall linear adjustment.}

The medial wall to IMLT adjustment. This adjustment allows for the medial fossa wall to be displaced medially. A. Superior view of condylar guide assembly. The amount of IMLT is measured on the vernier scale (black arrow). B. Inferior view of condylar guide assembly illustrating the straight medial fossa wall insert and flat superior wall insert. The red arrows depict the linear displacement of the medial wall [Source of notes: Denar Fully Adjustable Procedure Manual. (N. D. FN R0808). Whip Mix Corp., Fort Collins, $\mathrm{CO}]$. 

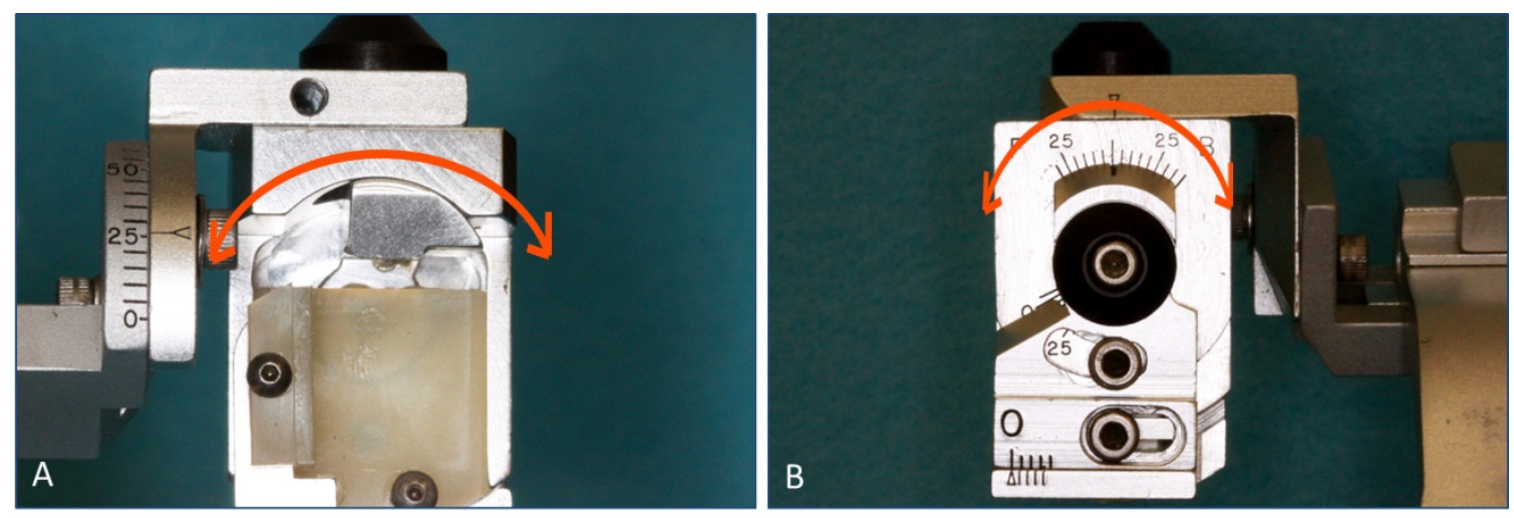

\section{Figure 3-6. Rear wall adjustment.}

The posterior fossa wall can be inclined anteriorly or posteriorly up to $30^{\circ}$ form the coronal plane to incorporate a forward (latero-protrusion) or back (latero-retrusion) movement of the working condyle (red arrows). The scale is in $5^{\circ}$ increments. A. Inferior view of condylar guide assembly. B. Superior view of condylar guide assembly [Source of notes: Denar Fully Adjustable Procedure Manual. (N. D. FN R0808). Whip Mix Corp., Fort Collins, CO]).
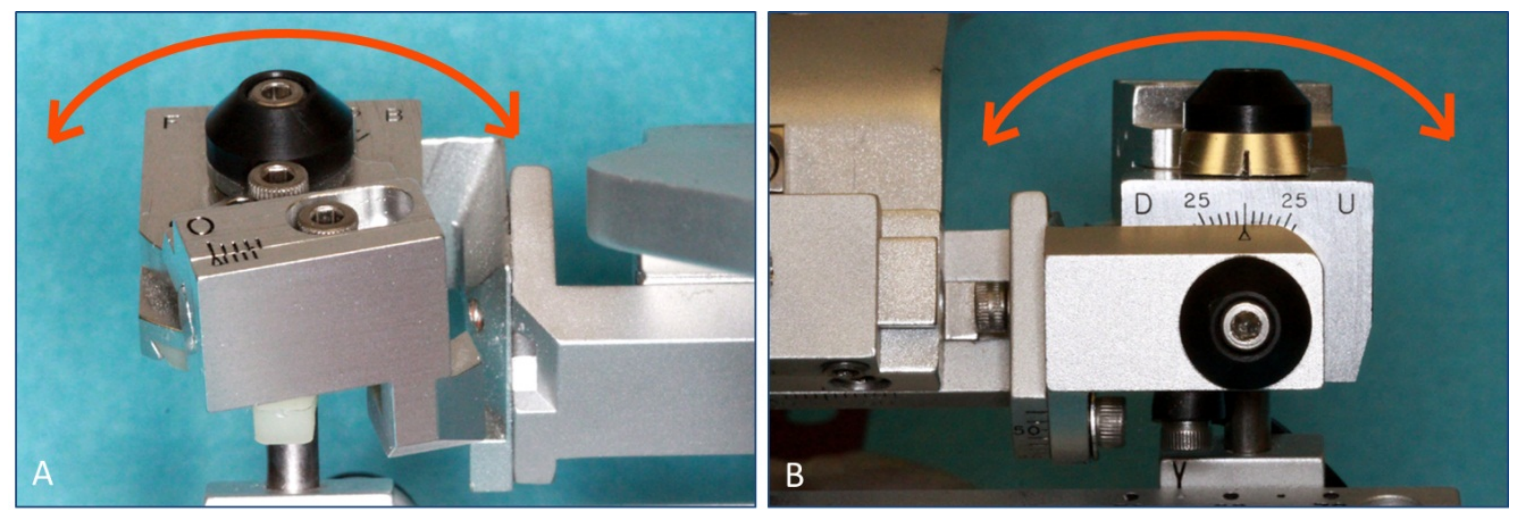

\section{Figure 3-7. Superior wall adjustment.}

The superior fossa wall can be inclined medio-laterally superiorly or inferiorly up to $30^{\circ}$ from the horizontal plane to incorporate an up (latero-surtrusion) and down (laterodetrusion) movement of the working condyle (red arrows). The scale is in $5^{\circ}$ increments. A. Frontal view. B. Rear view [Source of notes: Denar Fully Adjustable Procedure Manual. (N. D. FN R0808). Whip Mix Corp., Fort Collins, CO]. 


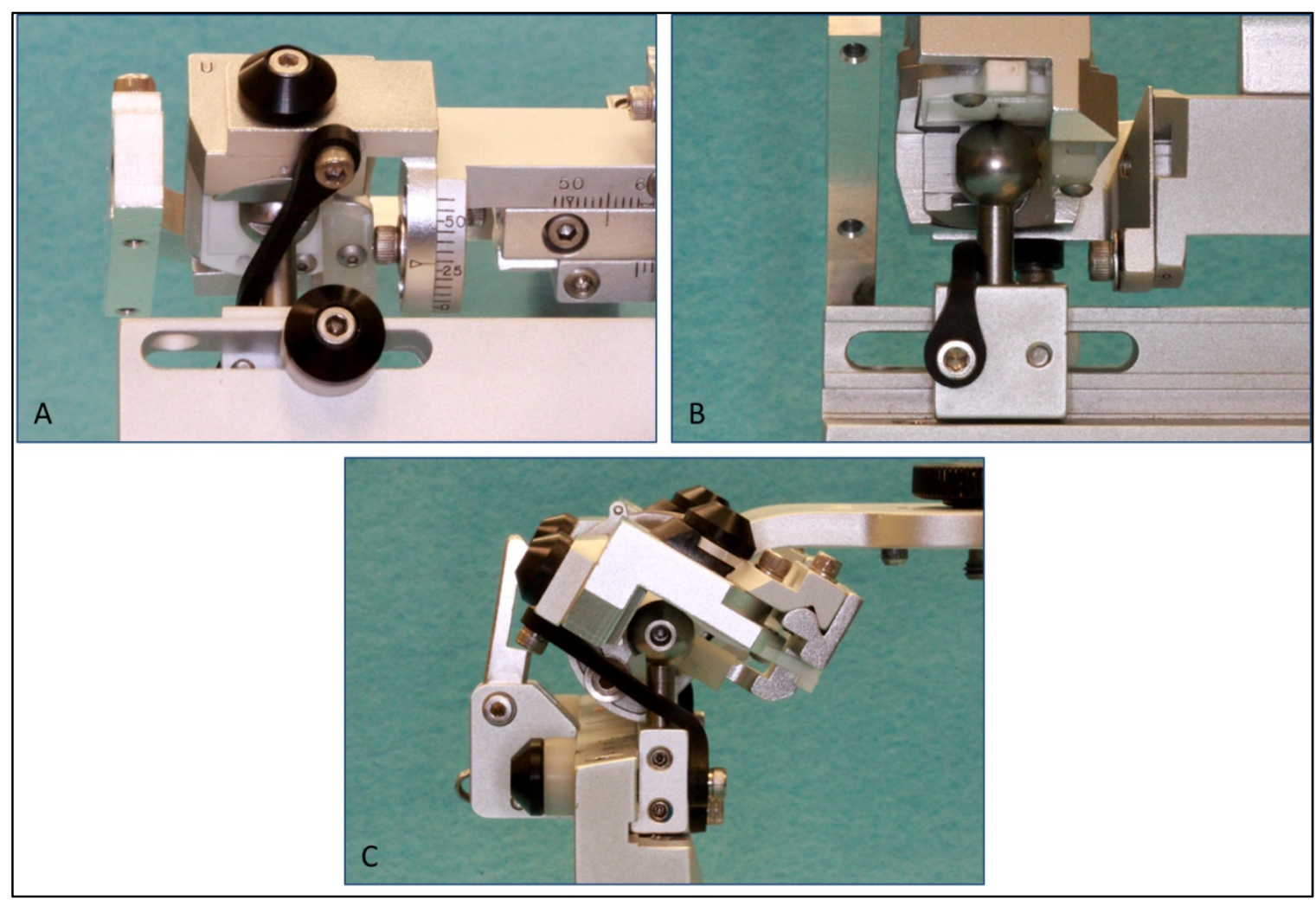

Figure 3-8. Modification of Denar ${ }^{\circledR}$ D5A.

The condylar guide assemblies and condylar element mounts were modified to accept elastics. The attachment of the elastics on the condylar element mount lateral to the vertical axis and on the condylar guide assembly medially to the vertical axis allowed the elastics to maintain contact of the condylar guide assembly path elements against the superior, rear and medial walls. A. Rear view showing elastic attachment medial to the vertical axis. B. Frontal view showing the elastic attachment lateral to the vertical axis. Contact with the superior and medial fossa walls can be seen. C. Lateral view showing the elastic attachment to the condylar guide assembly and condylar element mount. Contact with the rear wall is demonstrated. 
Whip Mix Corp., Fort Collins, CO). The mandibular cast was attached to the mandibular member of the articulator with split cast mounting plates (Hanau, Whip Mix Corp., Fort Collins, CO, Figure 3-9).

\section{Test Mandibular Recorders}

The Freecorder ${ }^{\circledR}$ Bluefox (Dentron, Germany, Figures 3-10 and 3-11) is an optoelectronic measuring device for recording temporomandibular joint movements (rotations and translations). It is computer controlled via an ethernet interface. A lightweight maxillary reference bow containing light reflectors with encoded patterns is placed on the patient like a conventional maxillary earbow. A lightweight mandibular reference bow containing light reflectors with encoded patterns is attached to the mandible with a para-occlusal clutch or a peri-occlusal bitefork. The sensors are optically tracked by cameras.

The Freecorder ${ }^{\circledR}$ Bluefox optoelectronic system records mandibular movement via non-contact pattern tracking. Three cameras track the encoded patterns 100 times per second to determine the angle of rotation and calibrate the size of the movement. The resolution is $0.001 \mathrm{~mm}$. Measured data is processed by the Freecorder ${ }^{\circledR}$ Bluefox camera computers and the passed on to the PC. The JAWS ${ }^{\circledR}$ software evaluates the recorded data. The recorded movements are shown on a computer screen in real-time. The patient's sagittal, vertical and transverse planes bilaterally are viewed simultaneously. The data is depicted graphically and numerically.

In addition to viewing the recorded mandibular movements, the system claims to be able to determine the THA location and calculate articulator-specific settings (LCI, PMLT and IMLT) for several articulator systems. This information can be displayed on the monitor, printed and/or stored.
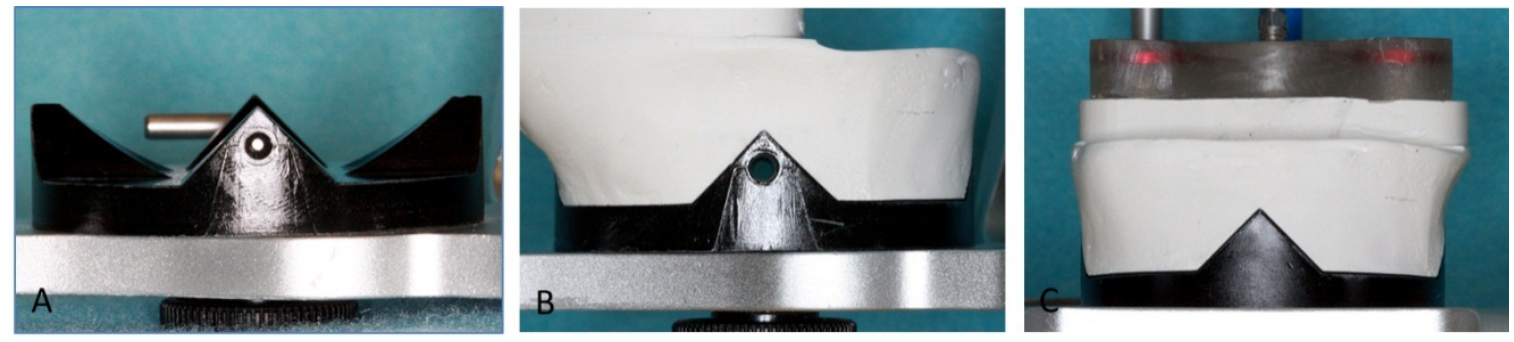

Figure 3-9. Split cast mounting plate.

A. Split cast mounting plate attached to mandibular member of articulator. B. Lateral view of mounting stone aligned with mounting plate. C. Rear view of mounting stone aligned with mounting plate. 


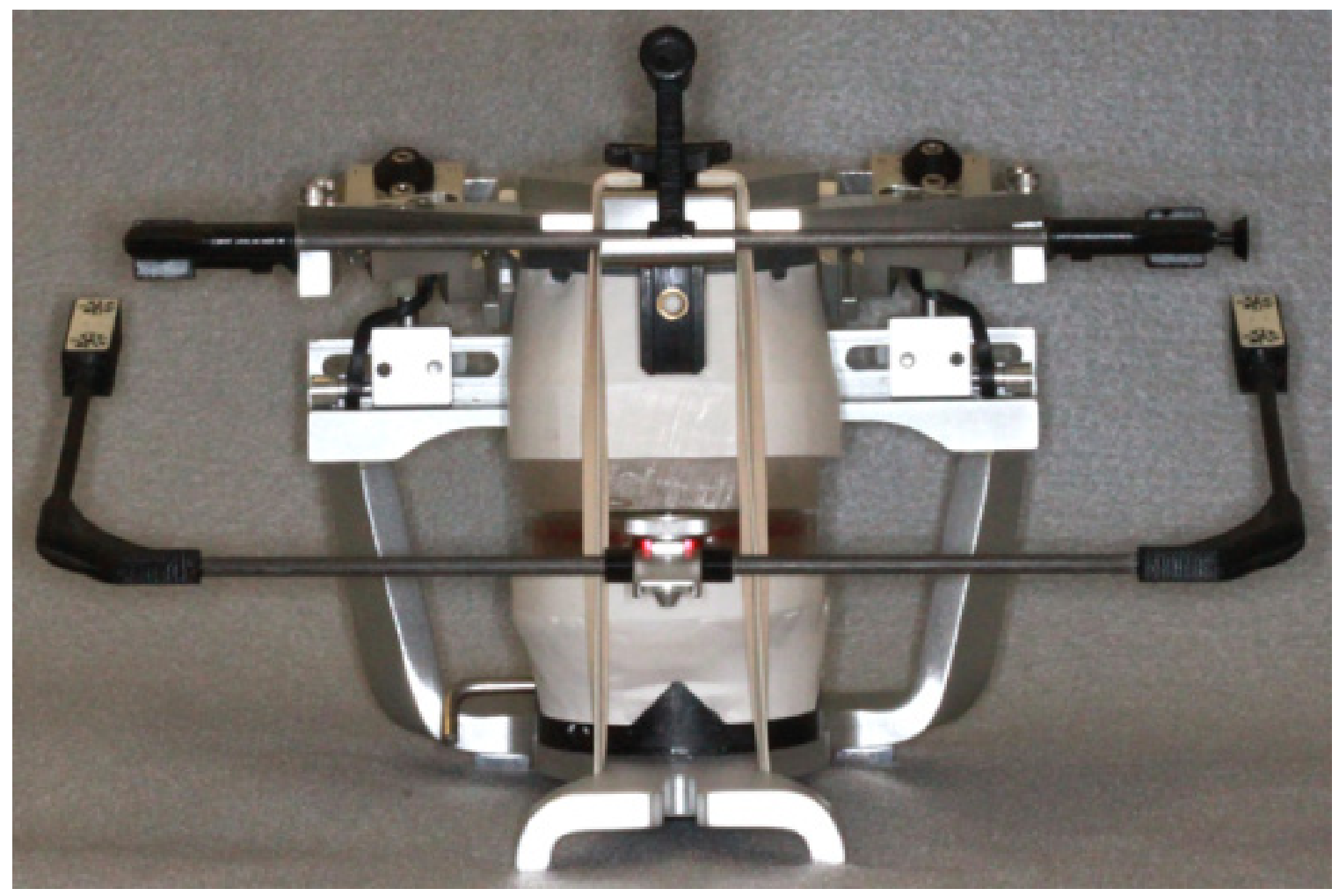

Figure 3-10. Freecorder ${ }^{\circledR}$ maxillary and mandibular face-bows attached to mock patient.
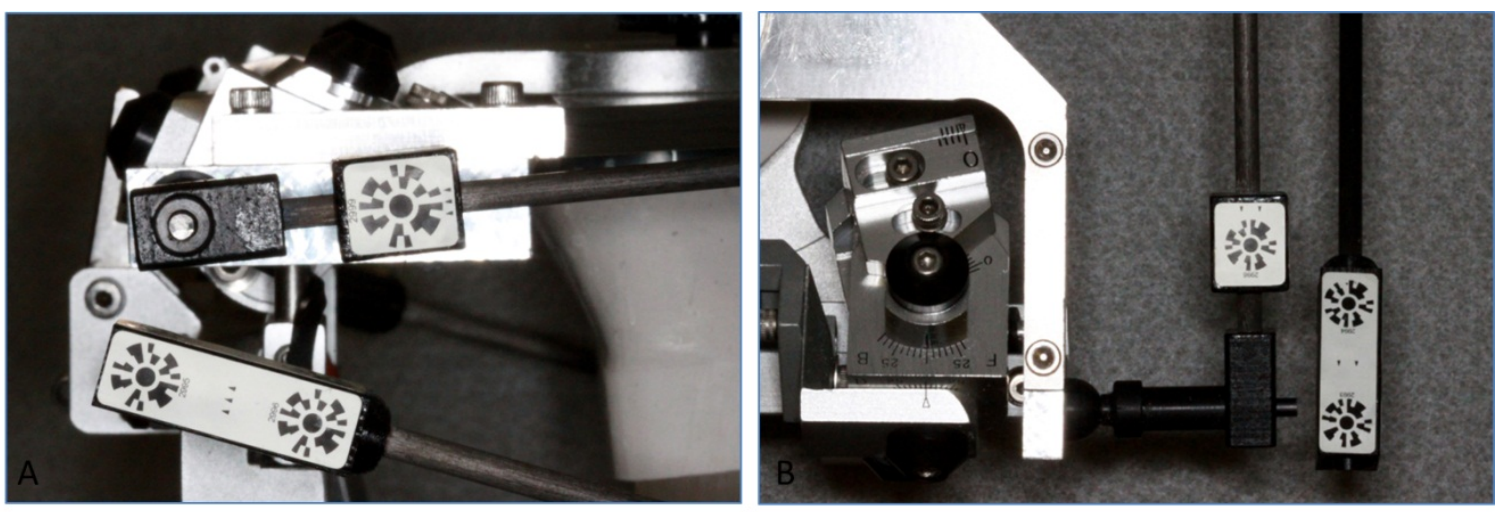

Figure 3-11. Close up view of Freecorder ${ }^{\circledR}$ Bluefox maxillary and mandibular facebows.

A. Lateral view of coded sensors. B. Superior view of coded sensors. The coded sensors are tracked by cameras in the C-arm of the Freecorder ${ }^{\circledR}$ Bluefox. 
The Cadiax Compact $2^{\circledR}$ (Whip Mix Corp., Louisville, KY, Figures 3-12 and 3-13) is a mechano-electronic pantograph (axiograph) capable of measuring mandibular joint movement. It is computer controlled and connected via USB cable. Digital magnetic recording flags are secured to the cross arms in the area of the THA. The mandibular bow is attached via an occlusal clutch to the mandible and has right and left micro-adjustable arms with axis pins or magnetic styli attached to the cross arm. The styli physically move across the digital recording plates. The styli are connected to the micro-processor which connects to a computer via a USB cable. The resolution is $0.01 \mathrm{~mm}$. The data is depicted graphically and numerically.

In addition to viewing the recorded mandibular movements, the system can determine the individual value settings for several articulator systems and perform instrumental functional analyses in the preliminary examination. The information can be displayed on the monitor, printed and/or stored.

\section{Mounting Apparatuses}

Heavy gauge stock aluminum was used to construct a mounting device to attach earpieces of maxillary face-bows of both devices to the maxillary member of the Denar ${ }^{\circledR}$ D5A articulator. Figures 3-14 and 3-15 illustrate the maxillary face-bow mounting device. The horizontal portion of the mounting device attaches to the maxillary member of the articulator with a modified thumbscrew (Hanau ${ }^{\circledR}$, Whip Mix Corp., Fort Collins, $\mathrm{CO}$ ). The thumbscrew was made longer by adjusting the flat portion of the engaging surface. The thumbscrew traversed the maxillary member of the articulator, maxillary face-bow mounting apparatus and metal mounting plate. A condylar housing adapter extends from the horizontal component of the mounting device. The adapter has a conical indentation corresponding to the horizontal axis of the articulator. The center of the conical hole to receive the earpiece of the face-bow is $13 \mathrm{~mm}$ from the horizontal axis of the articulator (Teteruck and Lundeen 1966 and Palik et al 1985).

A wood dowel and stock aluminum were used to construct a device to mount the maxillary member of the Denar ${ }^{\mathbb{B}}$ D5A articulator to the C-arm of the Freecorder ${ }^{\mathbb{B}}$ Bluefox. The aluminum cross arm on the superior portion of the dowel formed the bracing arm against the undersurface of the Freecorder ${ }^{\circledR}$ Bluefox C-arm and were secured by nylon cable ties (75lb Tensil Strength Double Lock Cable Tie, Home Depot). Figure 3-16 depicts Denar ${ }^{\circledR}$ D5A articulator with Freecorder ${ }^{\circledR}$ Bluefox face-bows mounted in testing device. The same mounting apparatus was used for the Cadiax Compact $2^{\circledR}$ trials.

\section{Magnification}

Adjustments to the condylar guide assembly were made with through-the-lens, 3.5X magnification (Surgitel, General Scientific Corporation, Ann Arbor, MI). 


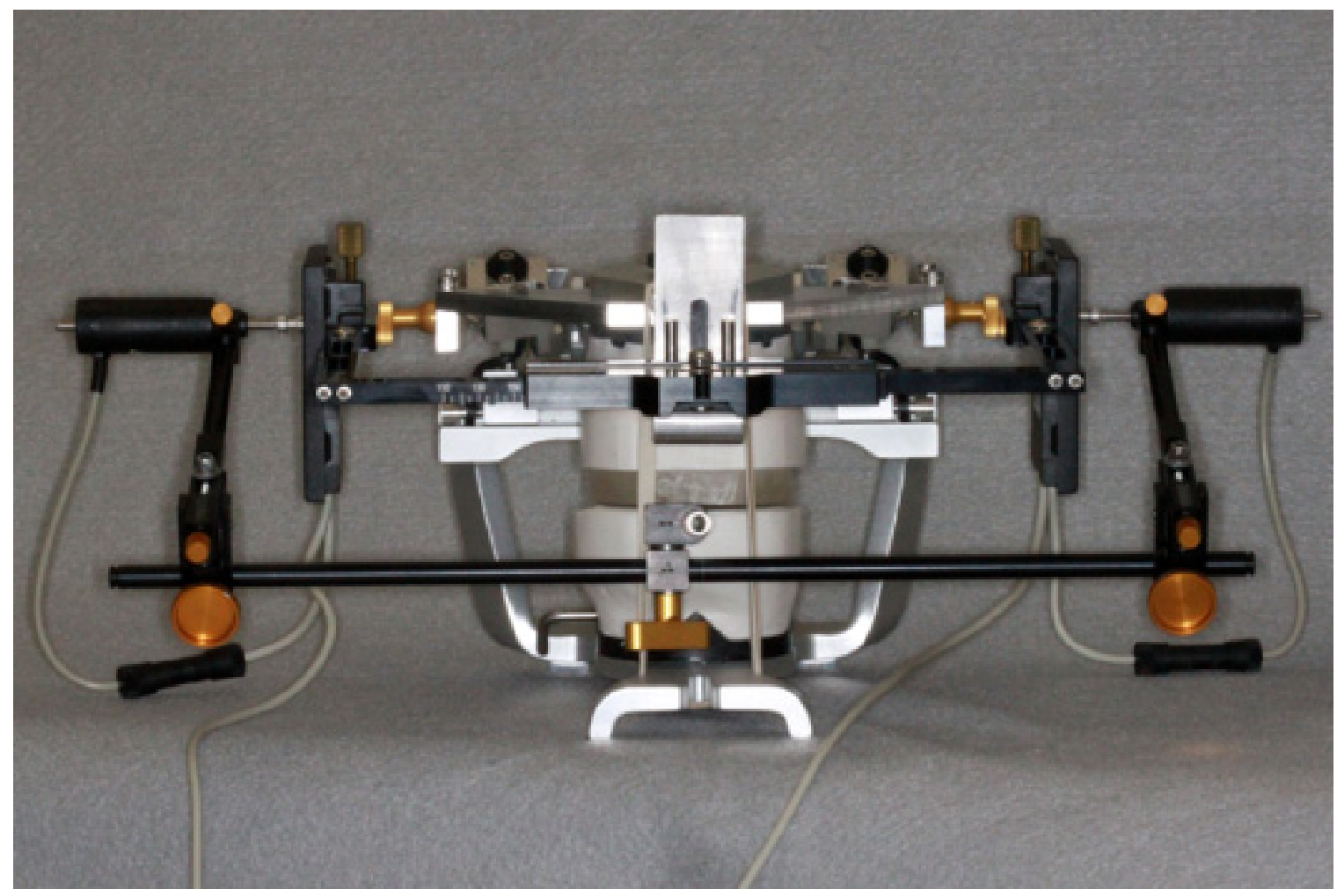

Figure 3-12. Cadiax maxillary and mandibular face-bows attached to mock patient.
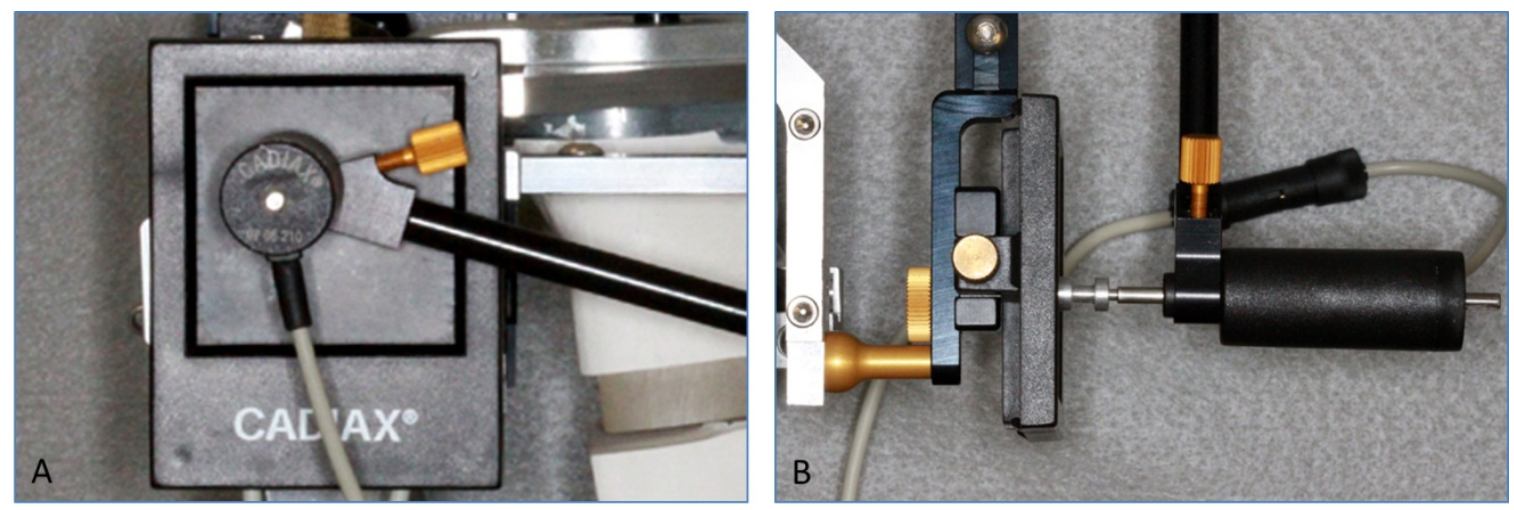

Figure 3-13. Close up view of Cadiax sensors.

A. Lateral view of magnetic plate and stylus. B. Superior view of magnetic stylus contacting magnetic plate. The magnetic plate physically tracks stylus movement and transmits data to computer. 

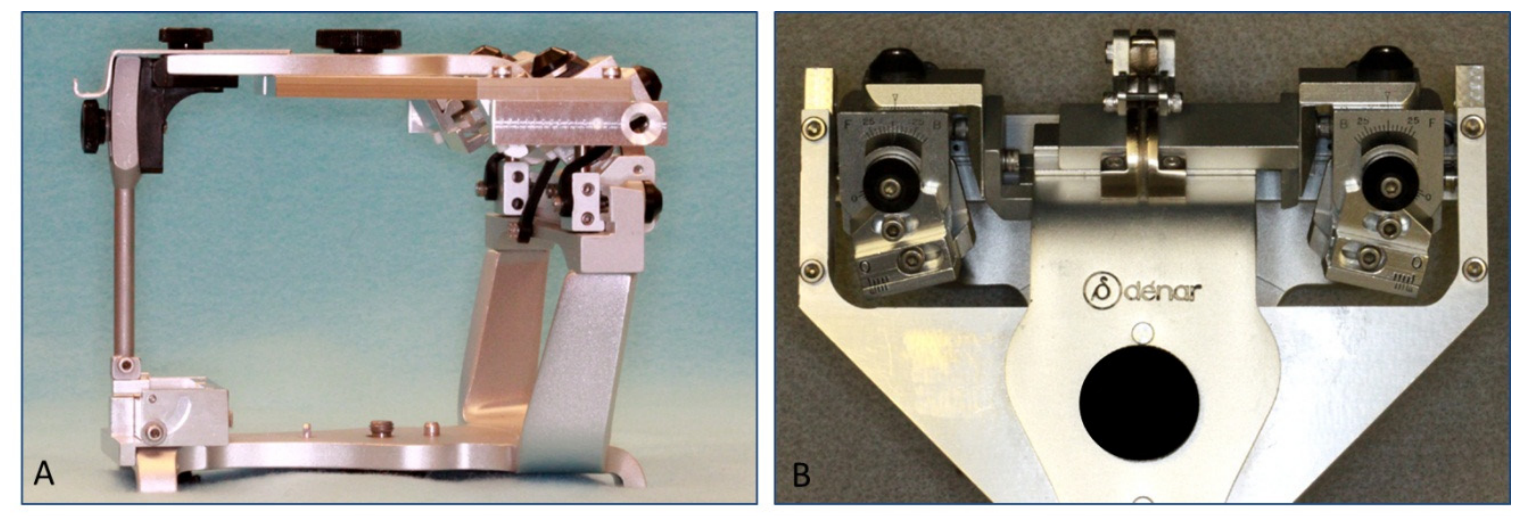

Figure 3-14. Maxillary face-bow mounting apparatus.

A. Lateral view of maxillary face-bow mounting apparatus. B. Superior view of maxillary face-bow mounting apparatus.
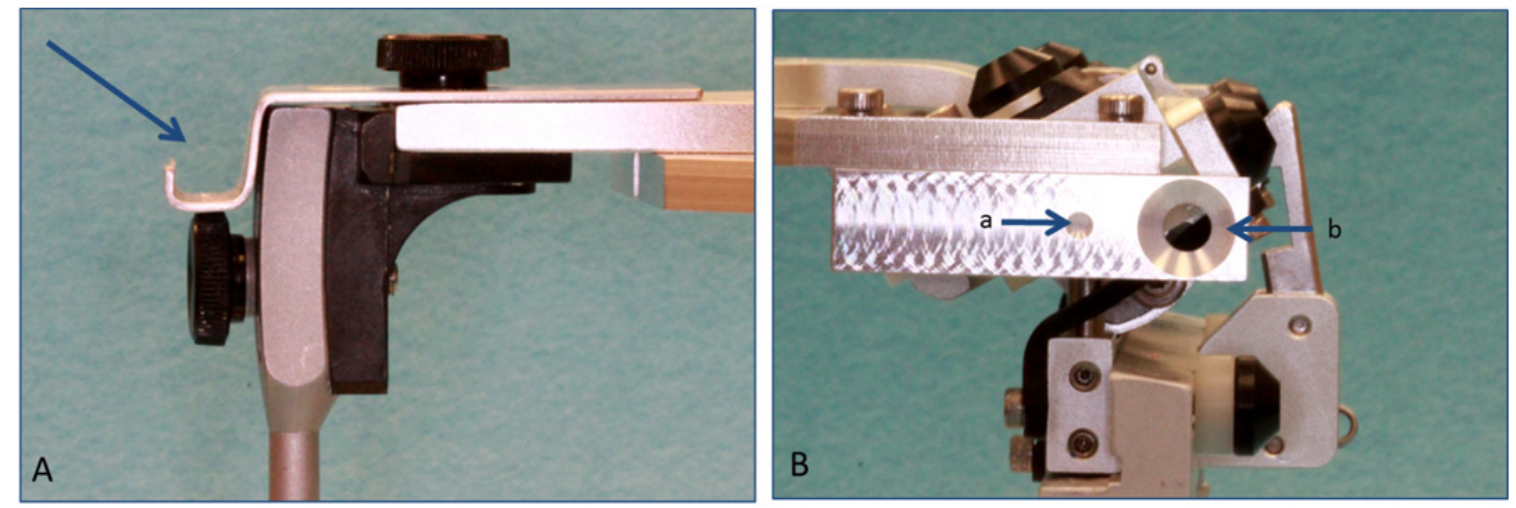

Figure 3-15. Close up view of maxillary face-bow mounting apparatus.

A. Lateral view of anterior support apparatus for cross bar of face-bow. B. Lateral view of posterior component of mounting apparatus. Arrow (a) corresponds to the horizontal axis of the articulator and arrow (b) corresponds to the receptacle for the porus support (earpiece) of the maxillary face-bows. 

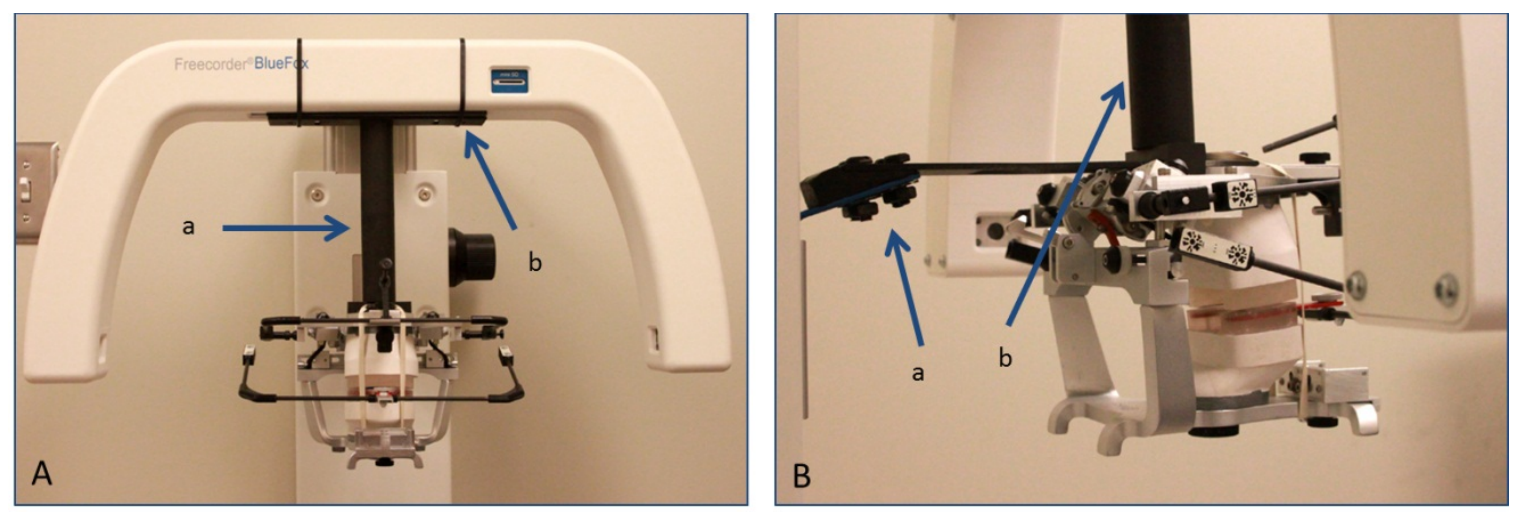

Figure 3-16. Articulator holding and suspending apparatus.

A. Frontal view of mounting apparatus to attached to the maxillary member of the articulator. Arrow (a) corresponds to the vertical beam to suspend the articulator in the Freecorder ${ }^{\circledR}$ Bluefox. Arrow (b) corresponds to the cross beam attaching the support apparatus to the cross arm of the scanning apparatus. B. Angled view of mounting apparatus. Arrow (a) corresponds to the horizontal apparatus attaching the articulator to the base of the Freecorder ${ }^{\circledR}$ Bluefox. Arrow (b) corresponds to the vertical beam. The mounting apparatus allowed for simulated clinical movements of the mandibular member of the articulator. The mounting apparatus was used for both the Freecorder ${ }^{\circledR}$ Bluefox trials and the Cadiax Compact $2^{\circledR}$ trials. 


\section{Methods: General}

The investigation was designed to verify and compare the accuracy of the mechano-electronic computerized pantograph and the optoelectronic computerized pantograph. For this investigation an articulator with known condylar settings was employed as the patient. When referring to "manipulation of the articulator", the term "mock patient" will be used. When referring to "programming of the articulator" based on the Freecorder ${ }^{\circledR}$ Bluefox and/or the Cadiax Compact $2^{\circledR}$, the term "articulator" will be used. The constants were LCI, PMLT, IMLT, superior Wall and rear Wall. The variables were the pantographs. The optoelectronic pantograph claims the ability to locate the THA. The mechano-electronic and the optoelectronic pantographs are able to perform LCI, PMLT and IMLT determinations. The mechano-electronic pantograph is able to evaluate movements of the rotating condyle (laterotrusion). This investigation was designed to make comparisons of the instrument capabilities.

An apparatus was fabricated and attached to the maxillary element of the mock patient that securely supported the maxillary face-bow of each test pantograph in a similar manner to patient treatment. The mandibular recording device was secured to the mandibular element of the mock patient via the corresponding clutch or reference plate. The test pantographs recorded mock patient movements in a clinically relevant fashion while attached to the mock patient and support apparatus. This allowed the in vitro THA determination, LCI, PMLT, IMLT and laterotrusion determinations to be performed in a clinically relevant manner.

The investigation casts for the maxillary and mandibular elements of the mock patient were fabricated using Silky Rock improved dental stone. The casts were mounted in the articulator with White Mounting Stone in accordance with the manufacturer's instructions. The bitefork and central bearing screw, embedded in Orthodontic Resin, for the Freecorder ${ }^{\circledR}$ Bluefox was secured to the mandibular member of the articulator with white mounting stone. The clutch and central bearing screw, embedded in Silky Rock Stone, for the Cadiax Compact $2^{\circledR}$ was secured to the mandibular member of the articulator with white mounting stone. The central bearing screw was raised to allow the casts to move past each other without interferences during functional movements. The central bearing screw articulated against a preformed concavity, in the orthodontic resin, formed with the Denar clutch die. The central bearing screw maintained the vertical dimension in the absence of an incisal guide pin. In order to maintain the bearing surfaces against one other during movements, posterior elastics, anterior elastics, central bearing screw and manual guidance were employed.

\section{Methods: Specific Aim 1}

The conventional procedure to transfer the patient information (maxillary cast) to the articulator is with a maxillary face-bow. The conventional face-bow is attached to the maxillary teeth with a bitefork, has posterior reference bilaterally on the THA (located with kinematic axis locator) and has a third anterior reference point. The maxillary cast 
is positioned in the articulator relative to the three points. The Freecorder ${ }^{\circledR}$ Bluefox instead transfers the patient information to the articulator through the mandibular arch. The posterior reference is the THA.

The optoelectronic axis location was accomplished by selecting the hinge axis location function from the program menu. The coded sensors on the Freecorder ${ }^{\circledR}$ Bluefox face bow were attached to the patient and adjusted to stay within view of the cameras through the guided movements Figures 3-17 and 3-18 illustrate the camera tracking device and onscreen adjustment window. At the computer prompt, initiated by depressing the unit foot pedal, a four to nine millimeter opening movement of the mandibular element of the articulator was performed. At the appropriate opening, the red line turns green prompting the operator to stop the recording. The right and left center of rotations are plotted on a graph (Figure 3-19) based on the arc of curvature during opening. The data was stored and transferred to the technician page (Figure 3-20). In the mounting table section, coordinates (values) for the mounting table (Figure 3-21) were generated. With the given coordinates the mandibular arch position (mandibular cast) relative to the THA was transferred to the articulator. The mounting table has anterior and posterior adjustable arms.

To evaluate the accuracy of the optoelectronic axis location, the mandibular casts were attached to the mandibular element of the articulator with a split cast plate (Figure 3-9). The split cast is a key and key-way configuration. When mounted properly, the split cast plate and the mounting stone will coincide confirming the transfer of the known THA. If they do not coincide, then the transfer was inaccurate and the THA was not transferred. The evaluation for this part of the investigation was a yes/no assessment. The aim of this investigation did not permit for a quantitative or qualitative assessment.

\section{Methods: Specific Aim 2}

The mock patient condylar settings for each trial were adjusted under $3.5 \mathrm{X}$ magnification and covered by Operator 1 . The selected test settings remained the same for all determinations. Operator 2 attached the optoelectronic pantograph to mock patient. Figure 3-22 illustrates patient and mock patient with Freecorder ${ }^{\circledR}$ Bluefox facebows attached. Operator 2 started the recording session by locating the THA as described in Specific Aim 1. Per manufacturer's instruction manual (JAWS Version 8.0 Registrier-und Analyseprogramm für den Freecorder ${ }^{\circledR}$ Bluefox,German version, Germany), Operator 2 the guided mock patient in a protrusive, left lateral and right lateral movement for each recording session. Figure 3-23 diagrammatically outlines the evaluation protocol for the Freecorder ${ }^{\circledR}$ Bluefox. The data was stored and transferred to the Technician's page (Figure 3-24). The data was displayed graphically and numerically. A screen capture depicting the graphical and numerical representations of mock patient condylar movements in sagittal, frontal and horizontal planes for the left and right sides for protrusive movement are shown in Figure 3-25. Figure 3-26 depicts a left lateral movement and Figure 3-27 depicts a right lateral movement. The proprietary software is JAWS ${ }^{\circledR}$ version 8.0. Operator 2 made a total of 30 recording sessions. The 


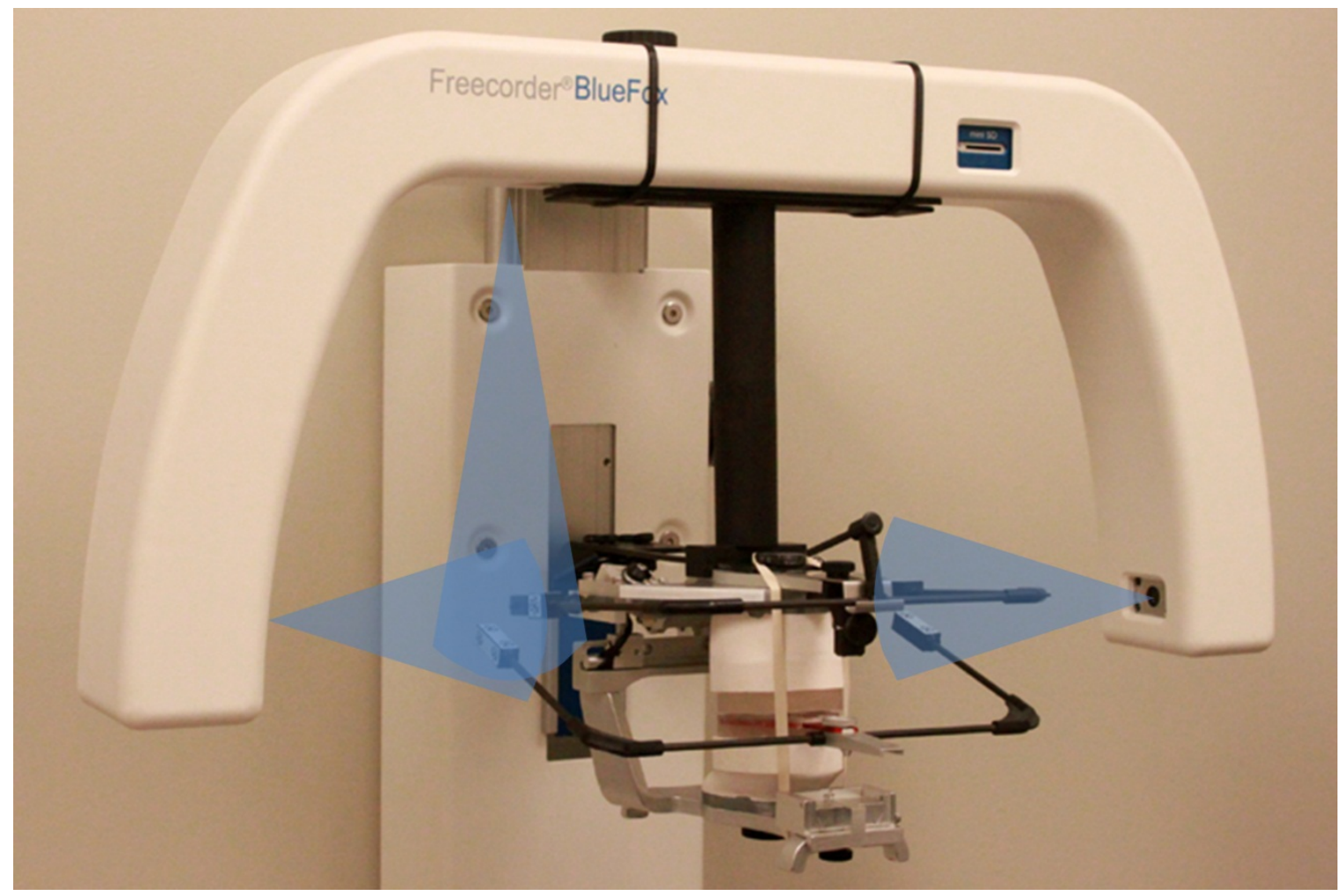

Figure 3-17. Simulation of sensors in view of camera.

The illustration simulates the three cameras that track movement of the sensors attached to the face bows. 


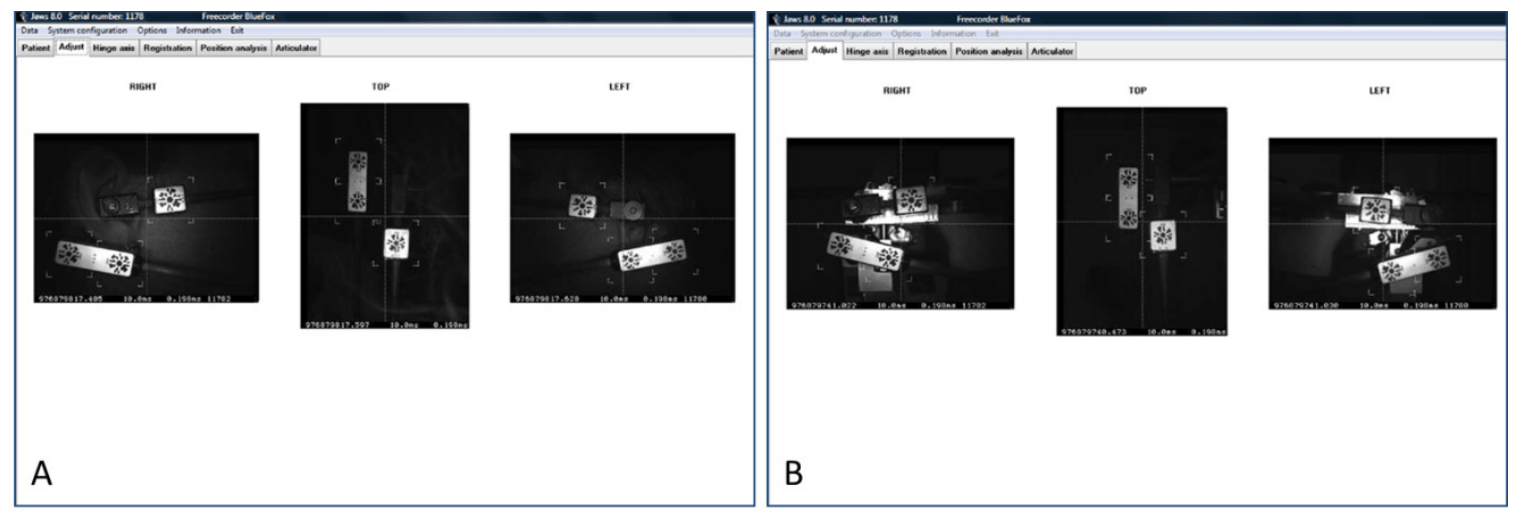

Figure 3-18. Camera view of sensors.

The software allows for real-time adjustment of the Freecorder ${ }^{\circledR}$ Bluefox face bow. A. View of patient positioned in the device. B. View of mock patient positioned in the device. Ensure that sensors stay within camera view through all mandibular movements. This step is completed prior to any recordings of the horizontal axis or mandibular movement. 


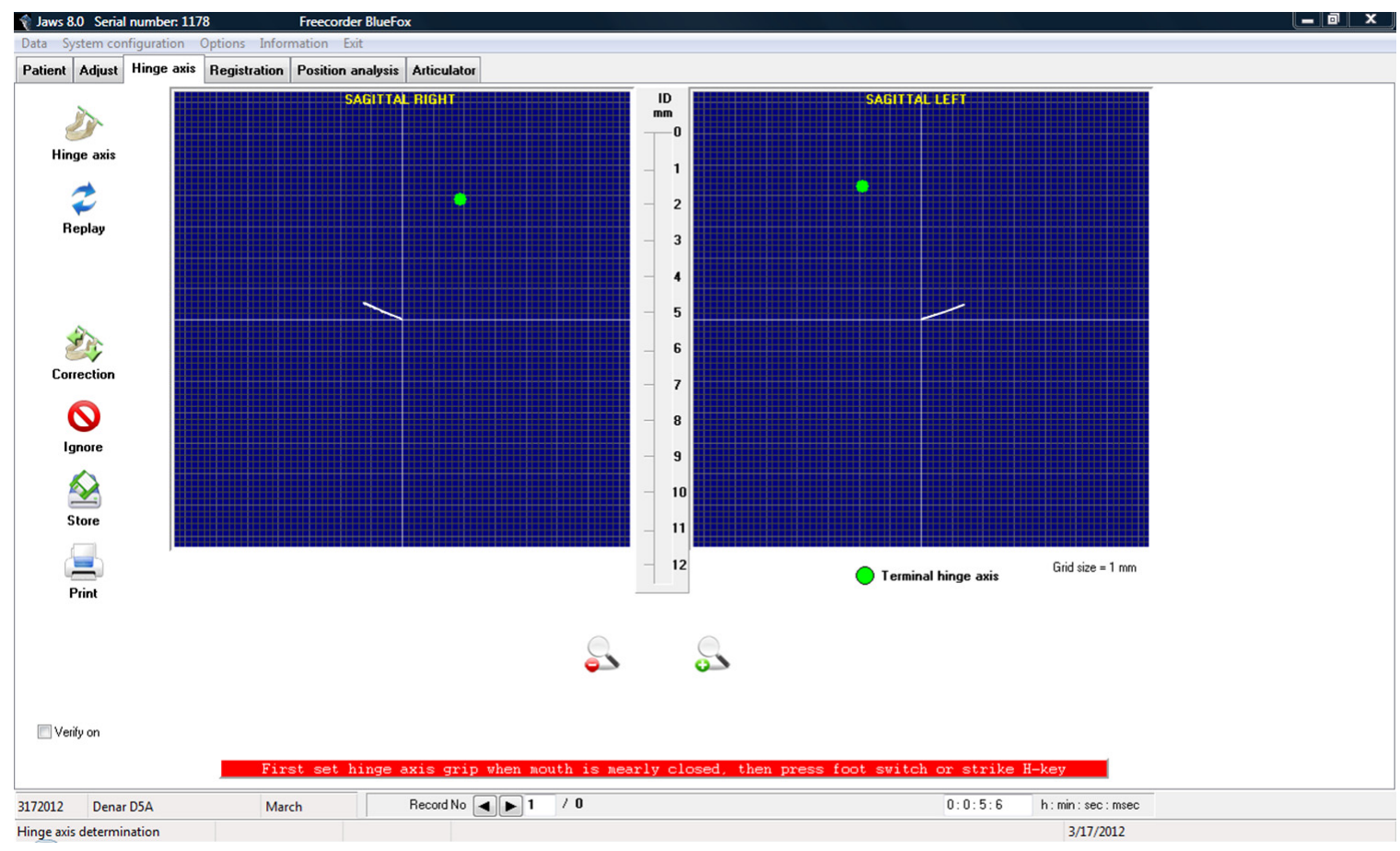

Figure 3-19. Screen capture of hinge axis location.

The patient opens between four to nine millimeters and the JAWS ${ }^{\circledR}$ software calculates the horizontal axis. The white lines simulate movement of the mandibular sensors during a rotational movement. 


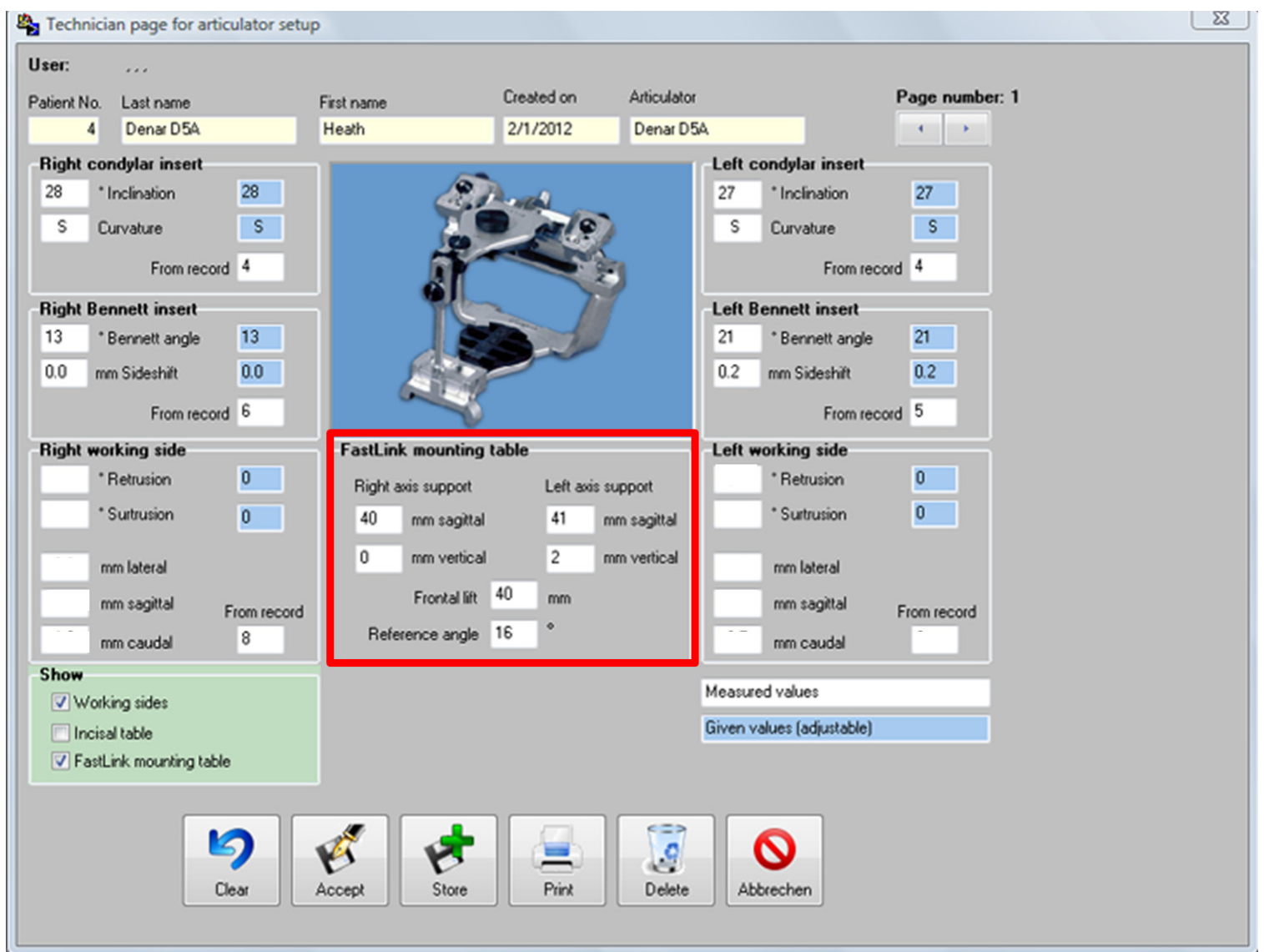

Figure 3-20. Screen capture of technician's page.

The values in the red box were used to program the mounting table. 


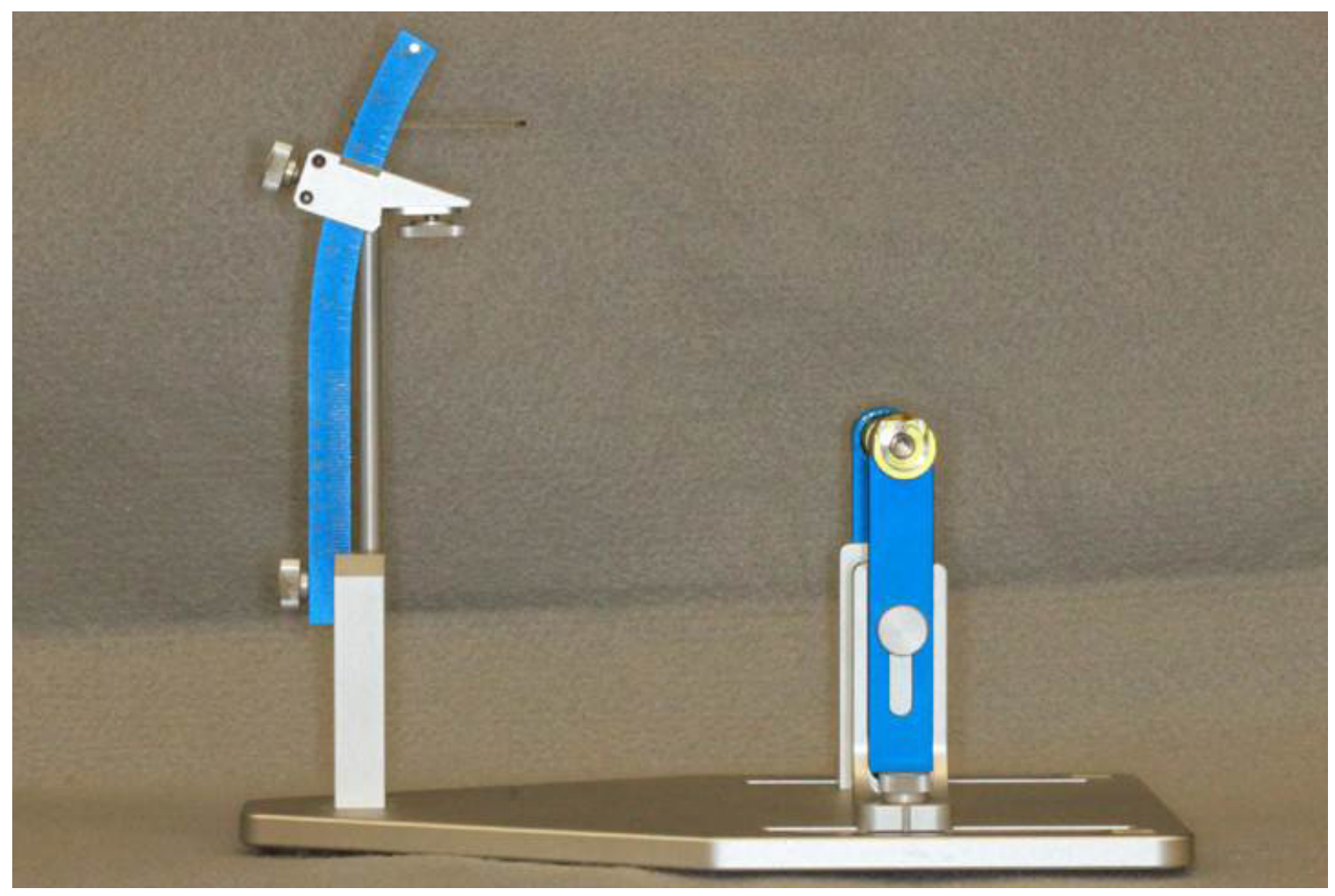

Figure 3-21. Mounting table.

The FastLink ${ }^{\circledR}$ mounting table was used to position the mandibular cast relative to the mandibular member of the articulator transferring the patient's mandibular relationship to the horizontal axis to the articulator. The mounting table has anterior and posterior adjustment arms. 

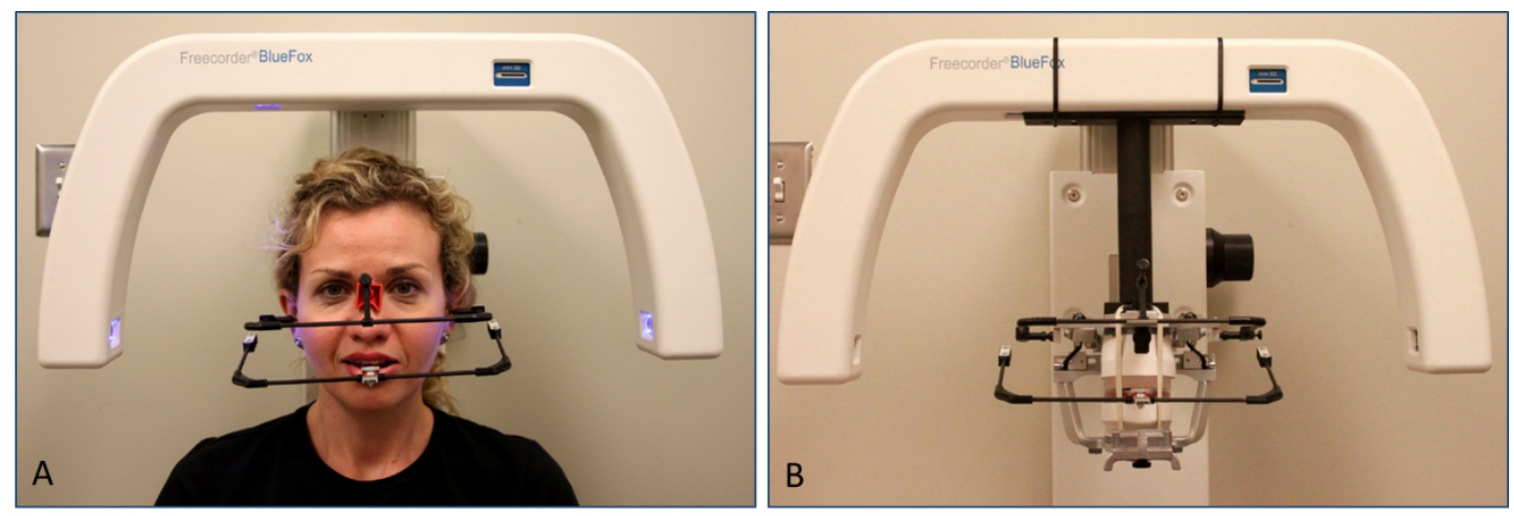

Figure 3-22. Comparison of patient and mock patient positioned in Freecorder ${ }^{\circledR}$ Bluefox.

A. The patient positioned in the recording device. B. Mock patient positioned in the recording device.

\begin{tabular}{|c|c|c|c|}
\hline \multirow{6}{*}{ Mock Patient Settings } & Trial 1 & Trial 2 & Trial 3 \\
\hline & \multirow{5}{*}{$\frac{\mathrm{Cl}}{\mathrm{PSS}}$} & $\mathrm{Cl}$ & $\mathrm{Cl}$ \\
\hline & & PSS & PSS \\
\hline & & ISS & ISS \\
\hline & & & Superior Wall \\
\hline & & & Rear Wall \\
\hline Movements & $\begin{array}{r}\text { Protrusive } \\
\text { Right Lateral } \\
\text { Left Lateral }\end{array}$ & $\begin{array}{r}\text { Protrusive } \\
\text { Right Lateral } \\
\text { Left Lateral }\end{array}$ & $\begin{array}{r}\text { Protrusive } \\
\text { Right Lateral } \\
\text { Left Lateral }\end{array}$ \\
\hline
\end{tabular}

Figure 3-23. Freecorder ${ }^{\circledR}$ Bluefox protocol. 


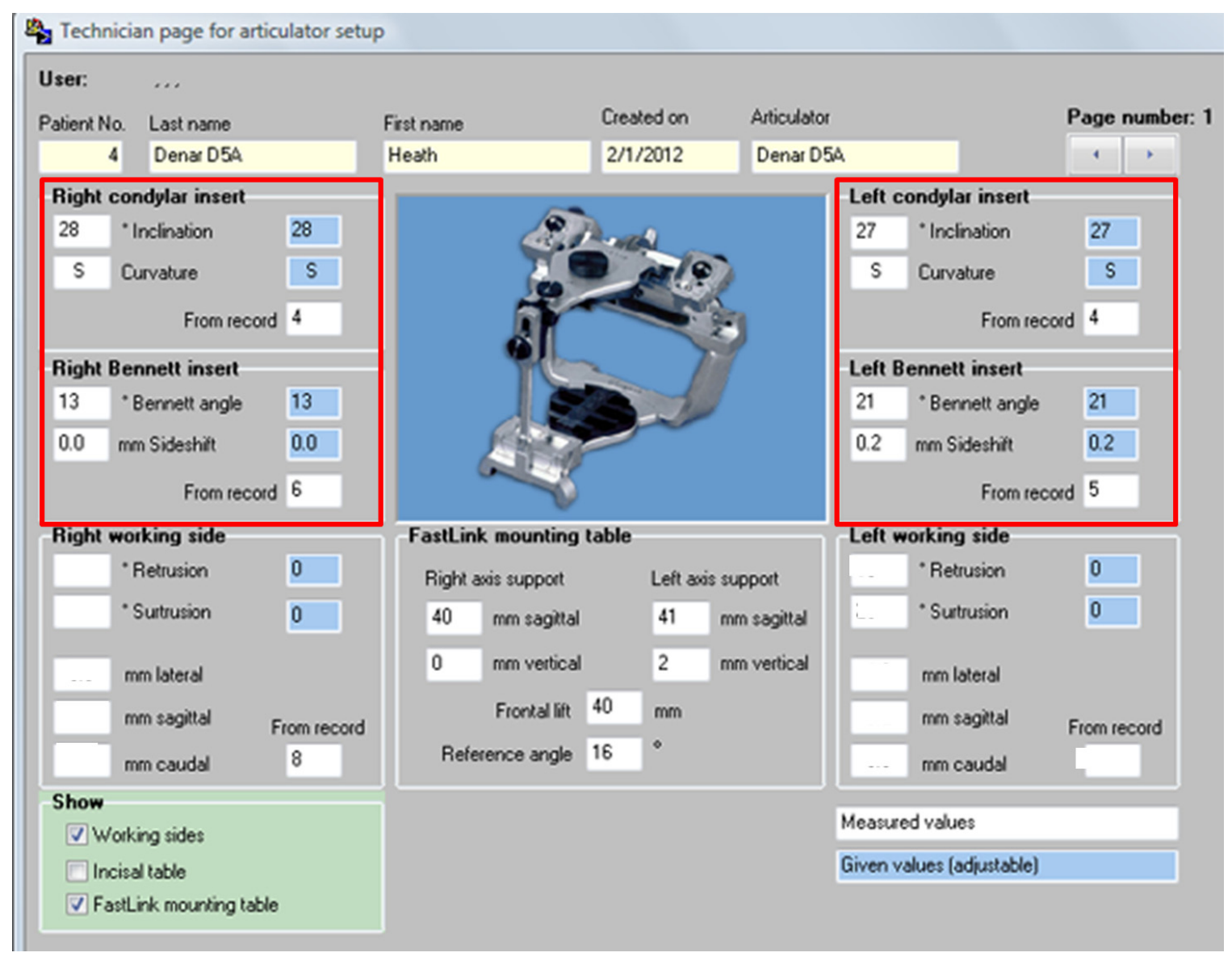

Figure 3-24. Technician page to program articulator.

The values in the red boxes were used to program the corresponding condylar guide assembly settings of the selected articulator. This investigation used the Denar ${ }^{\mathbb{B}}$ D5A articulator. 


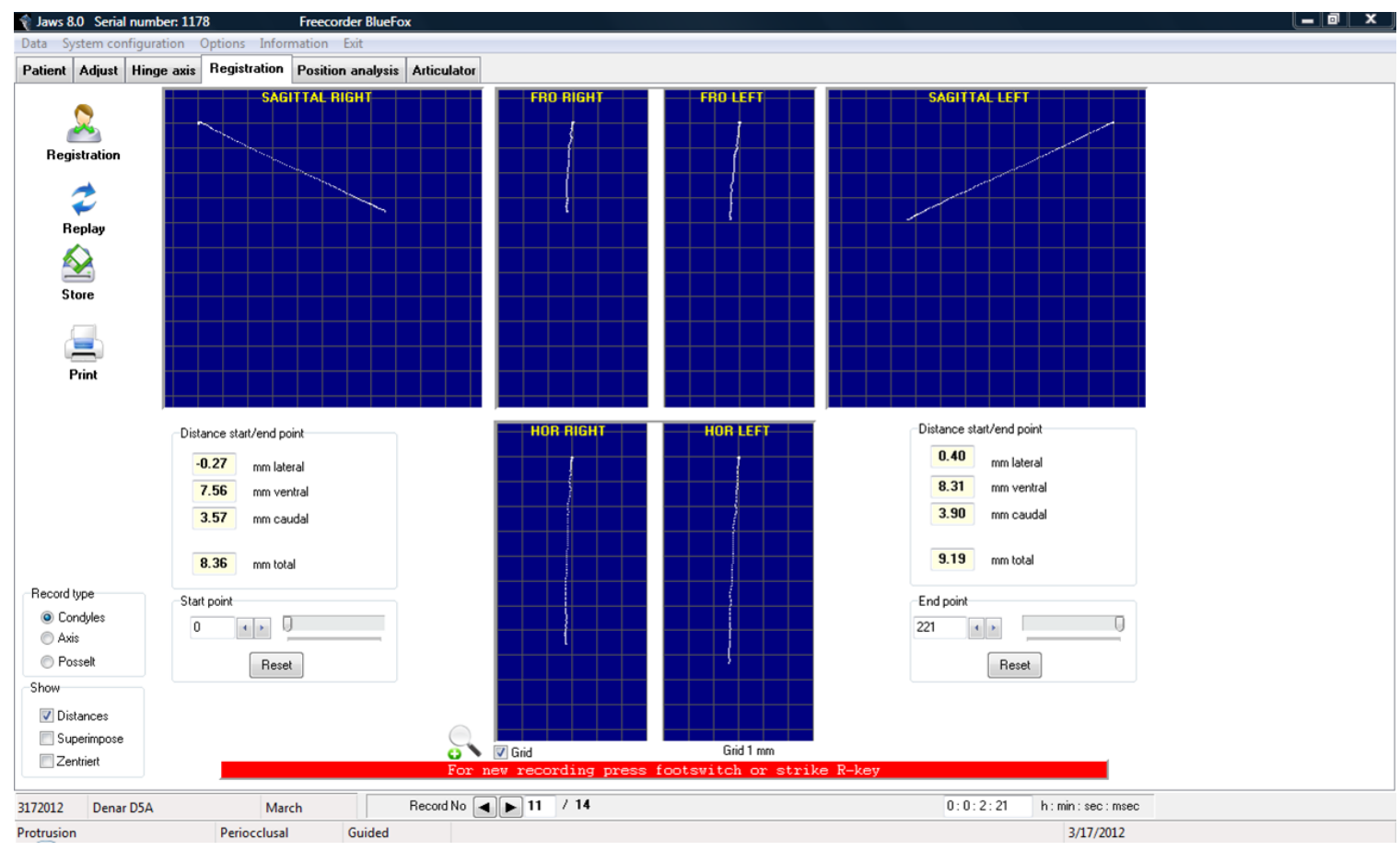

Figure 3-25. Screen capture of protrusive recording. 


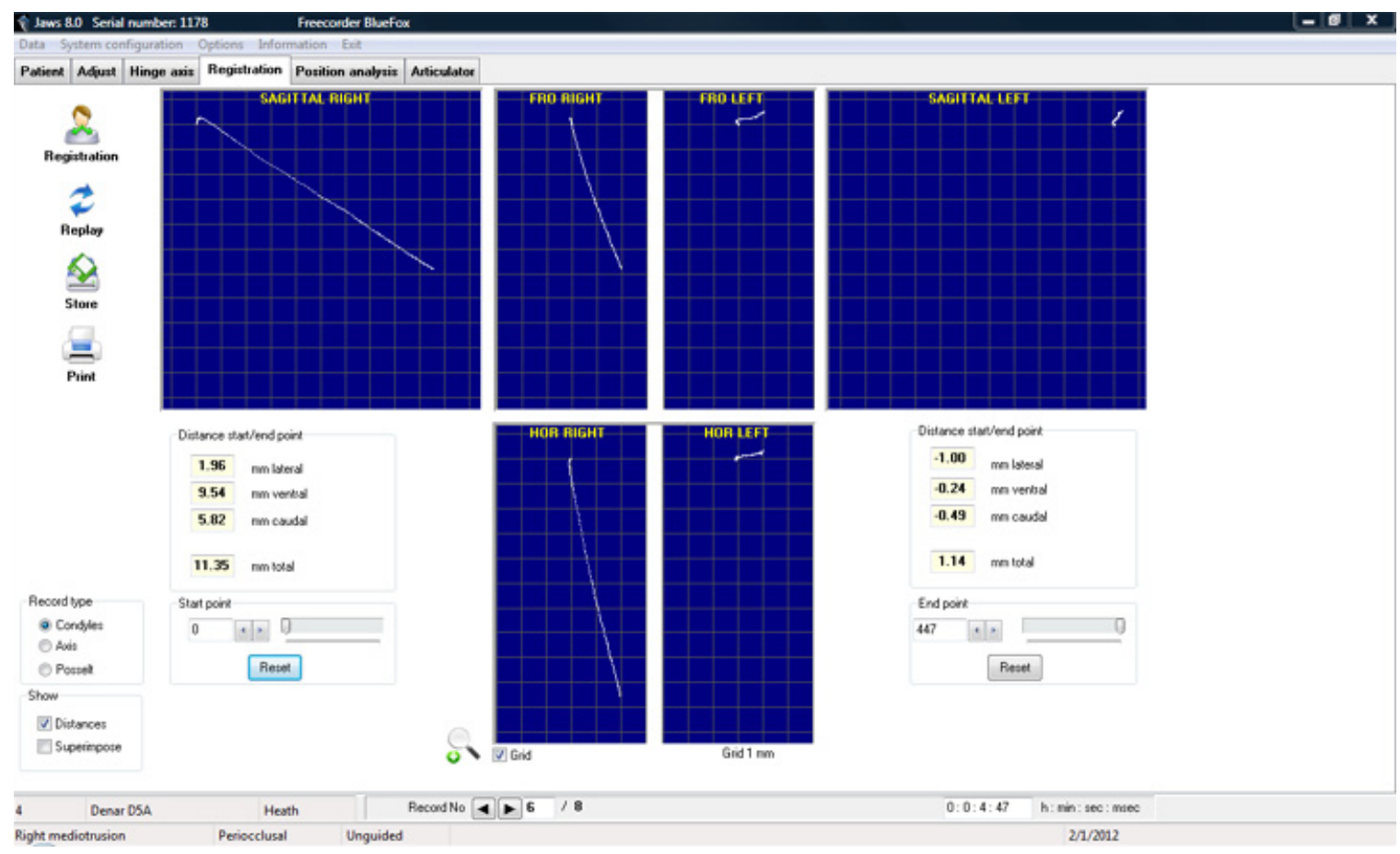

Figure 3-26. Screen capture of right lateral movement. 


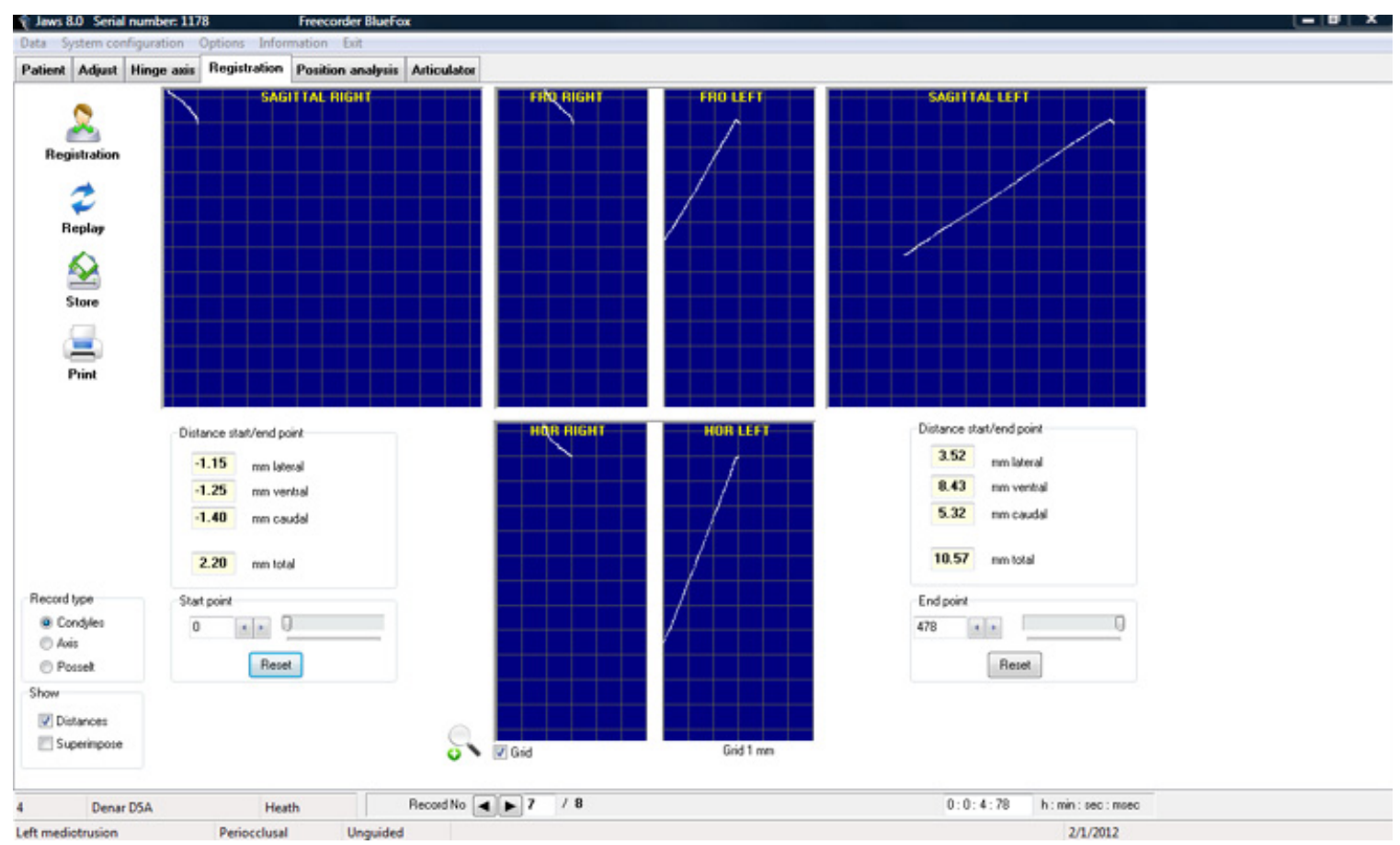

Figure 3-27. Screen capture of left lateral movement. 
condylar guide assembly values were transferred to a Microsoft ${ }^{\circledR}$ Excel 2010 spreadsheet for statistical analysis.

\section{Trial 1}

Operator 1 adjusted mock patient condylar settings LCI and PMLT under 3.5X magnification and covered values. The selected test settings remained the same for all determinations. Operator 2 performed guided movements of mock patient. Data recorded and transferred to spreadsheet.

\section{Trial 2}

Operator 1 adjusted mock patient condylar settings LCI, PMLT and IMLT under 3.5X magnification and covered values. The selected test settings remained the same for all determinations. Operator 2 performed guided movements of mock patient. Data recorded and transferred to spreadsheet.

\section{Trial 3}

Operator 1 adjusted mock patient condylar settings for LCI, PMLT, IMLT and laterotrusion under 3.5X magnification and covered values. The selected test settings remained the same for all determinations. Operator 2 performed guided movements of mock patient. Data recorded and transferred to spreadsheet.

\section{Methods: Specific Aim 3}

The mock patient condylar settings for each trial were adjusted under $3.5 \mathrm{X}$ magnification and covered by Operator 1 . The selected test settings remained the same for all determinations. Operator 2 attached the mechano-electronic pantograph to mock patient. Figure 3-28 illustrates patient and mock patient with Cadiax Compact $2^{\circledR}$ facebows attached. Face-bow information and articulator selection was performed prior to recording movements. Operator 2 started the recording session by recording the reference position. The origin of the reference point is the beginning of all movements. Per manufacturer's instruction manual [GAMMA Dental Software ${ }^{\circledR}$ Version 3 for Windows 2000/XP Revision B. (2002). GAMMA Medizinisch-wissenschaftliche Fortbildungs-GmbH, Klosterneburg, Austria], the mechano-electronic pantograph performed three protrusive, left lateral and right lateral movements for each recording session. Operator 2 made a total of 30 recordings for each trial. Figure 3-29 diagrammatically outlines the evaluation protocol for the Cadiax Compact $2^{\circledR}$. The data was stored and transferred to the Articulator setting page (Figure 3-30). The data was displayed graphically and numerically. A screen capture depicting the graphical and numerical representations of mock patient condylar movements in sagittal, frontal and 

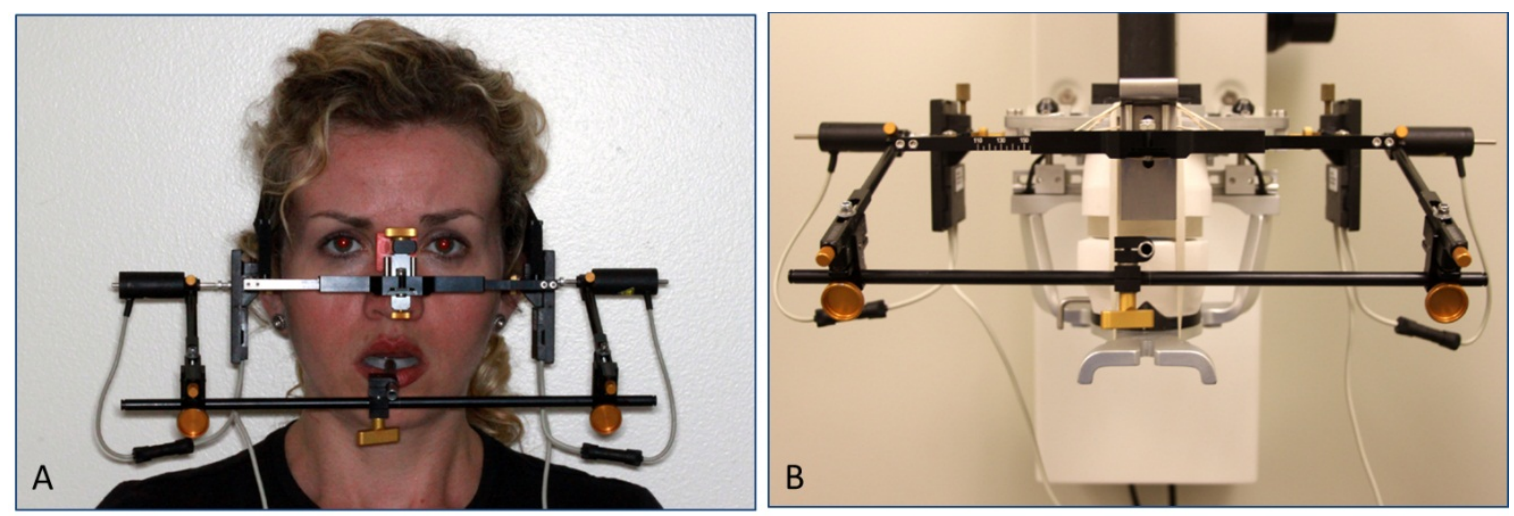

Figure 3-28. Comparision of patient and mock patient with Cadiax Compact $2^{\circledR}$ mandibular recorder.

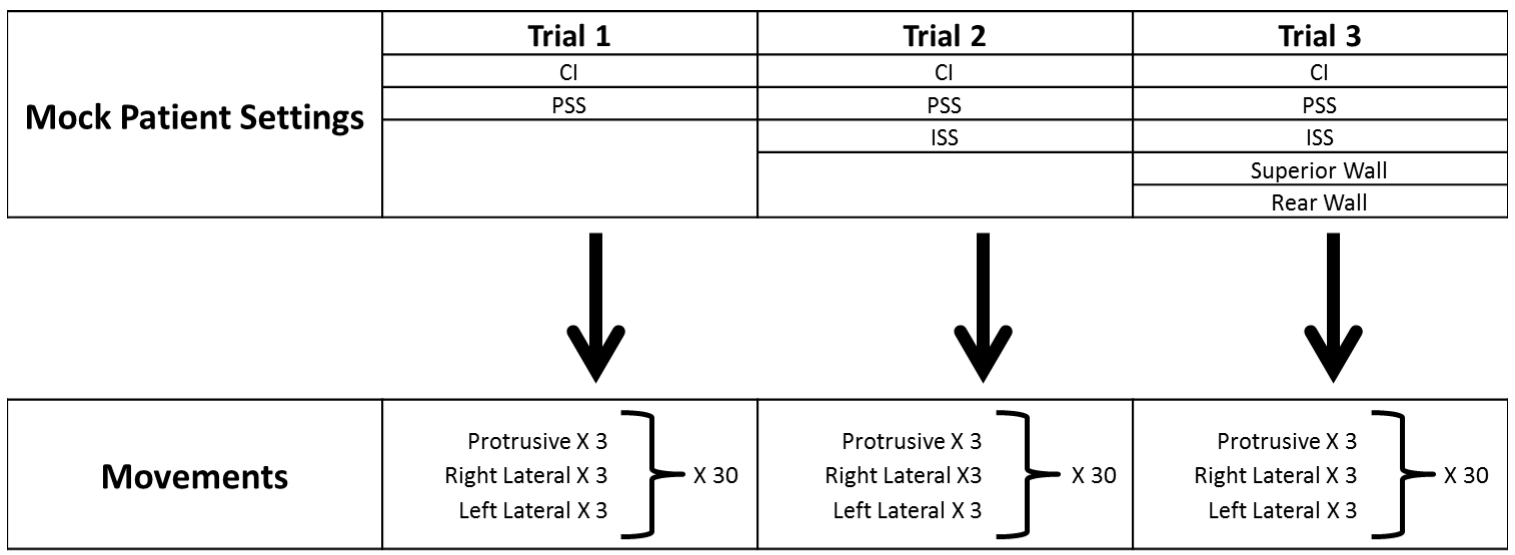

Figure 3-29. Cadiax Compact $2^{\circledR}$ protocol. 


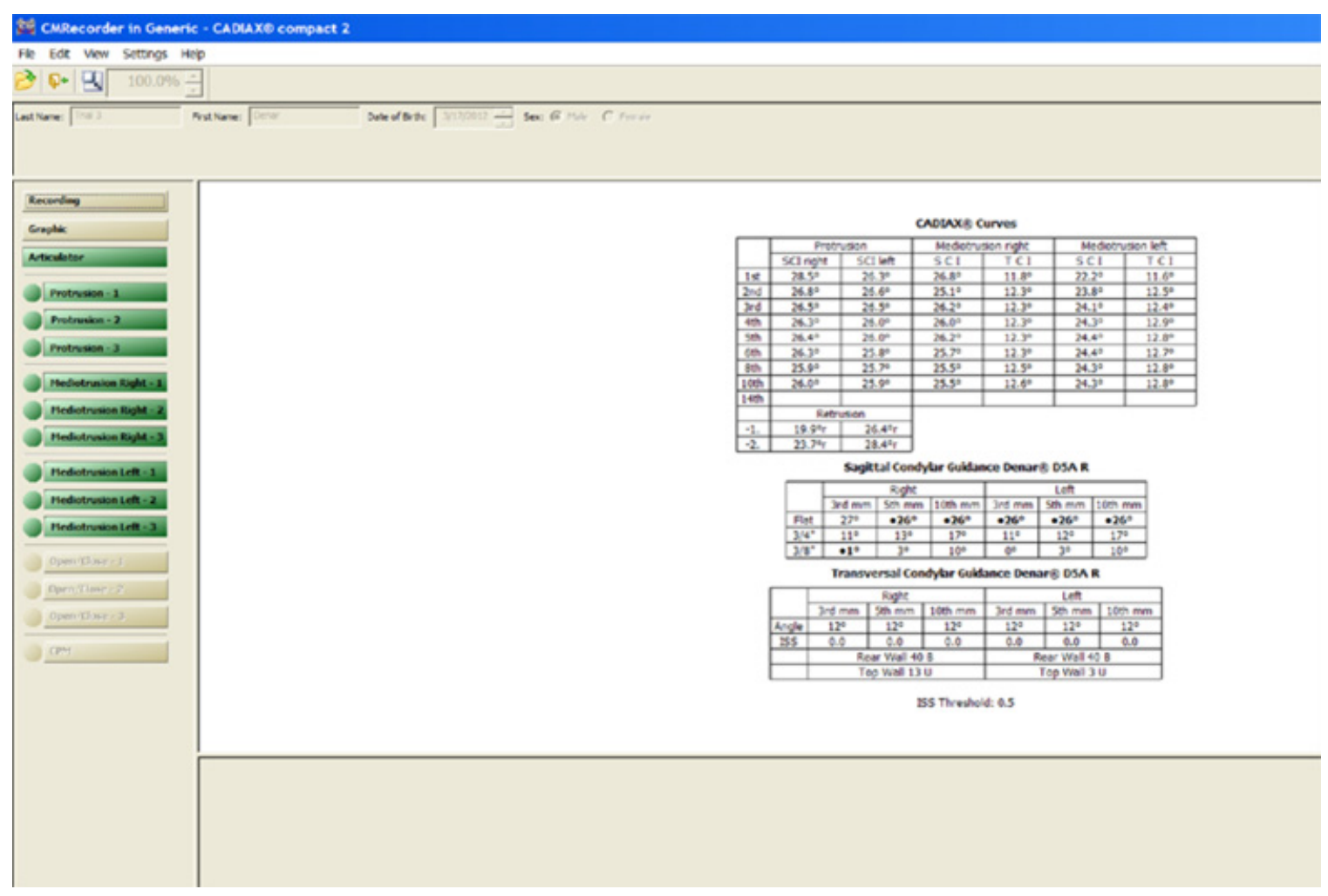

Figure 3-30. Screen capture of articulator page.

The values in the lower right were used to program the condylar guide assembly settings of the selected articulator. This investigation used the Denar ${ }^{\circledR}$ D5A R articulator. 
horizontal planes for the left and right sides for protrusive movement are shown in Figure 3-31. Figure 3-32 depicts a left lateral movement and Figure 3-33 depicts a right lateral movement. The proprietary software is GAMMA Dental Software ${ }^{\circledR}$. Operator 2 made a total of 30 recording sessions. The condylar guide assembly values were transferred to a Microsoft ${ }^{\circledR}$ Excel 2010 spreadsheet for statistical analysis.

\section{Trial 1}

Operator 1 adjusted mock patient condylar settings LCI and PMLT under 3.5X magnification and covered values. The selected test settings remained the same for all determinations. Operator 2 performed guided movements of mock patient. Data recorded and transferred to spreadsheet.

\section{Trial 2}

Operator 1 adjusted mock patient condylar settings LCI, PMLT and IMLT under 3.5X magnification and covered values. The selected test settings remained the same for all determinations. Operator 2 performed guided movements of mock patient. Data recorded and transferred to spreadsheet.

\section{Trial 3}

Operator 1 adjusted mock patient condylar settings LCI, PMLT, IMLT and laterotrusion under 3.5X magnification and covered values. The selected test settings remained the same for all determinations. Operator 2 performed guided movements of mock patient. Data recorded and transferred to spreadsheet.

\section{Methods: Specific Aim 4}

Compared predicted condylar guide assembly values of Freecorder ${ }^{\circledR}$ Bluefox and Cadiax Compact $2^{\circledR}$. Statistical evaluation made in Microsoft ${ }^{\circledR}$ Excel 2010. 


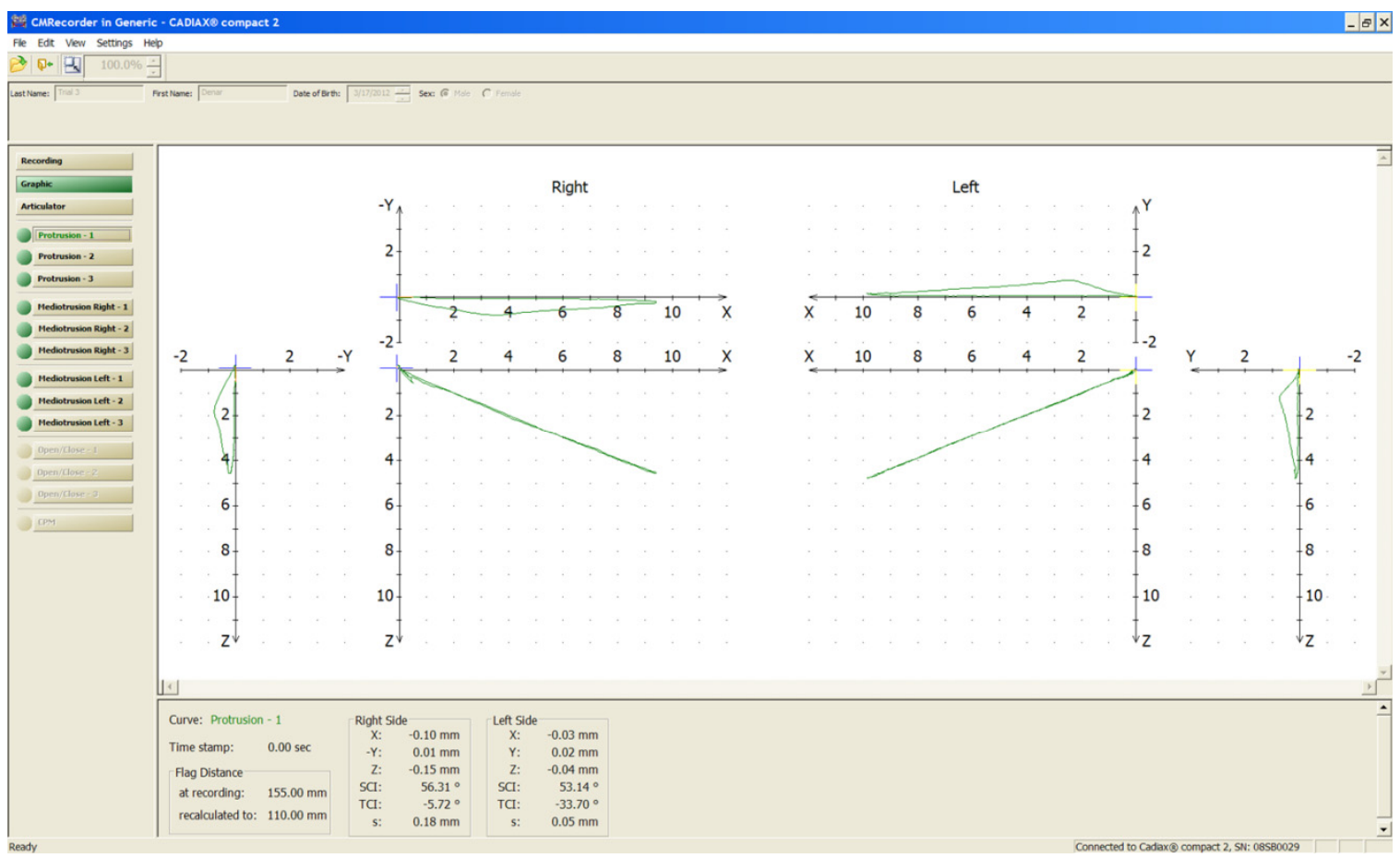

Figure 3-31. Screen capture of a protrusive movement. 


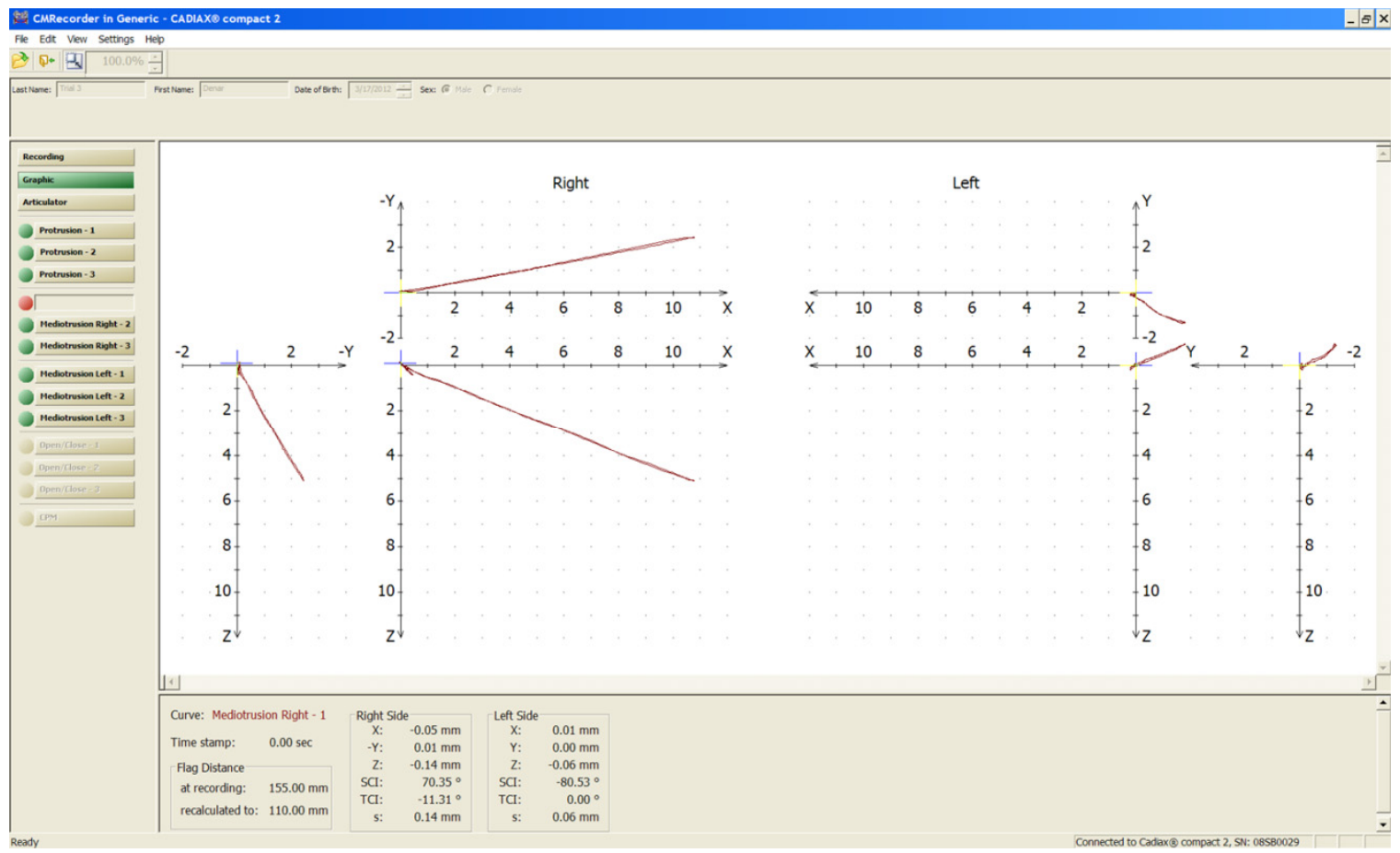

Figure 3-32. Screen capture of left lateral movement. 


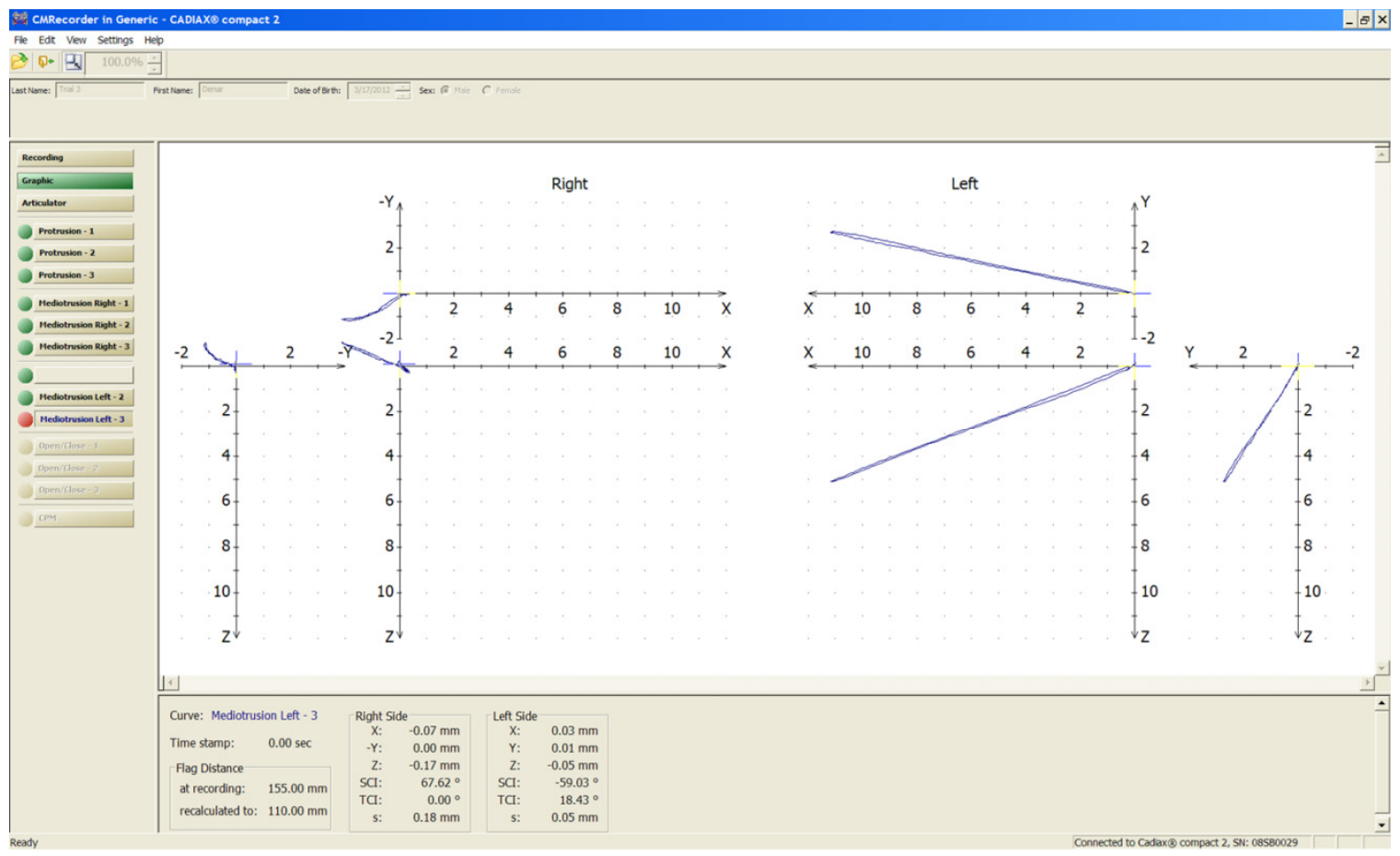

Figure 3-33. Screen capture of right lateral movement. 


\section{CHAPTER 4. RESULTS}

This investigation consists of four specific questions. Specific Aim One investigated the ability of the Freecorder ${ }^{\mathbb{B}}$ Bluefox to accurately locate a known THA. A split-cast assessment was utilized to evaluate the accuracy of the Freecorder ${ }^{\mathbb{B}}$ Bluefox to locate a known THA. The split-cast method of articulator adjustment is used to verify the accuracy of casts mounted on the THA (Needles 1923, Lauritzen and Wolford 1964 and Lucia 1964). Due to the limitations of this study, neither a quantitative nor qualitative assessment was performed. The evaluation was a simple verification or rejection of the mounting. Figures 4-1 and 4-2 compare mock patient mounted mandibular cast with a representative mounting based on coordinates generated by the JAWS ${ }^{\circledR}$ software. Mediolateral and anteroposterior inaccuracies were present.

Experimental evaluation with respect to Specific Aim One indicated that all mountings based on the Freecorder ${ }^{\circledR}$ Bluefox THA location did not verify with the splitcast mounting plate.

The data from each Trial for Specific Aims One, Two and Three are displayed graphically in Figures 4-3, 4-4, 4-5, 4-6 and 4-7. The gold bar is the gold standard based on the mock patient settings, red bars are the mean values for the Freecorder ${ }^{\circledR}$ Bluefox and green bars are the mean values for the Cadiax Compact $2^{\circledR}$. The black bars represent the $95 \%$ confidence interval. If the black bars overlap the gold standard or each other, then the mean values are statistically similar. If the black bars do not overlap, then the mean values are statistically different.

Experimentation related to Specific Aim Two evaluated the ability of the Freecorder ${ }^{\circledR}$ Bluefox optoelectronic pantograph to accurately determine the preset values of the mock patient for LCI, medial wall angles and amount of IMLT in three separate trials. The mean values generated by the Freecorder ${ }^{\mathbb{B}}$ Bluefox were compared to the known values of the mock patient. Mean values for right $(25.20 \pm 0.58)$ and left $(25.37 \pm 0.50)$ side LCI in Trial 1 were statistically similar ( $95 \%$ confidence interval) to mock patient as illustrated in Figure 4-3. No mean values in Trial 2 or Trial 3 were statistically similar to mock patient as illustrated in Figures 4-4, 4-5, 4-6 and 4-7.

The majority of condylar guide assembly mean values from Trials 1, 2 and 3 predicted by the Freecorder ${ }^{\mathbb{B}}$ Bluefox for the mock patient were statistically inaccurate (95\% confidence interval) as shown in Tables 4-1, 4-2 and 4-3.

Experimentation related to Specific Aim Three evaluated the ability of the Cadiax Compact $2^{\circledR}$ mechano-electronic pantograph to accurately determine the preset values of the mock patient for LCI, medial wall angles and amount of IMLT, rear wall angle and superior wall angle in three separate trials. Mean values for right $(25.00 \pm 0.29)$ side LCI and right (14.77 \pm 0.33$)$ side medial wall angles in Trial 2 (Figure 4-4) and mean values for right (24.73 \pm 0.35$)$ and left $(25.27 \pm 0.27)$ side LCI (Figure 4-6) and right ( $0.98 \pm 0.04)$ 


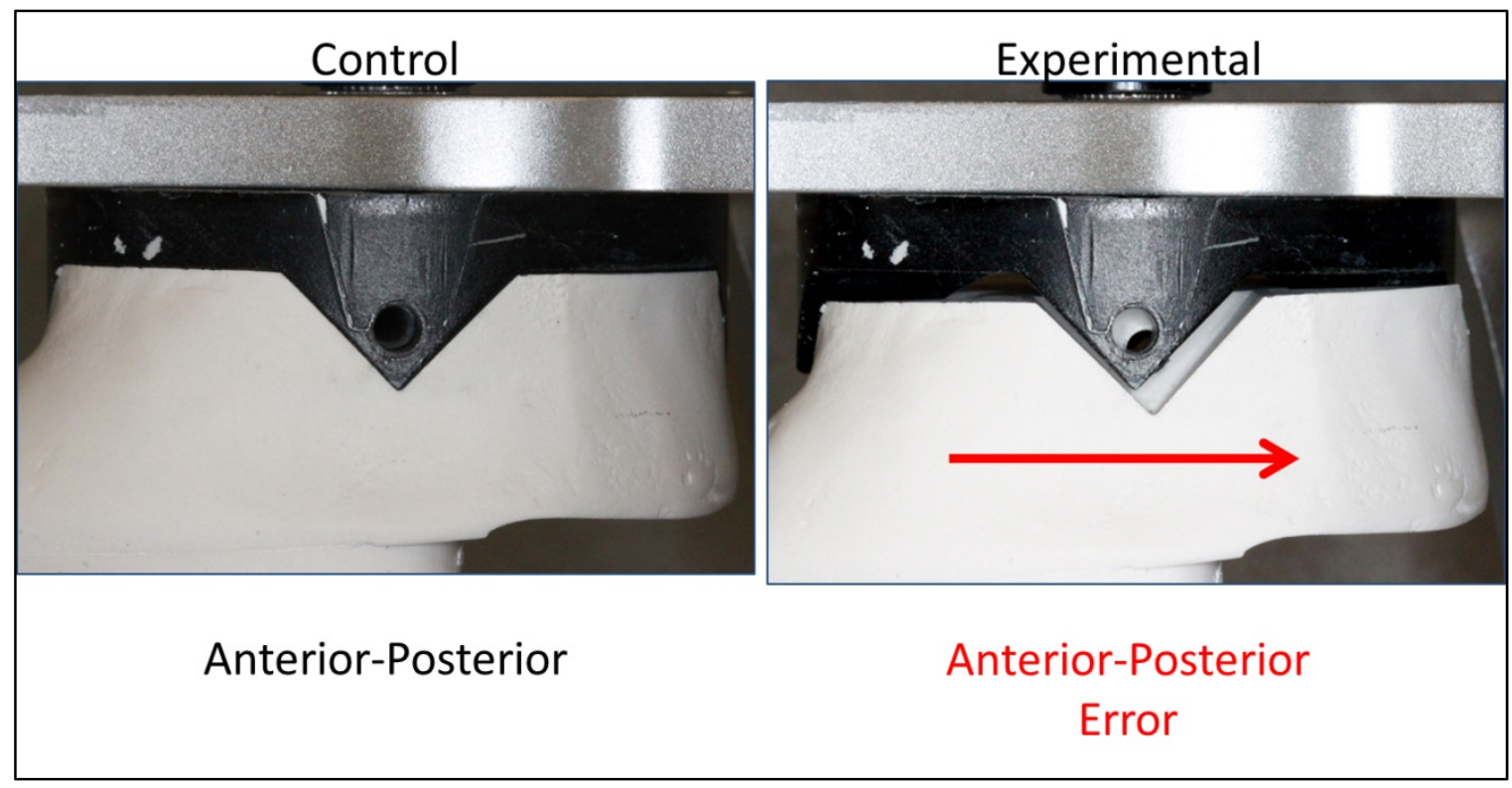

Figure 4-1. Lateral view comparing mock patient mounting with Freecorder ${ }^{\circledR}$ Bluefox mounting.

The image on the left demonstrates accurate alignment of the split cast mounting plate and the mandibular cast in the mounting table. The image on the right illustrates a representative mounting based on coordinates from the JAWS ${ }^{\circledR}$ software. The red arrow indicates a shift of the mounting with respect to computer-generated horizontal axis coordinates resulting in failure of split-cast verification. 


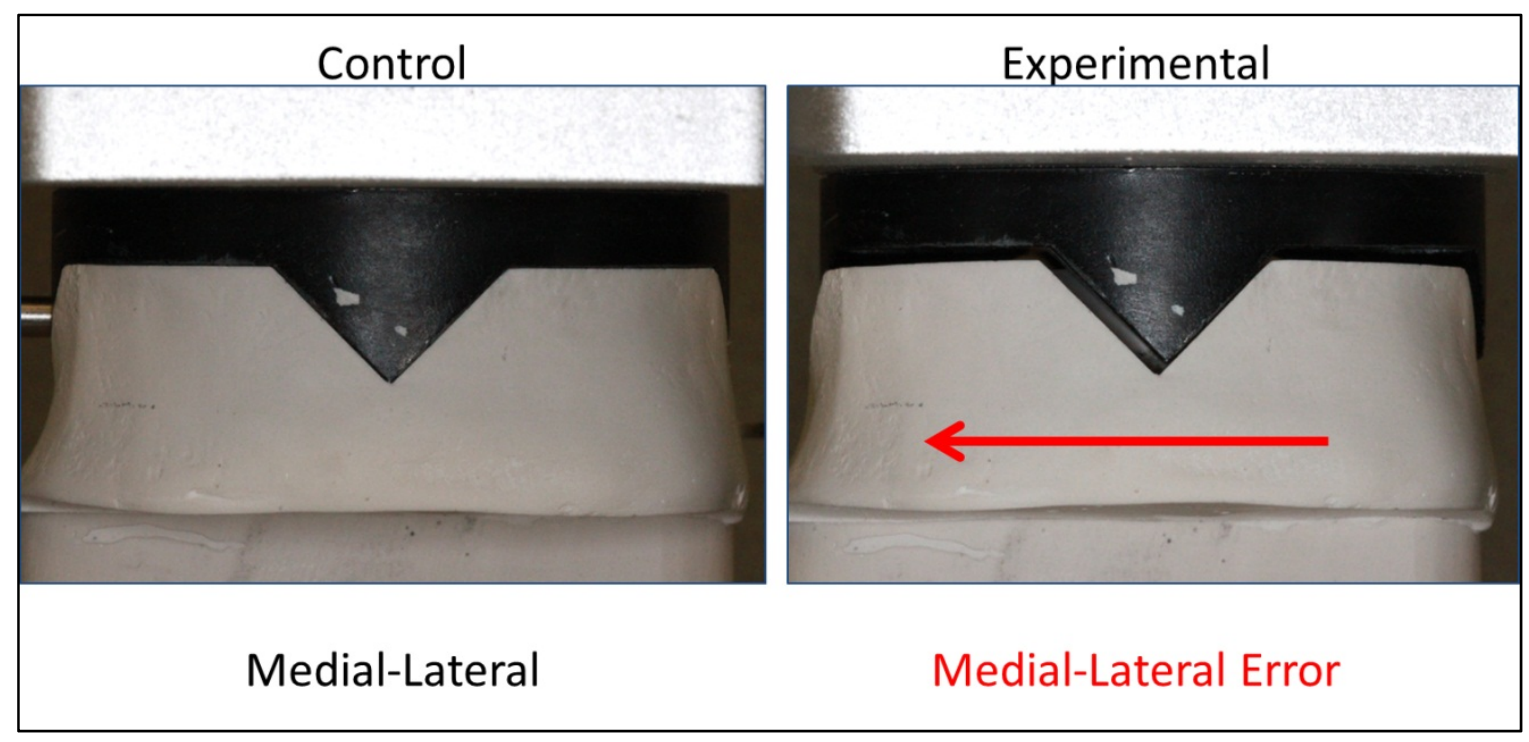

\section{Figure 4-2. Rear view comparing mock patient mounting with Freecorder ${ }^{\circledR}$ Bluefox mounting.}

The image on the left demonstrates proper alignment of the split cast mounting plate with the mock patient mandibular cast. The image on the right is a representative mounting based on coordinates of the JAWS ${ }^{\circledR}$ software. The red arrow indicates a medio-lateral shift of the mounting with respect to the computer-generated horizontal axis coordinates resulting in failure of split-cast verification. 


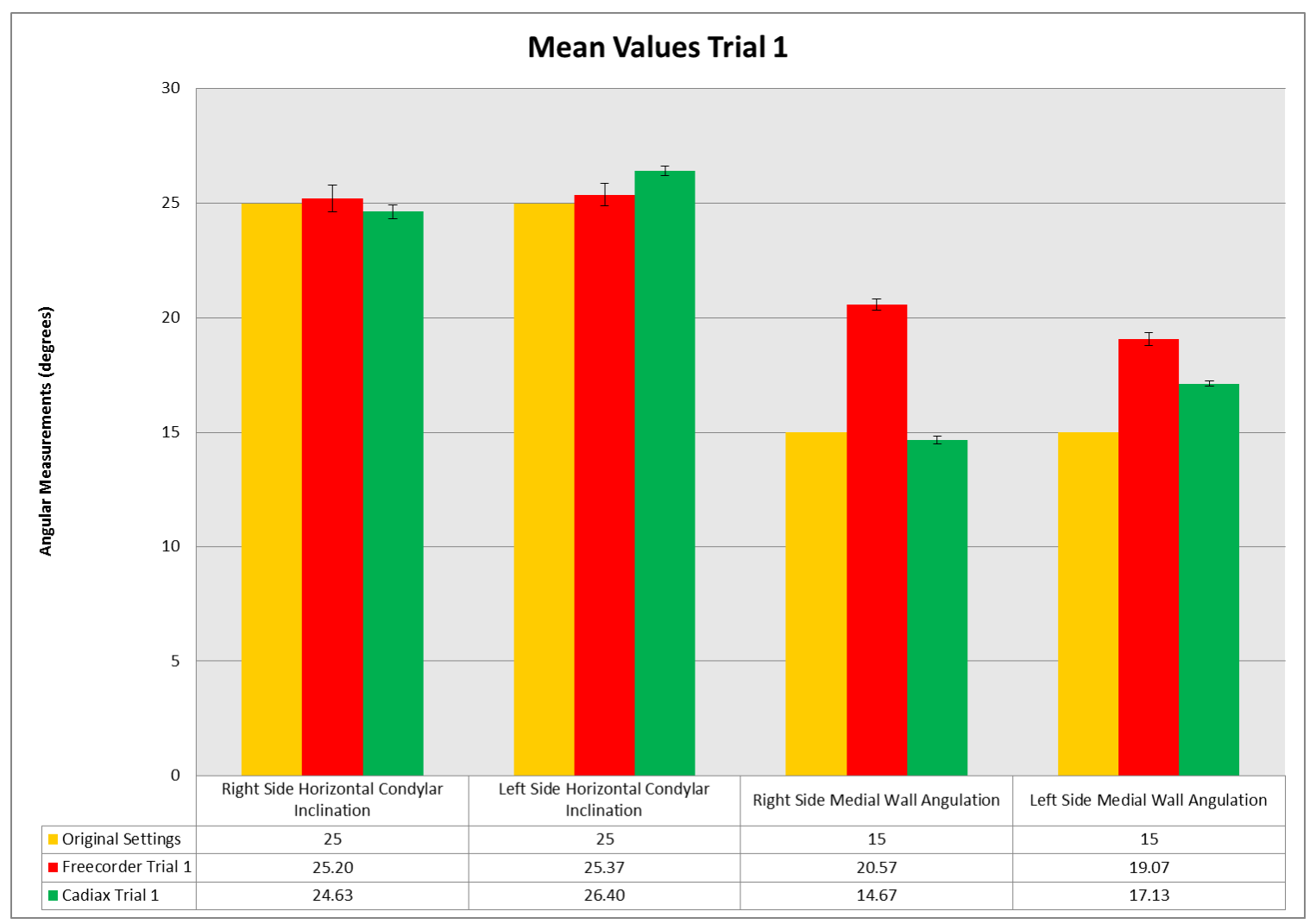

Figure 4-3. Trial 1.

Mock patient settings and mean values for Freecorder ${ }^{\circledR}$ Bluefox and Cadiax Compact $2^{\circledR}$. Black bars indicate 95\% confidence interval. Confidence intervals that overlap indicate statistically similar values. Right and left side horizontal condylar inclinations for the Freecorder ${ }^{\circledR}$ Bluefox overlap the gold standard. The confidence interval bars for the right side horizontal condylar inclinations for the Freecorder ${ }^{\circledR}$ Bluefox and Cadiax Compact $2^{\circledR}$ overlap. 


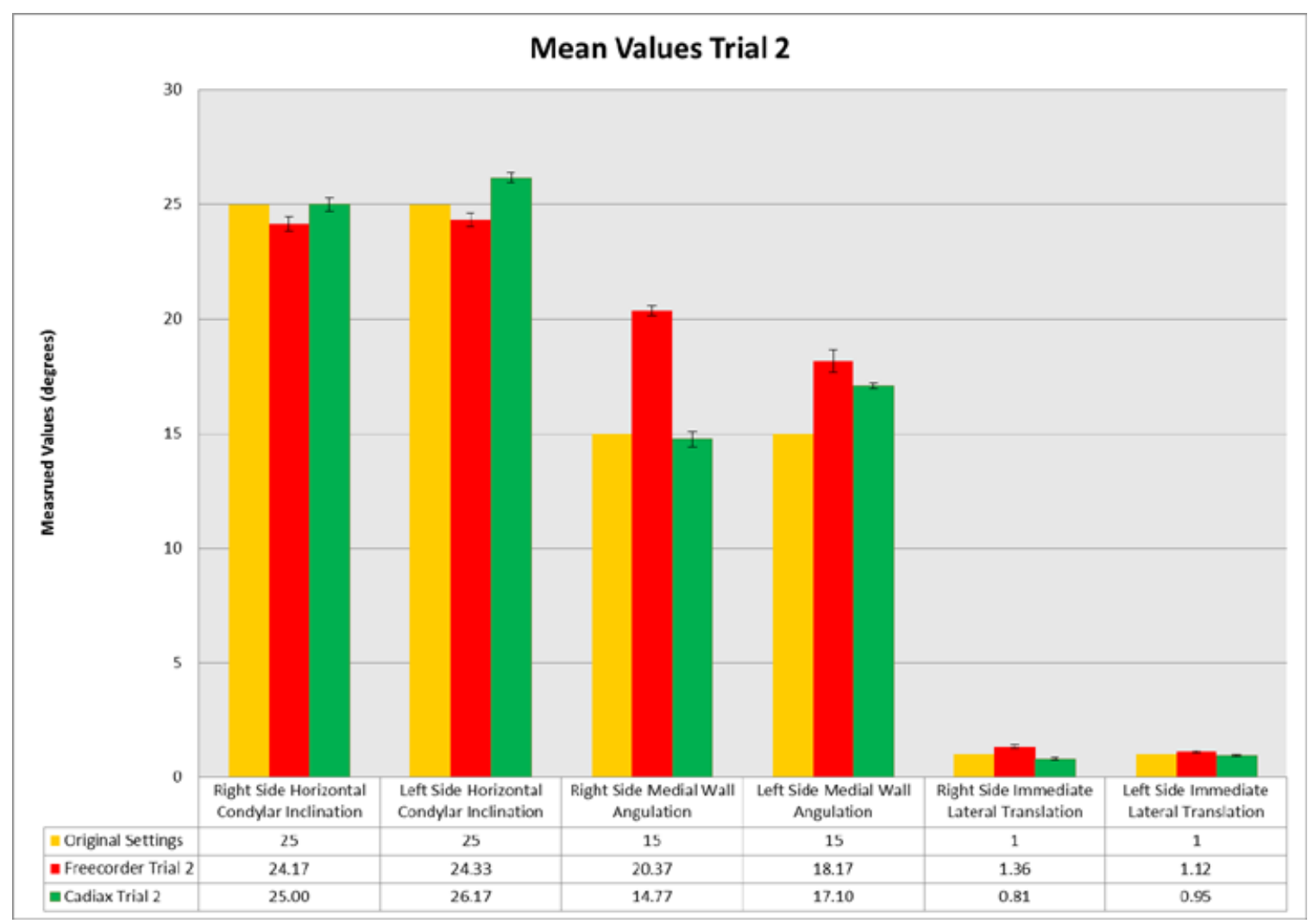

Figure 4-4. Trial 2.

Mock patient settings and mean values for Freecorder ${ }^{\circledR}$ Bluefox and Cadiax Compact $2^{\circledR}$. Black bars indicate 95\% confidence interval. Confidence intervals that overlap indicate statistically similar values. Right side horizontal condylar inclination and right side medial wall mean values for Cadiax Compact $2^{\circledR}$ are statistically similar. 


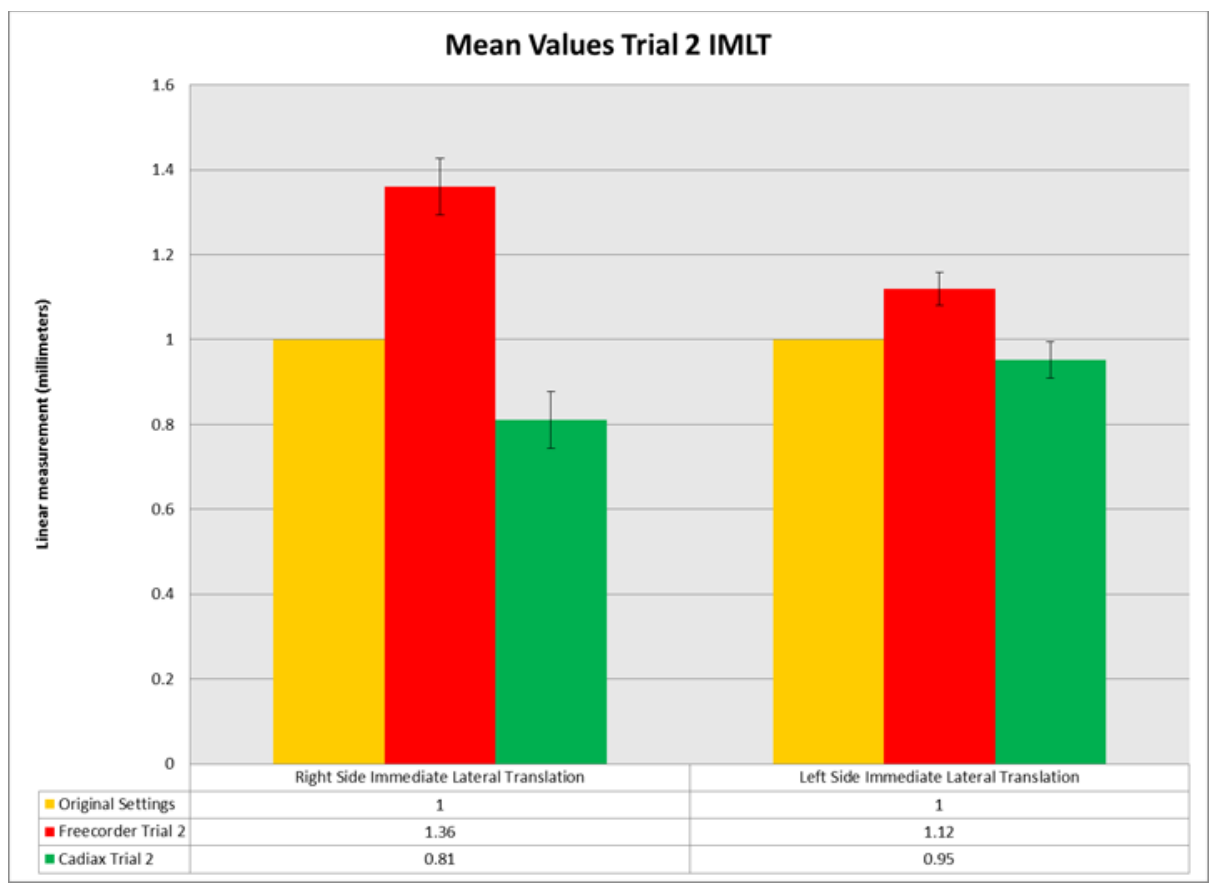

Figure 4-5. Trial 2 Immediate Mandibular Lateral Translation.

Enlarged view of mean values for Immediate Mandibular Lateral Translation (IMLT). Black bars indicate 95\% confidence interval. Confidence intervals that overlap indicate statistically similar values. IMLT is measured in millimeters. 


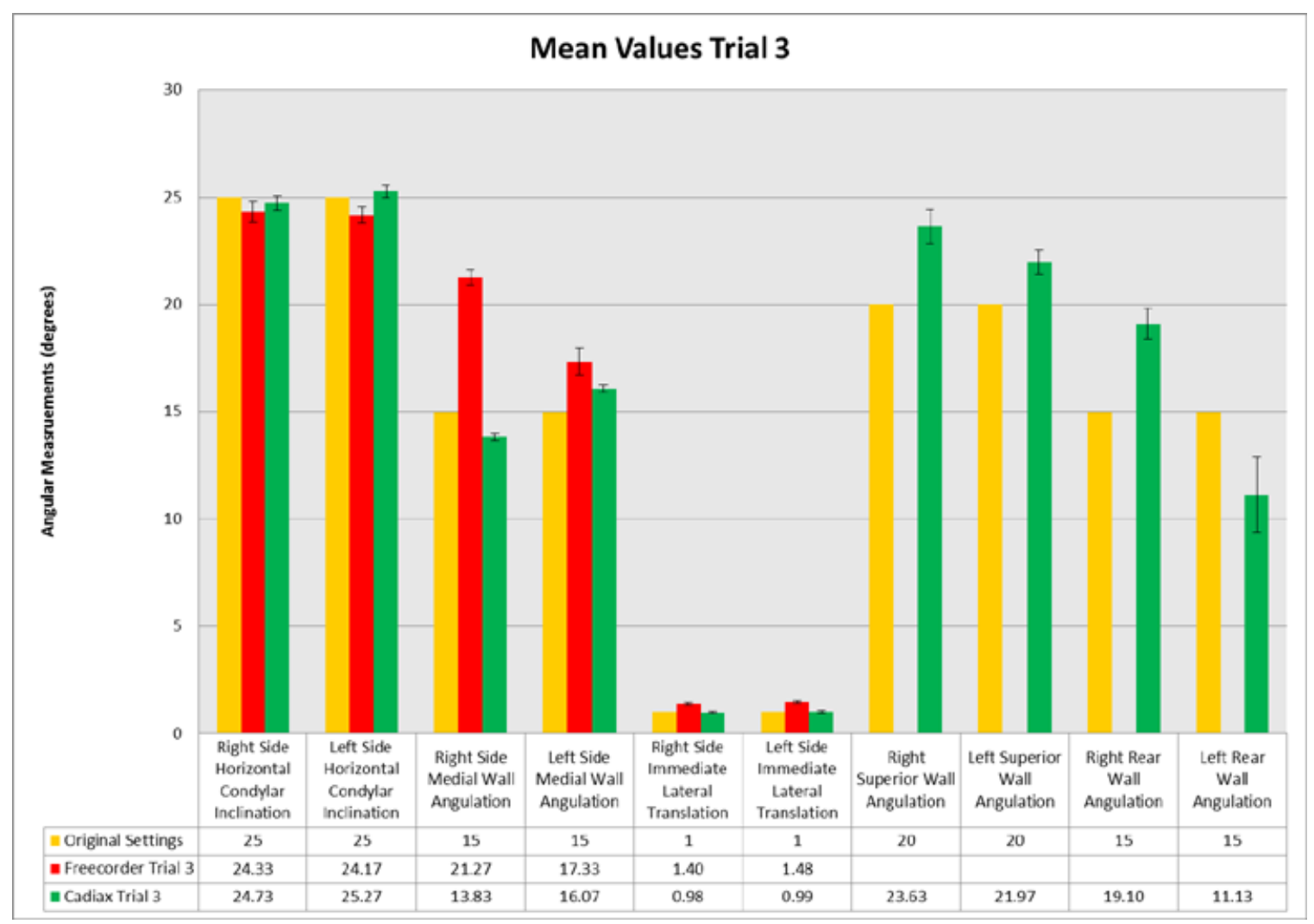

Figure 4-6. Trial 3.

Mock patient settings and mean values for Freecorder ${ }^{\circledR}$ Bluefox and Cadiax Compact $2^{\circledR}$. Black bars indicate 95\% confidence interval. Confidence intervals that overlap indicate statistically similar values. Values for right and left side horizontal condylar inclination and right and left side Immediate Mandibular Lateral Translation for Cadiax Compact $2^{\circledR}$ are statistically similar to mock patient settings. 


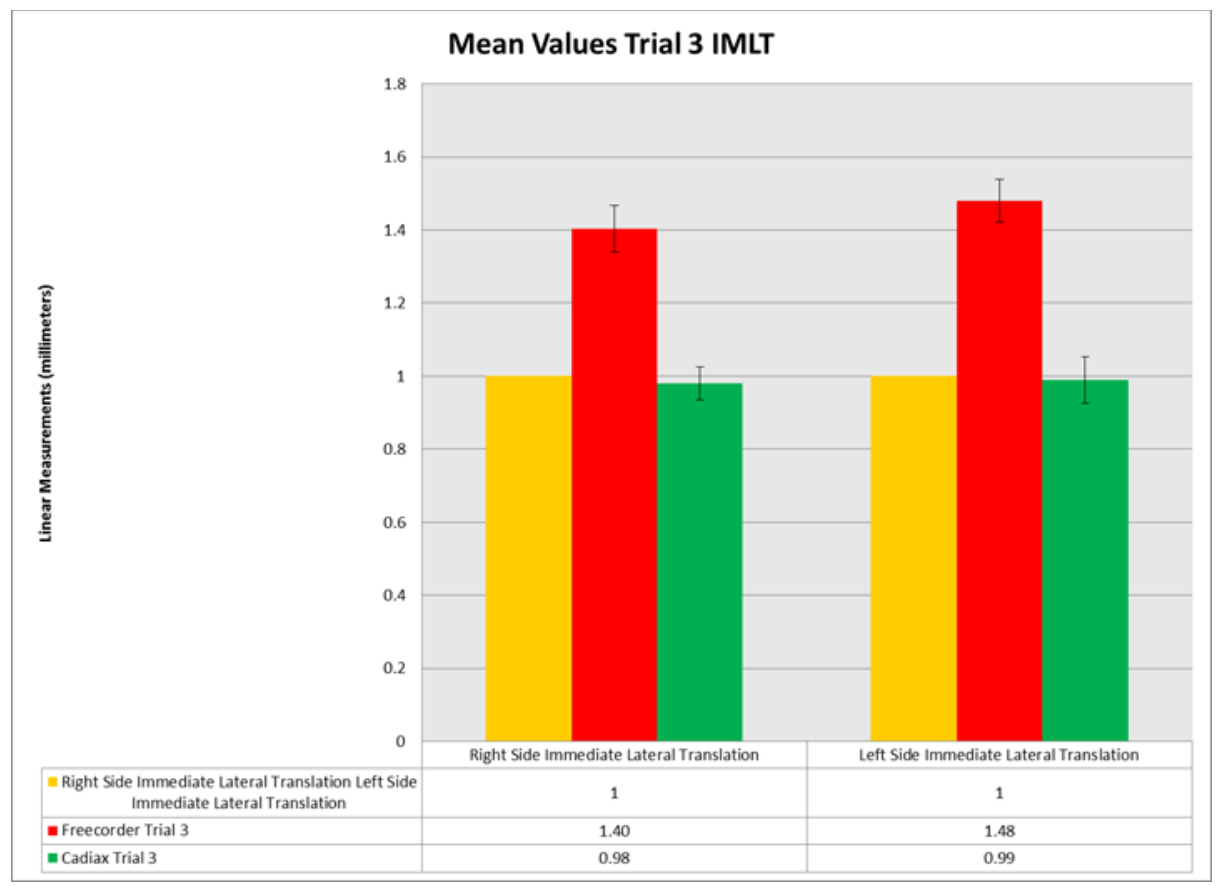

Figure 4-7. Trial 3 Immediate Mandibular Lateral Translation.

Enlarged view of mean values for Immediate Mandibular Lateral Translation (IMLT). Black bars indicate 95\% confidence interval. Confidence intervals that overlap indicate statistically similar values. IMLT is measured in millimeters. 
Table 4-1. Results Trial 1.

\begin{tabular}{cccccc}
\hline $\begin{array}{c}\text { Mock } \\
\text { Patient } \\
\text { Settings }\end{array}$ & Side & $\begin{array}{c}\text { Original Articulator } \\
\text { Values }\end{array}$ & $\begin{array}{c}\text { Freecorder } \\
\text { Mean (95\% CI) }\end{array}$ & $\begin{array}{c}\text { Cadiax } \\
\text { Mean (95\% CI) }\end{array}$ & p value (0.05)* \\
\hline $\begin{array}{c}\text { Lateral } \\
\text { Condylar } \\
\text { Inclination }\end{array}$ & Right & 25 & $25.20( \pm 0.58)$ & $24.63( \pm 0.30)$ & 0.08814 \\
$\begin{array}{c}\text { Medial Wall } \\
\text { Angulation** }\end{array}$ & Right & Left & 15 & $25.37( \pm 0.50)$ & $26.40( \pm 0.21)$ \\
\hline
\end{tabular}

* Two sided t-test comparing Freecorder ${ }^{\circledR}$ Bluefox and Cadiax Compact $2^{\circledR}$. ** Medial Wall Angulation is a measure of progressive mandibular lateral translation. CI, confidence interval. 
Table 4-2. Results Trial 2.

\begin{tabular}{|c|c|c|c|c|c|}
\hline $\begin{array}{c}\text { Mock } \\
\text { Patient } \\
\text { Settings }\end{array}$ & Side & $\begin{array}{c}\text { Original Articulator } \\
\text { Values }\end{array}$ & Freecorder ${ }^{\circledR}$ Mean (CI) & Cadiax Mean (CI) & $\begin{array}{l}\text { p value } \\
(0.05) * * *\end{array}$ \\
\hline $\begin{array}{l}\text { Lateral } \\
\text { Condylar }\end{array}$ & Right & 25 & $24.17( \pm 0.32)$ & $25.00( \pm 0.29)$ & 0.00027 \\
\hline Inclination* & Left & 25 & $24.33( \pm 0.29)$ & $26.17(0.22)$ & 0.00000 \\
\hline \multirow{2}{*}{$\begin{array}{l}\text { Medial Wall } \\
\text { Angulation* }\end{array}$} & Right & 15 & $20.37( \pm 0.23)$ & $14.77( \pm 0.33)$ & 0.00000 \\
\hline & Left & 15 & $18.17( \pm 0.51)$ & $17.10( \pm 0.11)$ & 0.00027 \\
\hline $\begin{array}{l}\text { Immediate } \\
\text { Mandibular }\end{array}$ & Right & 1.0 & $1.36( \pm 0.07)$ & $0.81( \pm 0.07)$ & 0.00000 \\
\hline $\begin{array}{c}\text { Lateral } \\
\text { Translation** }\end{array}$ & Left & 1.0 & $1.12( \pm 0.04)$ & $0.95( \pm 0.04)$ & 0.00003 \\
\hline
\end{tabular}

$*$ Measurements in degrees. ** Measurements in millimeters. *** Two sided t-test comparing mean values of Freecorder ${ }^{\circledR}$ Bluefox and Cadiax Compact $2^{\circledR}$. CI, confidence interval. 
Table 4-3. Results Trial 3.

\begin{tabular}{|c|c|c|c|c|c|}
\hline $\begin{array}{c}\text { Mock } \\
\text { Patient } \\
\text { Settings }\end{array}$ & Side & $\begin{array}{c}\text { Original Articulator } \\
\text { Values }\end{array}$ & Freecorder ${ }^{\circledR}$ Mean (CI) & Cadiax Mean (CI) & $\begin{array}{c}\text { p value } \\
(0.05)^{* * * *}\end{array}$ \\
\hline $\begin{array}{l}\text { Lateral } \\
\text { Condylar }\end{array}$ & Right & 25 & $24.33( \pm 0.49)$ & $24.73( \pm 0.35)$ & 0.18324 \\
\hline Inclination* & Left & 25 & $24.17( \pm 0.36)$ & $25.27( \pm 0.27)$ & 0.00001 \\
\hline \multirow{2}{*}{$\begin{array}{l}\text { Medial Wall } \\
\text { Angulation* }\end{array}$} & Right & 15 & $21.27( \pm 0.33)$ & $13.83( \pm 0.17)$ & 0.00000 \\
\hline & Left & 15 & $17.33( \pm 0.63)$ & $16.07( \pm 0.19)$ & 0.00050 \\
\hline $\begin{array}{l}\text { Immediate } \\
\text { Mandibular }\end{array}$ & Right & 1.0 & $1.40( \pm 0.06)$ & $0.98( \pm 0.04)$ & 0.00000 \\
\hline $\begin{array}{c}\text { Lateral } \\
\text { Translation** }\end{array}$ & Left & 1.0 & $1.48( \pm 0.06)$ & $0.99( \pm 0.06)$ & 0.00000 \\
\hline \multirow{2}{*}{$\begin{array}{l}\text { Superior } \\
\text { Wall*** }\end{array}$} & Right & 20 & & $23.63( \pm 0.79)$ & \\
\hline & Left & 20 & & $21.97( \pm 0.55)$ & \\
\hline \multirow{2}{*}{$\begin{array}{c}\text { Rear } \\
\text { Wall*** }\end{array}$} & Right & 15 & & $19.10( \pm 0.72)$ & \\
\hline & Left & 15 & & $11.13( \pm 1.76)$ & \\
\hline
\end{tabular}

* Measurements in degrees. ${ }^{* *}$ Measurements in millimeters. *** Values not generated by Freecorder ${ }^{\circledR}$ Bluefox. **** Two sided $\mathrm{t}-$ test comparing mean values of Freecorder Bluefox and Cadiax Compact $2^{\circledR}$. CI, confidence interval. 
and left $(0.99 \pm 0.05)$ side IMLT (Figure $4-7)$ in Trial 3 were statistically similar $(95 \%$ confidence interval) to mock patient.

The majority of condylar guide assembly mean values for Trials 1,2 and 3 predicted by the Cadiax Compact $2^{\circledR}$ for the mock patient were statistically inaccurate (95\% confidence interval) as shown in Tables 4-1, 4-2 and 4-3.

Data evaluation related to Specific Aim Four was accomplished by two sided t-test to compare the accuracy between the Freecorder ${ }^{\circledR}$ Bluefox and Cadiax Compact $2^{\circledR}$ ability to determine known values for LCI angle, medial wall angle and amount of IMLT of the mock patient. Mean values for right side LCI for Trial 1 (Table 4-1) and Trial 3 (Table 4-3) generated by Freecorder ${ }^{\mathbb{B}}$ Bluefox (Trial 1: 25.20 \pm 0.58 ; Trial 3: 24.33 \pm 0.49 ) and Cadiax Compact $2^{\mathbb{B}}$ (Trial 1: $24.63 \pm 0.30$; Trial 3: $24.73 \pm 0.35$ ) were statistically similar (p-value $<0.05$ ).

The majority of condylar guide assembly mean values predicted by the Freecorder ${ }^{\circledR}$ Bluefox and Cadiax Compact $2^{\circledR}$ were both different and inaccurate $(95 \%$ confidence interval) as shown in Tables 4-1, 4-2 and 4-3. 


\section{CHAPTER 5. DISCUSSION}

Clinical goals of restorative dentistry include achieving an accurate occlusal relationship, simulating mandibular movement of patients in the laboratory and organizing occlusions. The pantograph has been used since the 1930's as a research tool to study mandibular movement and is suggested to be a practical tool to record mandibular movement and transfer maxillomandibular relations to the articulator. The pantograph is used to program highly adjustable articulators to simulate complex threedimensional patient movements (Stuart 1959, Clayton 1971, Clayton et al 1971 and Winstanley 1977).

Although the Freecorder ${ }^{\circledR}$ Bluefox claims the ability to locate a THA, this investigation did not support that claim. The use of arbitrary axis points has been reported in the literature. The arbitrary points are acceptable if they are within 5-6 mm of the kinematic axis (Schallhorn 1957, Beck 1959 and Teteruck and Lundeen 1966). Table 5-1 lists the arbitrary axis points and their location relative to the kinematic axis. If the Freecorder ${ }^{\circledR}$ Bluefox can transfer the mandibular relationship to the condyles and be within 5-6 mm of the kinematic axis, then it may have application in dentistry. No quantitative assessment of error for the Freecorder ${ }^{\circledR}$ Bluefox ability to locate a known THA was done in the current study. However, visually, the error did not appear to be more than the acceptable limits of the arbitrary face bows. The Freecorder ${ }^{\mathbb{B}}$ Bluefox may have application based on arbitrary location of the horizontal axis. This finding precludes the use of the Freecorder ${ }^{\circledR}$ Bluefox as a means of locating a transverse horizontal axis in complex restorative dentistry.

With regard to occlusal anatomy, teeth with taller cusps and deeper fossae allow for masticatory efficiency, have better esthetics, stabilize teeth and stabilize dental arches (Stuart and Stallard 1960, Stallard and Stuart 1963, Stuart 1964, Stuart 1979 and McHorris 2010). A potential disadvantage of taller cusps is increased risk of interferences during mandibular movement. Table 5-2 lists the advantages and disadvantages of cusp height.

Stuart and Stallard (1969), Stuart (1976) and Huffman and Regenos (1989) describe how misdiagnosis can cause errors at the occlusal level. Articulator medial wall settings will dictate whether the cusp tips may be longer or MUST be shorter and whether the placement of the cusp paths (the morphologie) will be more mesially or more distally directed. The angle of the emenetia influences the cusp height and shape of the lingual concavity of maxillary anterior teeth. The closer a tooth is to a control (the condyle) the more the tooth is influenced by the control (McHorris 1989). If the misdiagnosis is "may have longer cusps," then potential interferences related to long cusps are incorporated. If the misdiagnosis is "cusps MUST be shorter," then potential interferences are avoided; however, masticatory efficiency, tooth stability, arch stability and esthetics may be compromised. 
Table 5-1. Accuracy of arbitrary horizontal axis points.

\begin{tabular}{|c|c|c|c|c|}
\hline Investigator & Year & $\begin{array}{l}\text { Arbitrary } \\
\text { Point }\end{array}$ & Location & $\begin{array}{c}\text { (\%) Arbitrary } \\
\text { Points within } \\
\text { (x) of } \\
\text { Kinematic } \\
\text { Axis } \\
\end{array}$ \\
\hline Schallhorn & 1957 & Beyron's & $\begin{array}{l}13 \mathrm{~mm} \text { from posterior } \\
\text { tragus to canthus }\end{array}$ & $98 \%(5 \mathrm{~mm})$ \\
\hline Beyron & 1942 & Beyron's & $\begin{array}{l}13 \mathrm{~mm} \text { from posterior } \\
\text { tragus to canthus }\end{array}$ & $87 \%(5 \mathrm{~mm})$ \\
\hline \multirow[t]{3}{*}{ Beck } & 1959 & Beyron's & $\begin{array}{l}13 \mathrm{~mm} \text { from posterior } \\
\text { tragus to canthus }\end{array}$ & $33 \%(5 \mathrm{~mm})$ \\
\hline & & Bergström's & $\begin{array}{c}7 \mathrm{~mm} \text { below Frankfort } \\
\text { and } 10 \mathrm{~mm} \text { anterior to } \\
\text { mid external auditory } \\
\text { meatus }\end{array}$ & $67 \%(5 \mathrm{~mm})$ \\
\hline & & Prothero's & $\begin{array}{c}13 \mathrm{~mm} \text { anterior to } \\
\text { meatus }\end{array}$ & $16 \%(5 \mathrm{~mm})$ \\
\hline $\begin{array}{l}\text { Lauritzen \& } \\
\text { Bodnar }\end{array}$ & 1961 & Prothero's & $\begin{array}{c}13 \mathrm{~mm} \text { anterior to } \\
\text { meatus }\end{array}$ & $33 \%(5 \mathrm{~mm})$ \\
\hline \multirow[t]{3}{*}{$\begin{array}{l}\text { Teteruck \& } \\
\text { Lundeen }\end{array}$} & 1966 & Beyron's & $\begin{array}{l}13 \mathrm{~mm} \text { from foot of } \\
\text { tragus to canthus }\end{array}$ & $33 \%(6 \mathrm{~mm})$ \\
\hline & & $\begin{array}{l}\text { Whip Mix } \\
\text { Earbow } \\
\text { (Prothero's) }\end{array}$ & Whip Mix Ear Bow & $56 \%(6 \mathrm{~mm})$ \\
\hline & & $\begin{array}{l}\text { Prothero's } \\
\text { (modified) }\end{array}$ & Whip Mix Ear Bow & $75.5 \%(6 \mathrm{~mm})$ \\
\hline $\begin{array}{l}\text { Thorp, Smith, } \\
\text { Nicholls }\end{array}$ & 1978 & $\begin{array}{l}\text { Prothero's } \\
\text { Hanau's }\end{array}$ & $\begin{array}{c}\text { Whip Mix Ear-Bow } \\
\text { Hanau Ear-Bow }\end{array}$ & $55 \%(6 \mathrm{~mm})$ \\
\hline Simpson et al. & 1984 & Simpson's & $\begin{array}{c}10 \mathrm{~mm} \text { anterior to } \\
\text { posterior tragus on } \\
\text { Campers }\end{array}$ & $78 \%(5 \mathrm{~mm})$ \\
\hline $\begin{array}{l}\text { Palik, Nelson, } \\
\text { White }\end{array}$ & 1985 & Hanau's & Hanau Ear-Bow & $\begin{array}{l}50 \%(5 \mathrm{~mm}) \\
89 \%(6 \mathrm{~mm})\end{array}$ \\
\hline Nagy & 2002 & $\begin{array}{l}\text { SAM (earpiece } \\
\text { alignment } \\
\text { flags) }\end{array}$ & $\begin{array}{l}10 \mathrm{~mm} \text { anterior to } \\
\text { earpiece on Axis } \\
\text { Orbitale Plane }\end{array}$ & $96.2 \%(2 \mathrm{~mm})$ \\
\hline
\end{tabular}


Table 5-2. Cusp height considerations.

\begin{tabular}{ccc}
\hline Aspects & Tall Cusps & Flat Cusps \\
\hline \multirow{2}{*}{ Advantages } & Masticatory efficiency & \\
& Esthetics \\
Tooth stability & Arch stability & $\begin{array}{c}\text { Decreased risk of occlusal } \\
\text { interferences }\end{array}$ \\
& Increased risk of occlusal & \\
interferences & Poor efficiency \\
& Poor esthetics \\
& & $\begin{array}{c}\text { Poor tooth stability } \\
\text { Poor arch stability }\end{array}$ \\
\hline
\end{tabular}


Articulator settings affect the occlusal morphology of indirect occlusal coverage dental restorations. Aull (1965) demonstrated that large changes in the condylar guide assembly resulted in dramatic changes in cusp height and cusp paths. Lundeen et al (1978) concluded that patients with excessive immediate side shift and little or no anterior guidance are challenging. They found the average immediate side shift to be $0.75 \mathrm{~mm}$ and $80 \%$ of patients have immediate side shift of $1.5 \mathrm{~mm}$ or less. Price et al (1991) in an articulator based study demonstrated the relative effect errors in articulator settings have on occlusion. They found in the absence of anterior guidance, five degree changes in progressive side shift and (lateral) condylar inclination and $0.2 \mathrm{~mm}$ changes in immediate side shift resulted in potentially detectable interferences by the patient at the first molar. They noted that large errors in rear wall and superior wall settings had less effect on the occlusal tracings.

Figure 5-1 depicts teeth with tall cusps and deep fossae. Mandibular buccal cusp paths based on mock patient settings is illustrated in Figure 5-2. Though overly simplified for the sake of demonstration this is a frontal view of a patient's right side. Imagine that the maxillary first molar is to be restored with a gold crown. The design of cusps based on mock patient settings, predicted by Freecorder ${ }^{\circledR}$ Bluefox mean values and predicted by Cadiax Compact $2^{\circledR}$ mean values will be compared (Figures 5-3, 5-4 and 5-5). All comparisons in the following figures are for demonstration purposes only. No part of this investigation attempted to evaluate or determine the effect of predicted values of either device at the first molar. The illustrations are relative comparisons to aid in clinical relevant conclusions. Admittedly,this is a more simplified view of what is occurring at one cusp tip on one side of the mouth in one plane.

Figure 5-6 will be used to demonstrate the paths of the mesial-buccal cusp of the mandibular first molar in a horizontal plane. The gold arrows in Figure 5-6 are the cusp paths of the mock patient in working and nonworking movements. Note that the cusp travels through the buccal and lingual grooves between the ridges and the cusp tips. Figures 5-7, 5-8 and 5-9 demonstrate the relative cusp paths of the mock patient, as dictated by Freecorder ${ }^{\circledR}$ Bluefox and Cadiax Compact $2 \AA$ registrations. The cusp paths for the mandibular mesial-buccal cusp based on the Cadiax Compact $2^{\circledR}$ mean values on the maxilla will be more distal in working and nonworking movements (Figure 5-7).

Based on this investigation and previous studies (Aull 1965, Lundeen et al 1978 and Price et al 1991), a clinically acceptable range for lateral condylar inclination and progressive mandibular lateral translation may be $\pm 5^{\circ}$. Tolerance levels for immediate mandibular lateral translation are undoubtedly far less. 


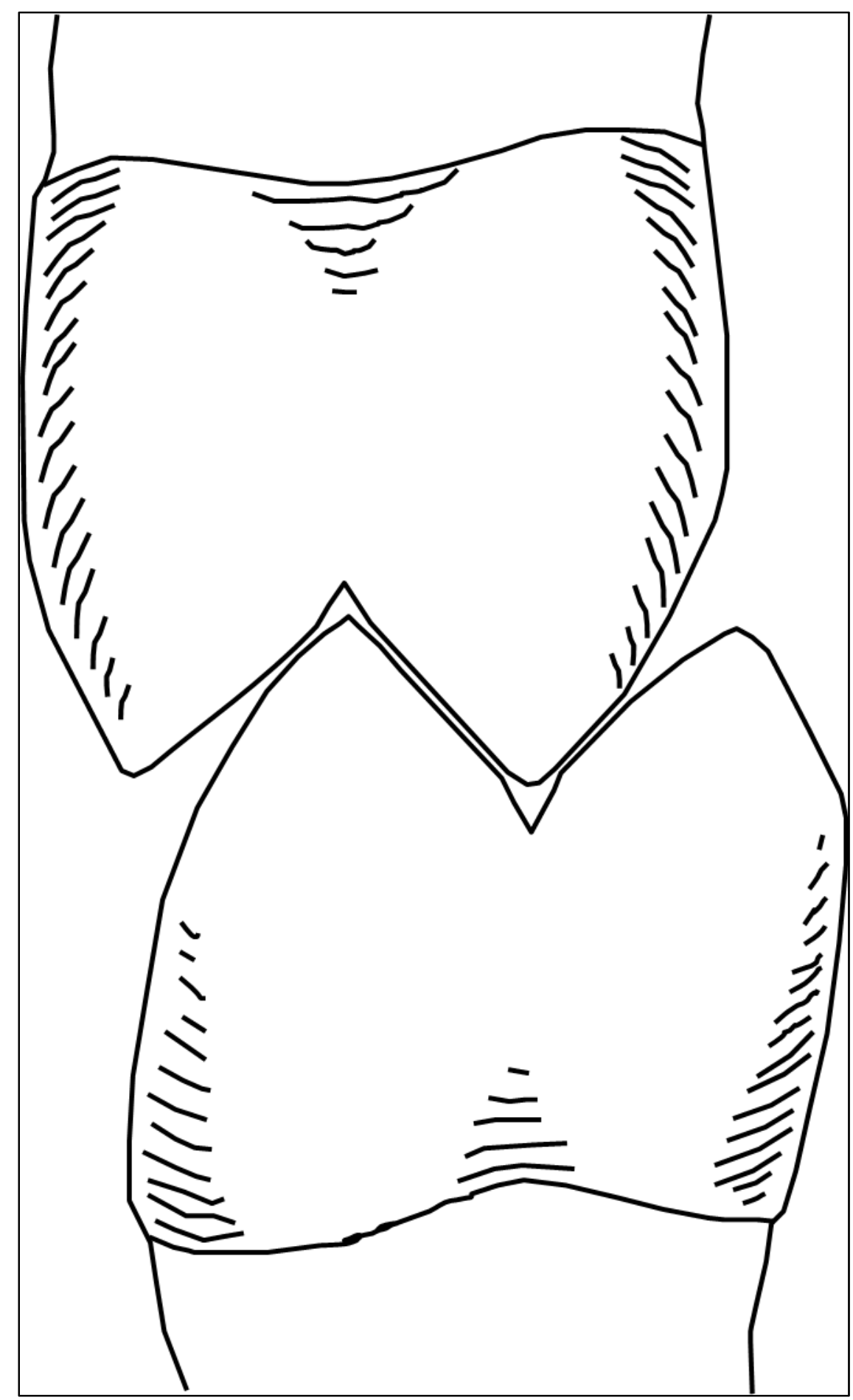

Figure 5-1. Teeth with tall cusps and deep fossae. 


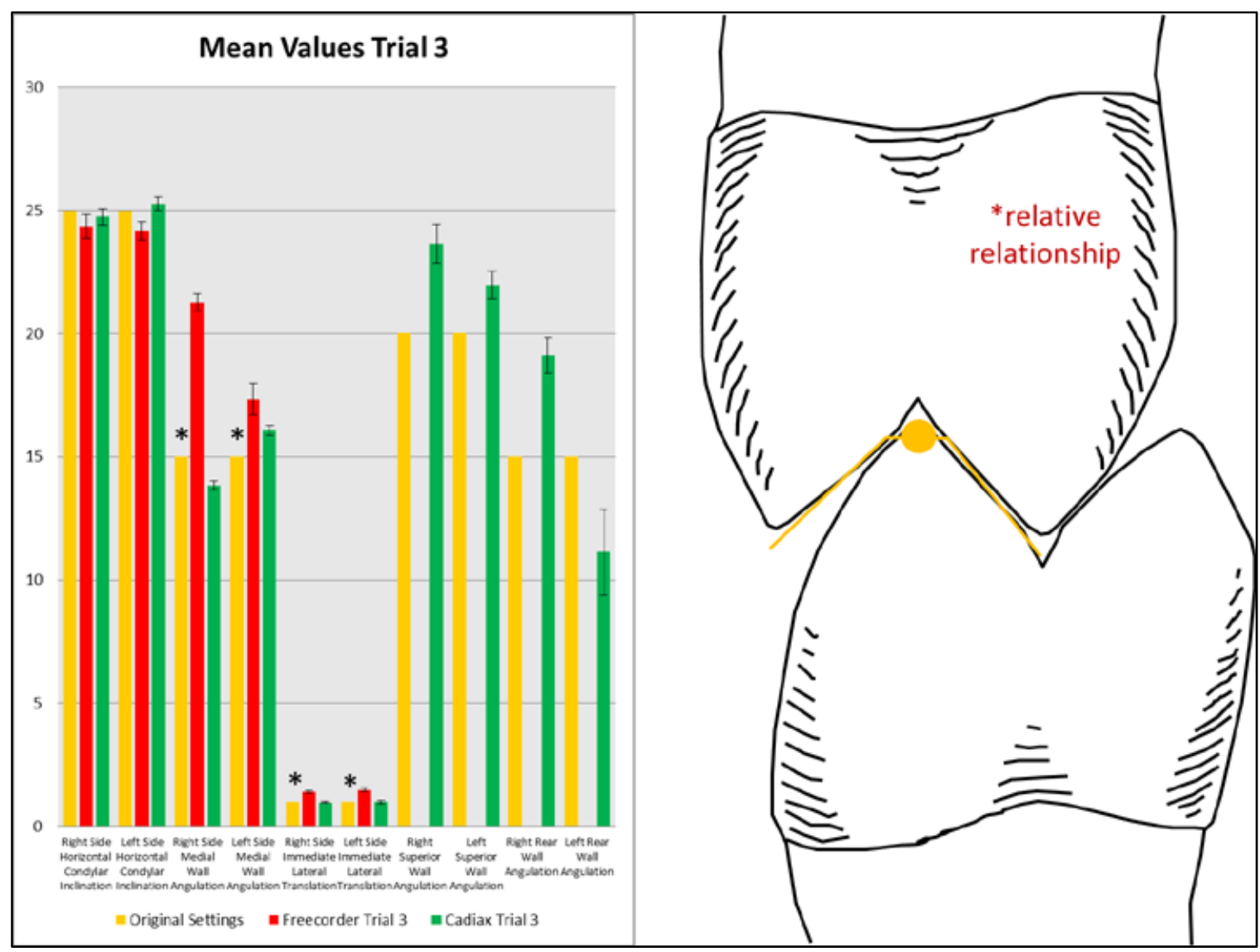

Figure 5-2. Mock patient settings.

The mock patient with one millimeter of immediate side shift. The gold lines on the triangular ridges are the gold standard of the mock patient settings. The gold lines represent the path of the mandibular buccal cusp. The asterisks above the bars are the values used to determine the cusp path. 


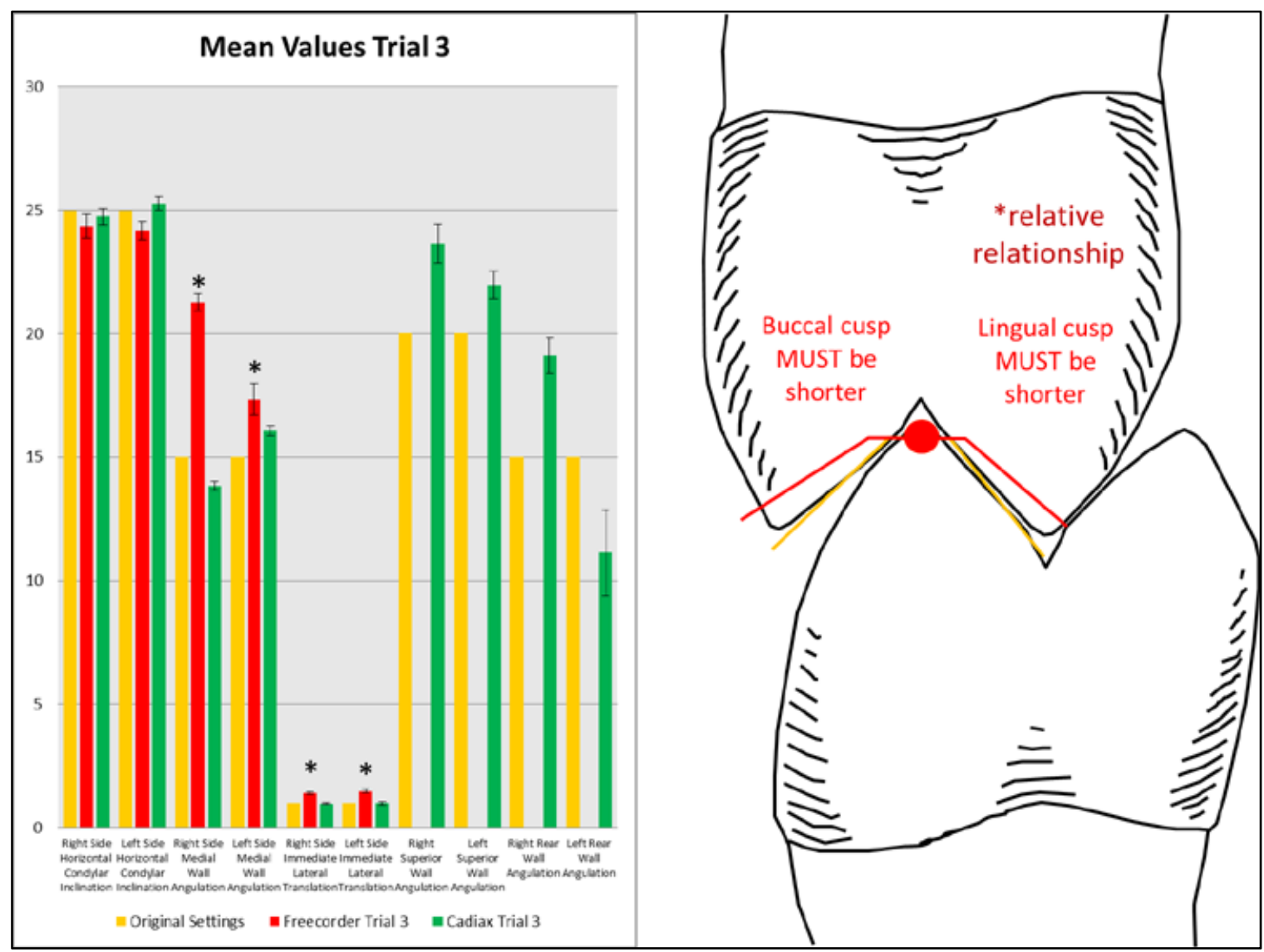

Figure 5-3. Mock patient relative to Freecorder ${ }^{\circledR}$ Bluefox.

The red line represents the relative movement of the mandibular mesial-buccal cusp with excessive immediate side shift and shorter cusps relative to the mock patient values. The red lines represent the movement of the mandibular buccal cusp when designing the maxillary restoration based off values generated by the Freecorder ${ }^{\circledR}$ Bluefox. Note the Freecorder ${ }^{\circledR}$ Bluefox mean values for Lateral Condylar Inclination and Immediate Mandibular Lateral Translation are greater than the mock patient; therefore, the cusps MUST be shorter. The asterisks above the bars are the values used to determine the cusp path. 


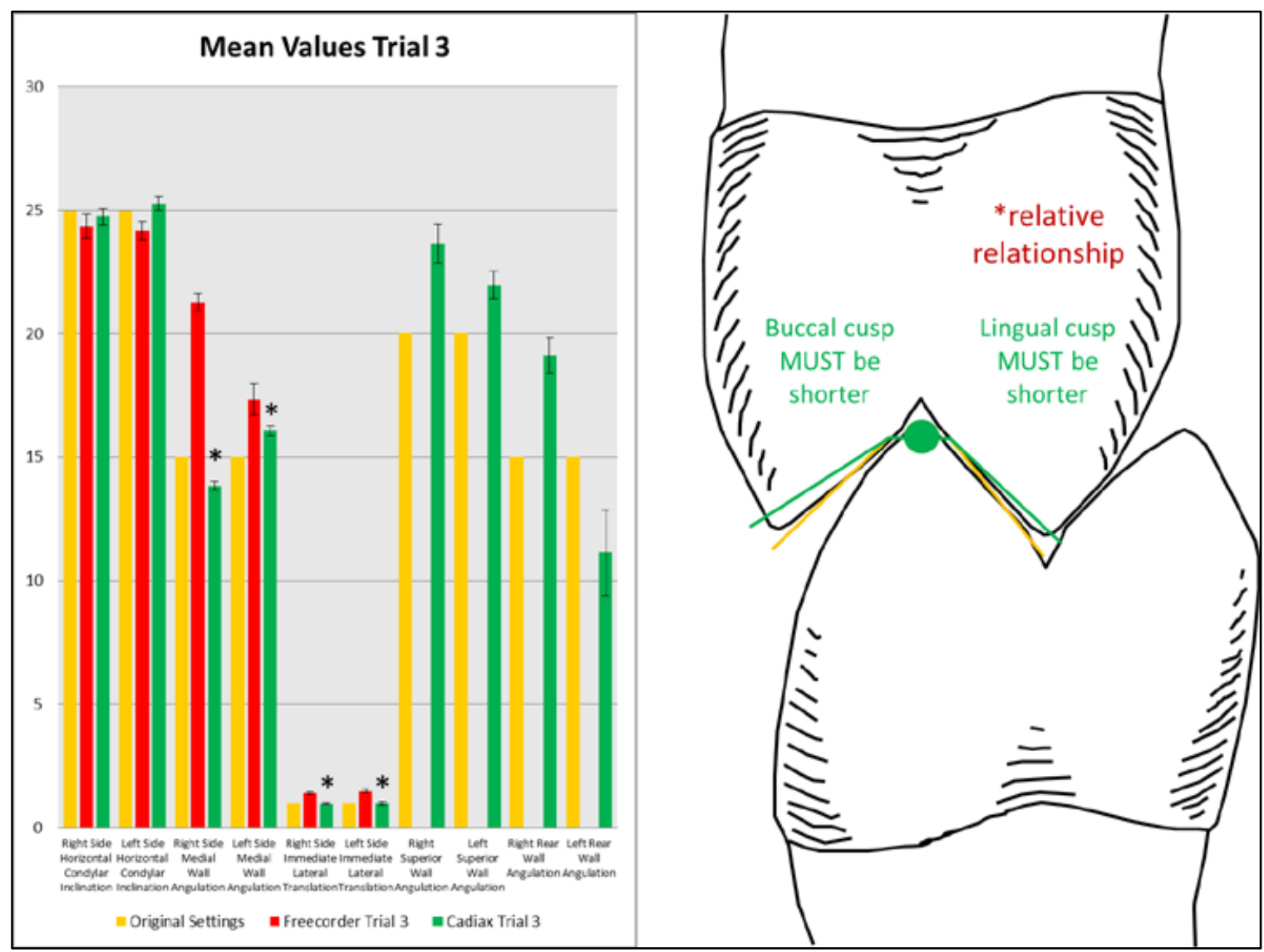

Figure 5-4. Mock patient relative to Cadiax Compact $2^{\circledR}$.

The green line represents the relative movement of the mandibular buccal cusp with similar immediate side shift and shorter cusps relative to mock patient. The green lines represent the movement of the mandibular buccal cusp when designing the maxillary restoration based off values generated by the Cadiax Compact $2^{\circledR}$. In working and nonworking movements, the cusp MUST be shorter. The asterisks above the bars are the values used to determine the cusp path. 


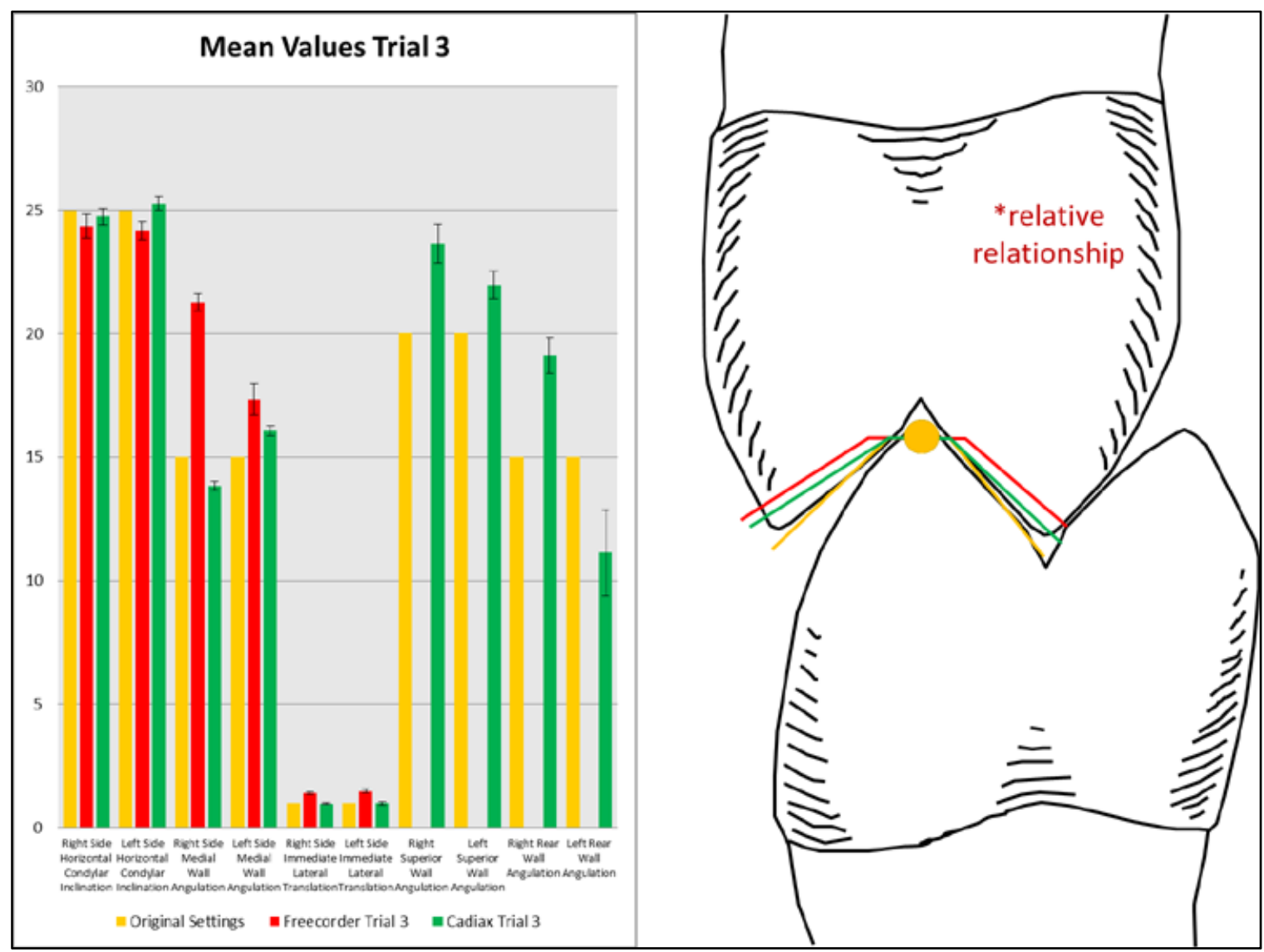

Figure 5-5. Relative relationship of the mock patient, Freecorder ${ }^{\circledR}$ Bluefox and Cadiax Compact $2^{\circledR}$.

The relative cups paths for the mandibular buccal cusp of the mock patient, Freecorder ${ }^{\circledR}$ Bluefox and Cadiax Compact $2^{\circledR}$. 


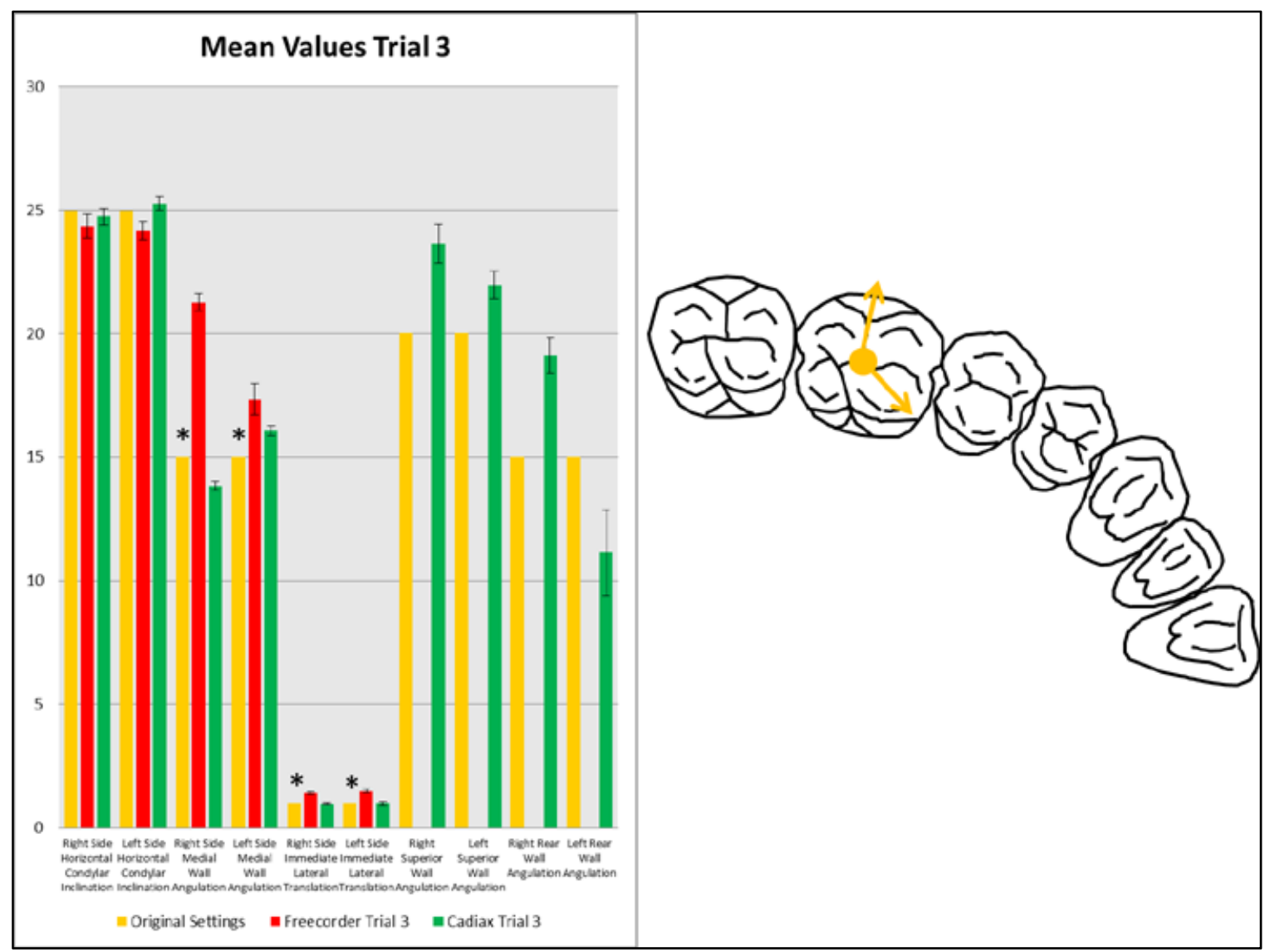

Figure 5-6. Cusp pathway mock patient.

The gold arrows are the cusp paths of the mock patient in a working and nonworking movement. The asterisks above the bars are the values used to determine the cusp path. Note that the cusp travels through the buccal and lingual grooves between the ridges and the cusp tips. 


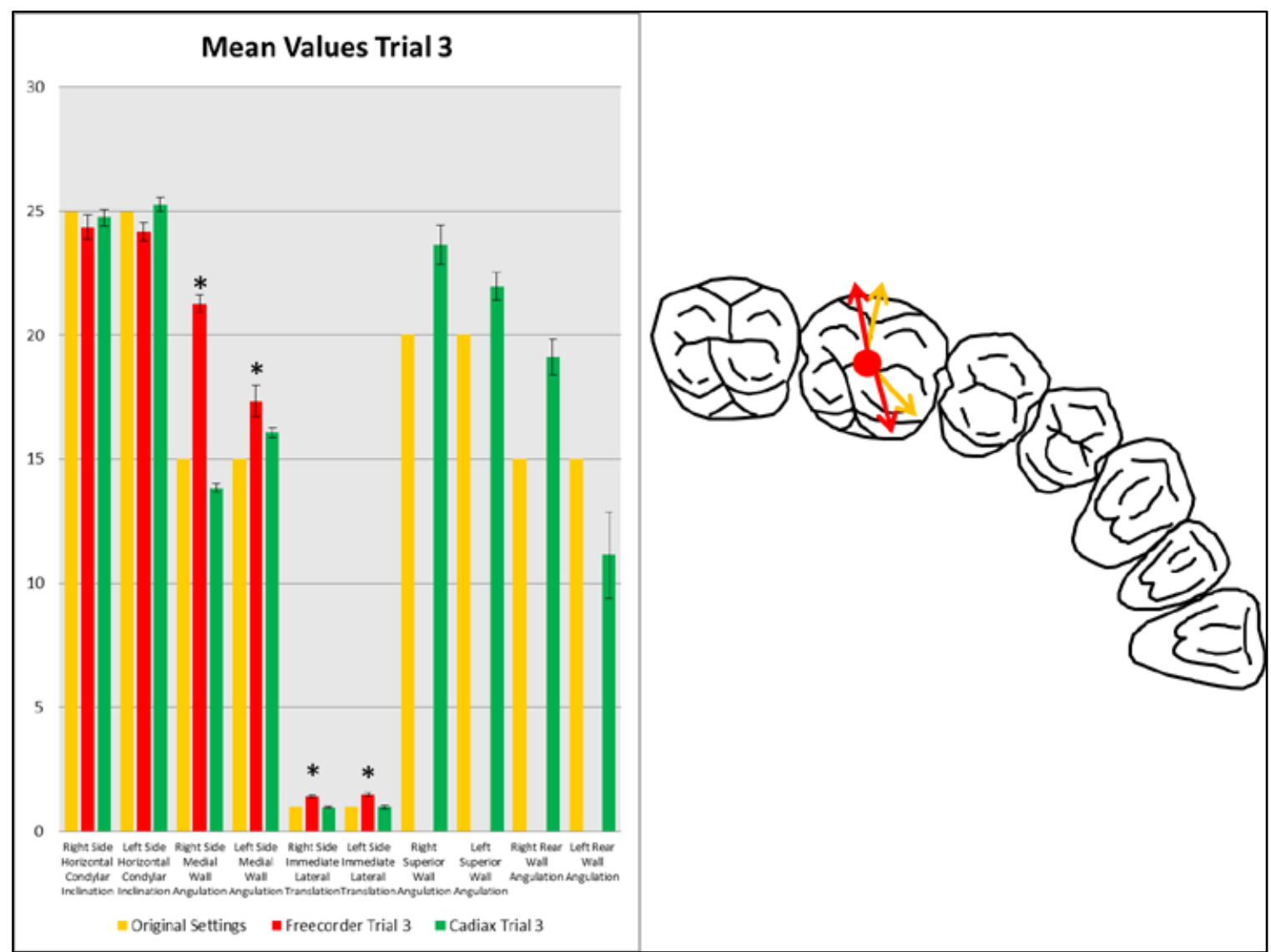

Figure 5-7. Cusp paths based on Freecorder ${ }^{\circledR}$ Bluefox mean values.

The cusp paths for the mandibular mesial-buccal cusp based on the Freecorder ${ }^{\circledR}$ Bluefox mean values will be more distal on the maxilla. The asterisks above the bars are the values used to determine the cusp path. 


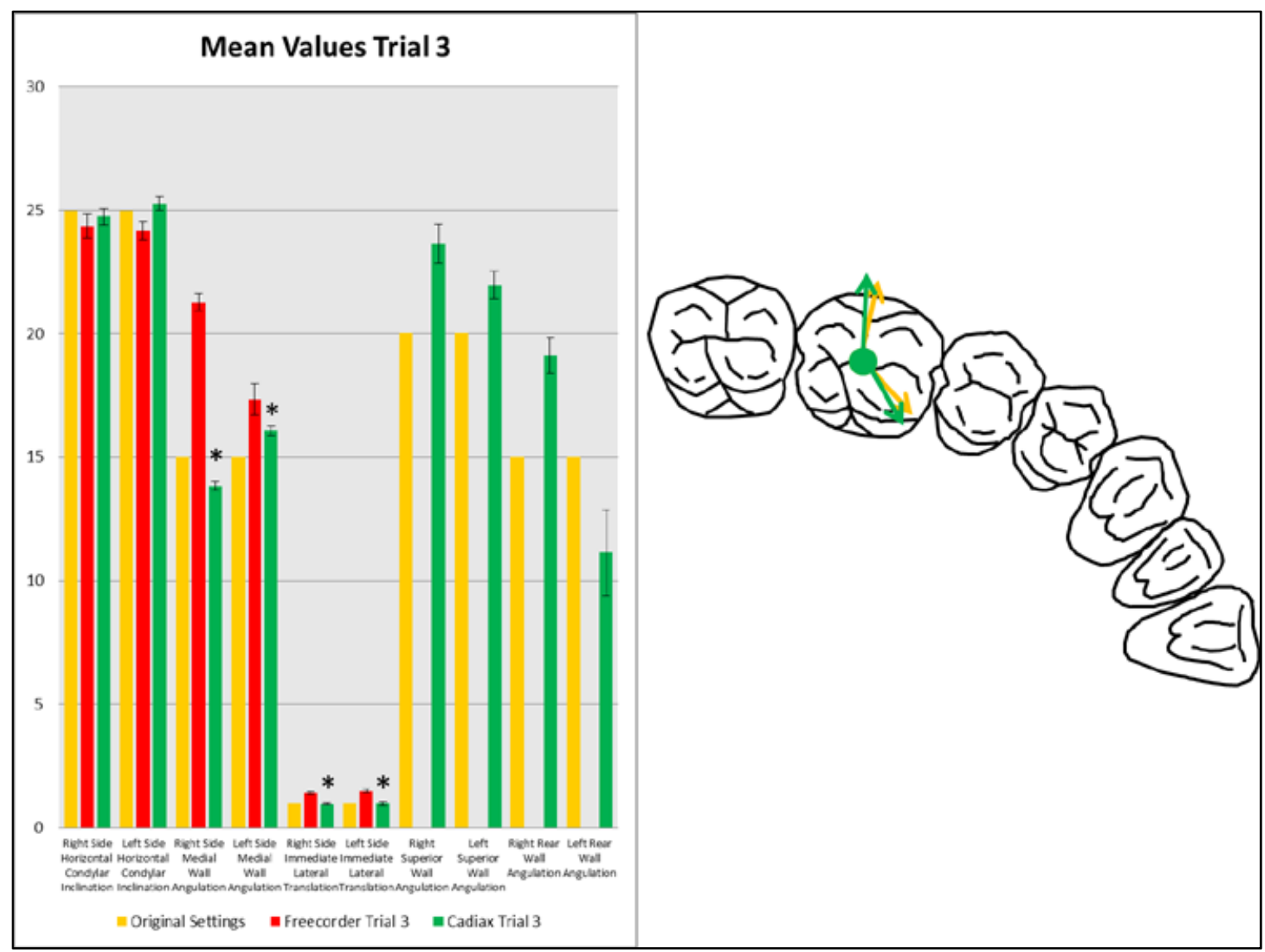

Figure 5-8. Cusp paths based on Cadiax Compact $2^{\circledR}$ mean values.

The cusp paths for the mandibular mesial-buccal cusp based on the Cadiax Compact $2^{\circledR}$ mean values on the maxilla will be more distal in working and nonworking movements. The asterisks above the bars are the values used to determine the cusp path. 


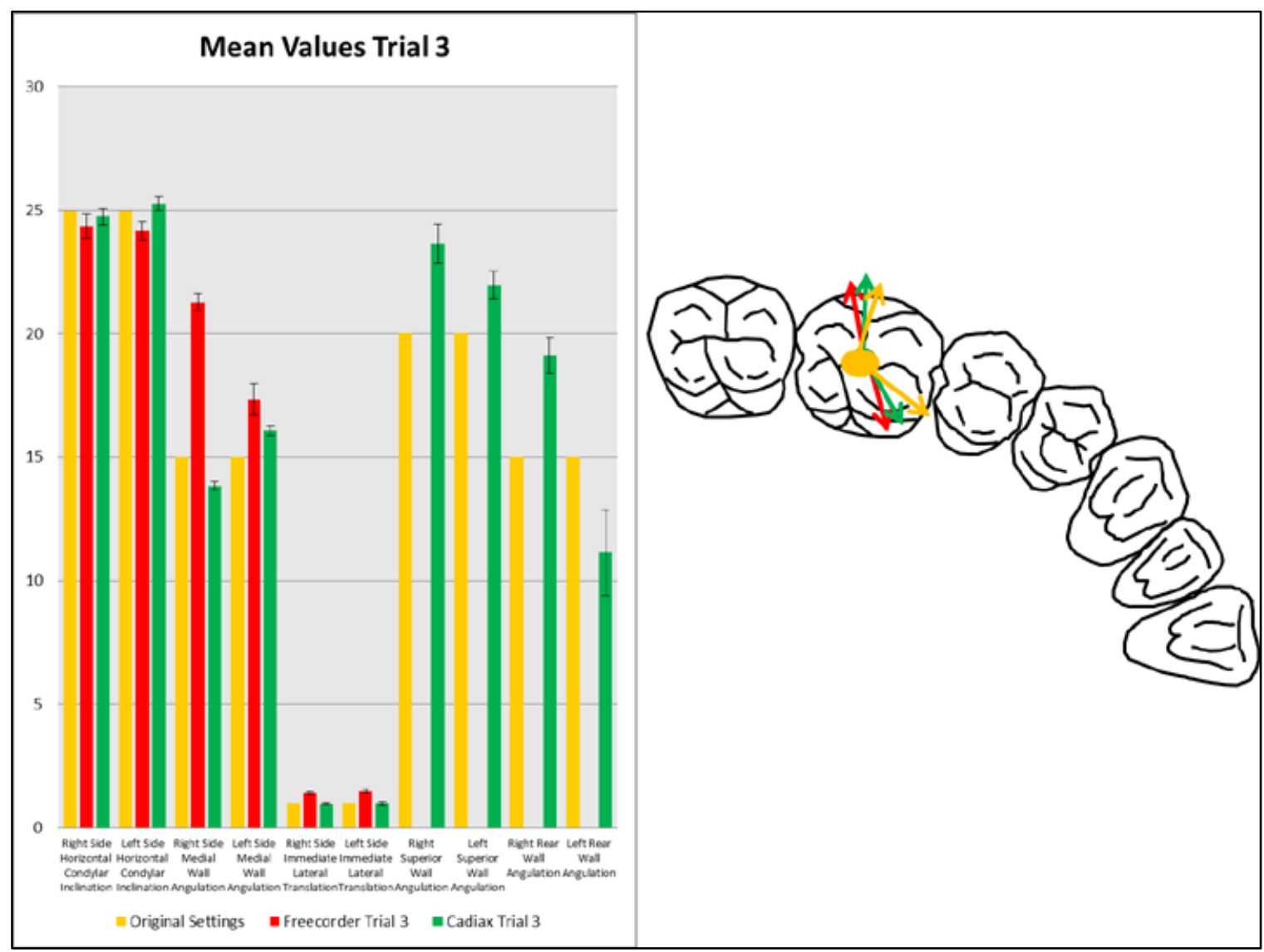

Figure 5-9. Cusp paths of mock patient, Freecorder ${ }^{\circledR}$ Bluefox and Cadiax Compact $2^{\circledR}$.

The relative cups paths for the mandibular mesial-buccal cusp of the Mock Patient, Freecorder ${ }^{\circledR}$ Bluefox and Cadiax Compact $2^{\circledR}$. 


\section{CHAPTER 6. CONCLUSION}

The results of this study suggest that:

- The optoelectronic device was unable to locate a known transverse horizontal axis.

- The majority of condylar guide assembly mean values predicted by the optoelectronic pantograph were statistically inaccurate.

- The majority of the condylar guide assembly mean values predicted by the mechano-electronic pantograph were statistically inaccurate.

- The majority of condylar guide assembly values predicted by the optoelectronic pantograph and mechano-electronic pantograph were statistically different and inaccurate.

Clinically, the predicted mean values for the LCI and PMLT were within five degrees of the known mock patient settings. The values predicted by the optoelectronic pantograph over-compensated mandibular movement requiring shorter cusps for restorations. The mechano-electronic pantograph prescribed longer cusps for restorations that have the potential to induce interferences. Though statistically significant inaccuracies were identified during the present study, both mandibular recording devices may be considered clinically acceptable. However, the use of both mandibular recording devices investigated here will potentially result in occlusal restorations that require adjustment when placed in the oral cavity. 


\section{CHAPTER 7. LIMITATIONS AND FUTURE DIRECTIONS}

Use of a coordinate measuring system to compare accurately mounted patient cast (the mock patient) to casts mounted using optoelectronicly-derived data would permit quantitative assessment of the capacity of the optoelectronic device to locate a horizontal axis.

Although means were employed to stabilize the mandibular member to the maxillary member of the articulator, manual manipulation of the mandibular member may have unintentionally influenced the recordings for each device. The amount of force produced by the elastics permitted ease of manipulation through eccentric movements. Guidance of the mock patient at the condyles (posteriorly) allows for incorporation of IMLT and PMLT during mandibular movement. Movement of the mandibular member by the anterior incisal guide table may not fully incorporate IMLT settings. Care was taken to avoid contacting the side arms of the maxillary face bows during manipulation of the mandibular member. However, a cam-activated mechanism to move the mandibular member of the articulator in protrusive and lateral movements could improve the existing protocol. Admittedly such a mechanism would be both complicated and costly to develop.

The ability to precisely adjust the Denar ${ }^{\circledR}$ D5A scales to specific values and the accuracy of the scales as depicted on the instrument may have influenced mean values generated by both devices. Electronic calibration of the condylar guide assemblies may have ruled out these potential articulator-induced errors.

Although a large number of recording sessions were carried out and measurements acquired for this investigation, the lack of an English instruction manual for the optoelectronic device may have precluded optimal use of the instrument.

Further investigation comparing kinematic and optoelectronic axis location, as well as manual, optoelectronic and mechano-electronic pantography are warranted. Effects of these technologies on occlusal errors would help to quantify and qualify the accuracy and precision of devices and determine a range of clinically tolerable error. 


\section{LIST OF REFERENCES}

Academy of Prosthodontics. (2005). The Glossary of Prosthodontic Terms, $8^{\text {th }}$ Ed. J Prosthet Dent, 94:10-92.

Anderson G., Schulte J., Arnold T. (1987). An in vitro study of an electronic pantograph. J Prosthet Dent, 57:577-80.

Aprile H, Saizar P. (1947). Gothic arch tracing and temporomandibular anatomy. J Am Dent Assoc, 35:256-61.

Atkinson H. F., Shephard R. W. (1955). A preliminary report of investigations into mandibular movement. Aust J Dent, 59:267-70.

Aull A. (1963). A study of the transverse axis. J Prosthet Dent, 13:469-79.

Aull A. (1965). Condylar determinants of occlusal patterns. J Prosthet Dent, 15:826-46.

Bauer A., Gutowski A. (1976). Gnathology, Introduction to Theory and Practice. Quintessence Publishing Co., Chicago, IL. pp. 19-22.

Beard C. C., Donaldson K., Clayton J.A. (1986). Comparison of an electronic and a mechanical pantograph. Part I: Consistency of an electronic computerized pantograph to record articulator settings. J Prosthet Dent, 55:570-4.

Beck H. O. (1959). A clinical evaluation of arcon concept of articulation. J Prosthet Dent, 9:409-21.

Becker C. M., Kaiser, D. A. (1993). Evolution of occlusion and occlusal instruments. J Prosthet Dent, 2:33-43.

Bennett N.G. (1958). A contribution to the study of movement of the mandible. J Prosthet Dent, 8:41-54.

Bernhardt O., Kuppers N., Rosin M., Meyer G. (2003). Comparative tests of arbitrary and kinematic transverse horizontal axis recording of mandibular movements. J Prosthet Dent, 89:175-9.

Berry H. M., Hofman F. A. (1956). Cineradiolographic observations of temporomandibular joint function. J Prosthet Dent, 9:21-33.

Boucher L. J. (1961). Limiting factors in posterior movements of mandibular condyles. J Prosthet Dent, 11:23-5. 
Boucher L. J., Jacoby J. (1961). Posterior border movements of the human mandible. J Prosthet Dent, 11:836-41.

Brandrup-Wognsen T. (1953). The face-bow. Its significance and application. J Prosthet Dent, 3:618-30.

Campion G. G. (1905). Some graphic records of movements of the mandible in the living subject. D Cosmos, 47:39-42.

Catic A. N., Naeije M. (1999). Location of the hinge axis and the kinematic centre in asymptomatic and clicking temporomandibular joints. J Oral Rehabil, 26:661-5.

Celar A. G.and Tamaki K. (2002). Accuracy of recording horizontal condylar inclination and Bennett angle with the Cadiax Compact. J Oral Rehabil, 29:1076-81.

Chance D. A., Williams E. O., Huff T. A., Andrews D. H. (1984). Determinations of chronology of mandibular border movements by optical pantography. J Prosthet Dent, 51:559-63.

Chang W. S. W., Romberg E., Driscoll C. F., Tabacco M. J. (2004). An in vitro evaluation of the reliability and validity of an electronic pantograph by testing with five different articulators. J Prosthet Dent, 92:83-9.

Clayton J. (1971). Border positions and restoring occlusion. Dent Clin North Am, $15: 525-42$.

Clayton J., Kotowicz W. E., Myers G. E. (1971a). Graphic recordings of mandibular movements: research criteria. J Prosthet Dent, 25:287-98.

Clayton J., Kotowicz W. E., Zahler J. (1971b). Pantographic tracings of mandibular movements and occlusion. J Prosthet Dent, 25:389-96.

Clayton J., Beard C. C., Donaldson K., Myers G. E. (1983). Clinical evaluation of electronic pantograph with mechanical pantograph. J Dent Res, 62:200 Abstract 275 (AADR).

Cohen R. (1956). The hinge axis and its practical application in the determination of centric relation. J Prosthet Dent, 10:248-57.

Coye R. B. (1977). A study of the variability of setting a fully adjustable Gnathologic articulator to a pantographic tracing. J Prosthet Dent, 37:460-5.

Curtis D., Sorensen J. (1986). Errors incurred in programming a fully adjustable articulator with a pantograph. J Prosthet Dent, 55:427-9. 
Denar Fully Adjustable Procedure Manual. (N. D. FN R0808). Whip Mix Corp., Fort Collins, CO.

DePietro A. J. (1963). Concepts of occlusion-A system based on rotational centers of the mandible. Dent Clin North Am, Nov:607-20.

Donaldson K., Clayton J. A. (1986). Comparison of mandibular movements recorded by two pantographs. J Prosthet Dent, 55:52-8.

GAMMA Dental Software ${ }^{\circledR}$ version 3 for Windows 2000/XP, Revision B. (2002). GAMMA Medizinisch-wissenschaftliche Fortbildungs-GmbH, Klosterneburg, Austria.

Gillings B. R. (1967). Photoelectric mandibulography. J Prosthet Dent, 17:109-21.

Gordon S. R., Stoffer W. M., Connor S. A. (1984). Location of the terminal hinge axis and its effect on second molar cusp position. J Prosthet Dent, 52:99-105.

Graver J. D. (2001). An in vitro comparison of pantographic techniques. Thesis. University of Texas Graduate School of Biomedical Sciences at San Antonio, San Antonio, TX.

Griffin C. J. (1963). The mandibular kinematograph. Aust Dent J, 8:230-36.

Guichet N. F. (1970). Occlusion: A Teaching Manual. Denar Corp., Anaheim, CA.

Gysi A. (1910). The problem of articulation. D Cosmos 52:1-19.

Hall R. E. (1930). An analysis of the development of the articulator. J Am Dent Assoc, 17:3-51.

Hight F. M. (1911). Taking of registrations for securing centric jaw relations. J Am Dent Assoc, 23:1447-50.

Hickey J. C., Allison M. L., Woelfel J. B., Boucher C. O., Stacy R. W. (1963). Mandibular movements in three dimensions. J Prosthet Dent, 13:72-92.

Hobo S., Mochizuki S. (1983). A kinematic investigation of mandibular border movement by means of an electronic measuring system. Part I: Development of the measuring system. J Prosthet Dent, 50:368-73.

House M. M. (1931). Studies in prosthesis (mandibular movements: articulators). J Am Dent Assoc, 18:827-52.

Huffman R., Regenos J. W., Taylor R. R. (1969). Principles of Occlusion: Laboratory and Clinical Teaching Manual. H \& R Press, Columbus, $\mathrm{OH}$. 
Jankelson B., Hofmann G. M., Hendron J. A. (1953). The physiology of the stomatognathic system. J Am Dent Assoc, 46:357-86.

JAWS ${ }^{\circledR}$ Version 8.0 Registrier-und Analyseprogramm für den Freecorder ${ }^{\circledR}$ Bluefox. (2008). Dental Innovations GmbH, Dortmund, Germany.

Jemt T. (1982). Positions of the mandible in chewing and swallowing recorded by lightemitting diodes. J Prosthet Dent, 48:206-209.

Knap F. J., Abler J. H., Richardson B.L. (1975). Computerized analysis and duplication of mandibular movement. J Prosthet Dent, 33:535-41.

Kurth L. E. (1942). Mandibular movements in mastication. J Am Dent Assoc, 29:176990.

Lauritzen A. G., Wolford L. W. (1961). Hinge axis location on an experimental basis. J Prosthet Dent, 11:1059-67.

Lee R. L. (1969). Jaw movements engraved in solid plastic for articulator controls. Part I: Recording apparatus. J Prosthet Dent, 22:209-24.

Lucia V. O. (1983). Modern Gnathological Concepts—Updated. Quintessence Publishing Co., Chicago, IL.

Lucia V. O. (1964). Centric relation—-theory and practice. J Prosthet Dent, 10:849-56.

Lundeen H. C., Shyrock E. F., Gibbs C. H. (1978). An evaluation of mandibular border movements: Their character and significance. J Prosthet Dent, 40:442-52.

Lundeen H. C., Savara B. S., Jump E. B. (1959). Preliminary report on a technique for studying mandibular motion. J Dent Res, 38:662 (abstract).

Martone A. L. (1964). Physiographic cinematography studies of a prosthodontic patient: an initial report. J Prosthet Dent, 14:1069-79.

McCollum B. B., Stuart C. E. (1955). Gnathology—A research report. Scientific Press, Ventura, CA.

McCollum B. B. (1960). The mandibular hinge axis and a method of locating it. J Prosthet Dent, 10:428-35.

McHorris W. H. (1986). Centric Relation: Defined. Journal of Gnathology, 5:5-21.

McHorris W. H. (1989). Focus on anterior guidance - Introduction. Journal of Gnathology, 8:3-13. 
McHorris W. H. (2010). Occlusal Waxing Manual, $2^{\text {nd }}$ Ed. William H. McHorris, D.D.S., Memphis, TN. pp:37-38.

Mitchell D.L., Wilkie N. D. (1978). Articulators through the years. Part I. Up to 1940. J Prosthet Dent, 39:330-8.

Needles J. W. (1923). Practical uses of the curve of Spee. J Am Dent Assoc, 10:918-27.

Olthoff L. W., van der Zel J. M., Ruiter W. J., Vlaar S. T., Bosman F. (2000). Computer modeling of occlusal surfaces of posterior teeth with the CICERO CAD/CAM system. J Prosthet Dent, 84:154-62.

Palik J. F., Nelson D. R., White J. T. (1985). Accuracy of the earpiece face-bow. J Prosthet Dent, 53:800-4.

Pelletier L. B., Campbell S. D. (1991). Comparison of condylar control settings using three methods: A bench study. J Prosthet Dent, 66:193-200.

Pokorny P. H., Weins J. P., Litvak H. (2008). Occlusion in fixed prosthodontics: A historical perspective of the Gnathological influence. J Prosthet Dent, 99:299-313.

Preston J. D. (1979). A reassessment of the mandibular transverse horizontal axis theory. J Prosthet Dent, 41:605-613.

Price R. B. Gerrow J. D., Ramier W. C. (1988). A comparison of articulator settings obtained using a computerized pantograph with settings obtained using lateral check bite recording. Quintessence 19:423-30.

Price R. B., Gerrow J. D., Ramier W. C. (1989). Potential errors when using a computerized pantograph. J Prosthet Dent, 61: 155-60.

Price R. B., Kolling J. F., Clayton J. A. (1991). Effects of changes in articulator settings on generated occlusal tracings. Part II. Immediate side shift, intercondylar distance, and rear and top wall settings. J Prosthet Dent, 65:377-82.

Rudd K. D., Morrow R. M., Welker W. A., Jendresen M. D. (1967). Some uses of fluorescence in prosthodontics. J Prosthet Dent, 18:543-49.

Rudd K. D., Morrow R. M., Jendresen M. D. (1969). Fluorescent photoanthropometry: a method for analyzing mandibular motion. J Prosthet Dent, 21:495-505.

Schallhorn R. G. (1957). A study of the arbitrary center and the kinematic center of rotation for face-bow mountings. J Prosthet Dent, 7:162-69.

Shanahan T. E., Leff A. (1959). Mandibular and articulator movements. J Prosthet Dent, 9:941-45. 
Solnit A., Curnett D. C. (1988). Occlusal Correction, Principles and Practice. Quintessence Publishing Co., Chicago, IL. pp:17-203.

Sonstebo H. R. (1961). C. E. Luce's recordings of mandibular movements. J Prosthet Dent, 11:1068-73.

Starke E. N. (1999a). The history of articulators: a perspective on the early years, part I. J Prosthodont, 8:209-11.

Starke E. N. (1999b). The history of articulators: a perspective on the early years, part II. J Prosthodont, 8:277-80.

Starke E. N. (2000a). The history of articulators: early attempts to reproduce mandibular movement. J Prosthodont, 9:51-6.

Starke E. N. (2000b). The history of articulators: early attempts to reproduce mandibular movement, Part II. J Prosthodont, 9:110-2.

Starke E. N. (2001). The history of articulators, a brief history of early devices developed for recording condylar movement: Part I. J Prosthodont, 10:241-48.

Starke E. N. (2002). The history of articulators: From facebows to the Gnathograph, a brief history of early devices developed for recording condylar movement: Part II. J Prosthodont, 11:53-62.

Starke E. N. (2004). The history of articulators: "Scribing" articulators: Those with functionally generated custom guide controls, Part I. J Prosthodont, 13:118-28.

Starke E. N. (2005). The history of articulators: "Scribing" articulators - Those with functionally generated custom guide controls, Part III. J Prosthodont, 14:198-207.

Stansberry C. J. (1929). Functional position checkbite technique. J Am Dent Assoc, $16: 421-40$.

Stallard H., Stuart C. E. (1963). Concepts of Occlusion. Dent Clin North Am, Nov:591606.

Stuart C. E. (1959). Accuracy in measuring functional dimensions and relations in oral prosthesis. J Prosthet Dent, 9:220-36.

Stuart C. E., Stallard H. (1960). Conservation of natural and restored cusps in organized occlusion. The Fortnightly Review of the Chicago Dental Society, June.

Stuart C. E. (1964). Good occlusion for natural teeth. J Prosthet Dent, 14:716-24.

Stuart C. E., Stallard H. (1964). Why an axis? J So Calif Dent Assoc, 32:204-5. 
Stuart C. E., Stallard H. (1969). Condylar determinants to be found in the patient and put in the controls of an articulator if cusps are to be reproduced on teeth correctly. BW Pavone's (Editor) Oral Rehabilitation and Occlusion - A compilation of Papers Written by Harvey Stallard, Ph.D, D.D.S. and Charles E. Stuart, D.D.S. Volume II, San Francisco: University of California San Francisco Medical Center, pp:43-53.

Stuart C. E. (1976). Determinants of occlusion. C. E. Stuart's (Editor) Oral Rehabilitation and Occlusion with some Basic Principles on Gnathology - Volume V, Ventura, CA: C. E. Stuart Gnathological Instruments, pp:107-116.

Stuart C. E. (1979). Use of the Stuart articulator in obtaining optimal occlusion. Dent Clin North Am, 23:259-270.

Stuart C. E., Golden I. B. (1981). History of Gnathology. C. E. Stuart Gnathological Insturments, Ventura, CA, pp:1-144.

Teteruck W. R., Lundeen H. C. (1966). The accuracy of an ear face-bow. J Prosthet Dent, 16:1039-46.

Wagner A., Seemann R., Schicho K., Ewers R., Piehslinger E. (2003). The comparative analysis of optical and conventional axiography for the analysis of temporomandibular joint movements. J Prosthet Dent, 90:503-9.

Waysenson B., Salomon J. (1977). Limitations of semiadjustable articulators. Part I: straight line articulators without setting for immediate side shift. J Prosthet Dent, 58:438-42.

Weinberg L. A. (1959). The transverse hinge axis: real or imaginary. J Prosthet Dent, 9:775-87.

Weinberg L. A. (1964). A cinematic study of centric and eccentric occlusions. J Prosthet Dent, 14:290-3.

Winstanley R. B. (1977). Observations on the use of the Denar pantograph and articulator. J Prosthet Dent, 38:661-72.

Winstanley R. B. (1985). The hinge axis: a review of the literature. J Oral Rehabil, 12:135-59.

Woelfel J. B., Hickey J. C., Allison M. L. (1962). Effect of posterior tooth form on jaw and denture movement. J Prosthet Dent, 12:922-39.

Zola A., Rothschild E. A. (1961). Condyle positions in unimpeded jaw movements. J Prosthet Dent, 11:873-81. 


\section{VITA}

Joshua Heath Balch was born in 1980 to Dennis D. and Patricia A. Balch in Newport, TN. He earned a Bachelor of Arts degree in Biology in 2002 from CarsonNewman College and received his doctoral degree in dentistry (Doctor of Dental Surgery) from the University of Tennessee Health Science Center, College of Dentistry, Memphis, TN in 2006. He married Dana F. Strong on March 2, 2008. Following three years in private practice (general dentistry) in Cookeville, TN he was accepted into the Advanced Prosthodontic Program at the University of Tennessee Health Science Center in 2009. Dr. Balch is currently a third year resident, specializing in implant, esthetic and reconstructive dentistry at UTHSC. He will be finishing his Master of Dental Science degree from the University of Tennessee. He is a current member of the American College of Prosthodontists, the Omnicron Kappa Upsilon Honorary Dental Society and the Southeastern Academy of Prosthodontics. Dr. Balch will enter a private prosthodontic practice in Knoxville, TN upon completion of his studies. 